Universidad de Lima

Facultad de Psicología

Carrera de Psicología

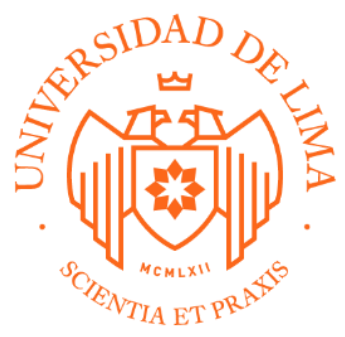

\title{
PERFECCIONISMO DE LAS MADRES Y SU RELACION CON LOS RASGOS PREDISPONENTES DE LOS TRASTORNOS \\ DE LA CONDUCTA ALIMENTARIA EN HIJAS ADOLESCENTES
}

Tesis para optar el Título Profesional de Licenciado en Psicología

MICHELE VANDER ELST LETZER

Código 19831866

Asesor

JORDANE BOUDESSEUL

Lima - Perú

Octubre de 2019 


\section{TABLA DE CONTENIDO}

CAPÍTULO I: PLANTEAMIENTO DEL PROBLEMA.............................2

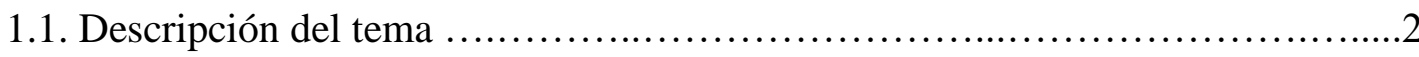

1.2. Justificación y relevancia...............................................

CAPÍTULO II: MARCO TEÓRICO...............................................9

2.1. El Perfeccionismo....................................................9

2.1.1. Teoría de la perfección...........................................9

2.1.2. Teoría del aprendizaje vicario e influencia del perfeccionismo..........13

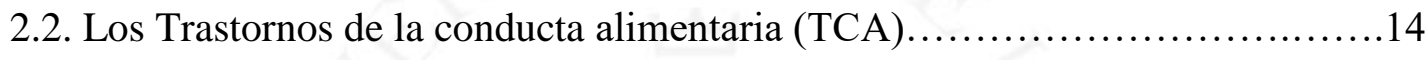

2.2.1. La imagen corporal........................................... 14

2.2.2. Los rasgos predisponentes de los TCA...............................16

2.2.3. Los trastornos de la conducta alimentaria (TCA) ........................17

2.2.4 La génesis y mantenimiento de los TCA..............................19

2.3. Relación entre el rasgo perfeccionismo en madres y el desarrollo de trastornos de la conducta alimentaria en hijas adolescentes ...............................25

CAPÍTULO III: OBJETIVOS, HIPÓTESIS Y DEFINICIÓN DE VARIABLES....................................................................26

3.1. Objetivos....................................................... 26

3.2. Hipótesis.......................................................26

3.3. Definición de Variables.....................................................27

3.3.1. Perfeccionismo...............................................2 27

3.3.2. Trastornos de la conducta Alimentaria ............................27

3.3.3. Mediadores: rasgos predisponentes de los trastornos de la conducta

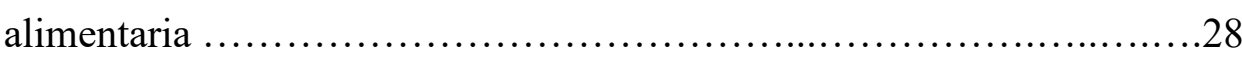




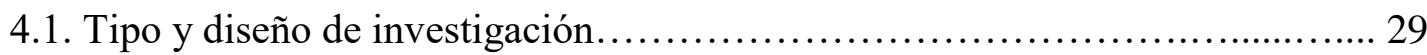

4.2. Participantes...................................................... 30

4.3. Técnicas de recolección de información...................................31

4.4. Procedimiento de recolección de datos...................................... 37

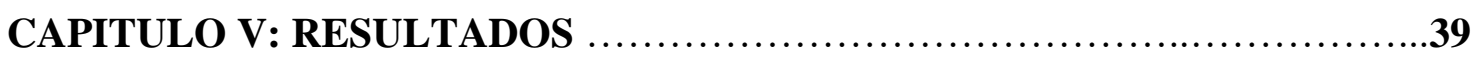

5.1. Análisis psicométricos..........................................40

5.1.1. Instrumento EMP ................................................... 40

5.1.1.1. Evidencias de confiabilidad ...............................40

5.1.2. Instrumento EDI-2 ........................................41

5.1.2.1. Evidencias de confiabilidad................................41

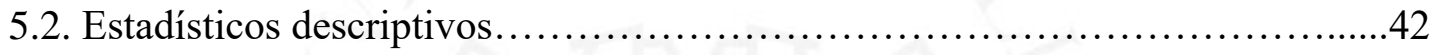

5.3. Estadísticos inferenciales.............................................44

5.3.1. Instrumento EMP ..............................................44

5.3.1.1. Evidencias de correlación $\ldots \ldots \ldots \ldots \ldots \ldots \ldots \ldots \ldots \ldots \ldots \ldots \ldots . \ldots \ldots$

5.3.2. Instrumento EDI-2 ............................................45

5.3.2.1. Evidencias de correlación .................................45

5.4. Modelo de Mediación Múltiple Paralelo....................................46

5.4.1. Análisis modelo múltiple paralelo modalidad

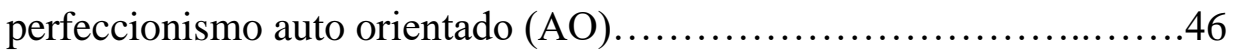

5.4.2. Análisis modelo múltiple Paralelo modalidad

perfeccionismo orientado a los demás (OD) .......................49

5.4.3. Análisis modelo múltiple paralelo modalidad

perfeccionismo socialmente prescrito (SP) ......................50

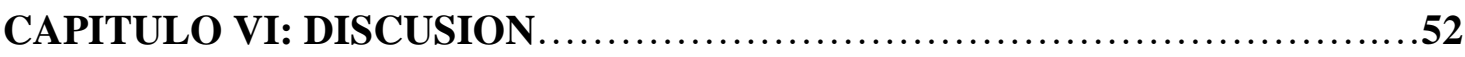

CONCLUSIONES..............................................................61 
RECOMENDACIONES..........................................................62

REFERENCIAS.............................................................64

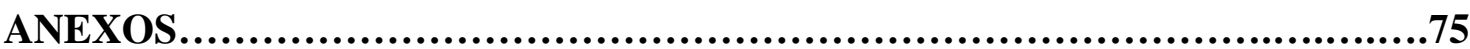




\section{INDICE DE TABLAS}

Tabla 1. Distribución de ítems directos e inversos del instrumento EMP ..............34

Tabla 2. Distribución de ítems directos e inversos del instrumento EDI-2 ...............37

Tabla 3. Confiabilidad de dimensiones del instrumento EMP......................41

Tabla 4. Confiabilidad de dimensiones del instrumento EDI $2 \ldots \ldots \ldots \ldots \ldots \ldots \ldots \ldots . \ldots 42$

Tabla 5. Estadísticos descriptivos de los puntajes de las dimensiones del instrumento

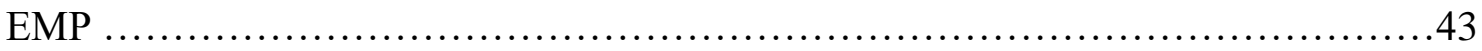

Tabla 6. Estadísticos descriptivos de los puntajes de las dimensiones del instrumento

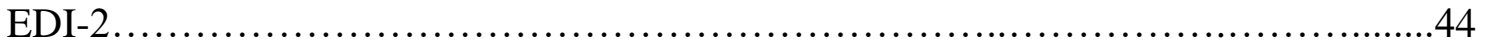

Tabla 7. Prueba de normalidad para los puntajes de las variables del instrumento EMP .45

Tabla 8: Resultados Bootstrap para efectos mediación. perfeccionismo AO........... 47

Tabla 9: Resultados Bootstrap para efectos mediación. perfeccionismo OD.............49

Tabla 10: Resultados Bootstrap para efectos mediación. perfeccionismo SP........... 51 


\section{ÍNDICE DE FIGURAS}

Figura 4.1. Modelo de mediación múltiple paralelo............................29

Figura 5.4.1. Mediación Perfeccionismo Auto orientado y TCA......................46

Figura 5.4.2. Mediación Perfeccionismo Orientado a los demás y TCA.................48

Figura 5.4.3. Mediación Perfeccionismo Socialmente Prescrito y TCA.................50 


\section{ÍNDICE DE ANEXOS}

Anexo 1. Ficha Socio Demográfica para Madres ..................................76

Anexo 2. Ficha Socio Demográfica para Adolescentes ...........................77

Anexo 3. Instrumento EMP.............................................. 78

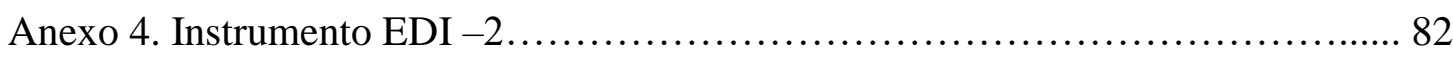

Anexo 5. Consentimiento informado para madres...............................89

Anexo 6. Consentimiento informado para menores de edad.......................90

Anexo 7. Autorización de uso de instrumentos............................... 91

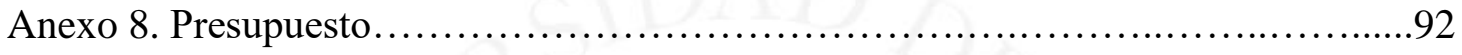

Anexo 9. Cronograma......................................................... 93

Anexo 10. Tabla 11- Correlación Spearman (rs) de dimensiones del

Instrumento EDI-2 ….................................................. 94 


\section{RESUMEN}

La prevalencia de la tendencia actual a padecer problemas alimentarios alcanza al $7.1 \%$ de la población adolescente femenina en Lima y Callao. Este estudio transversal tuvo como objetivo analizar la relación entre el perfeccionismo materno y la vulnerabilidad en desarrollar un TCA en las hijas adolescentes entre 15 y 22 años en Lima, Perú. Se evaluaron 109 pares de madres e hijas con la Escala Multidimensional de Perfeccionismo y el Inventario de Trastornos de la Conducta Alimentaria 2. Los resultados no revelaron caminos mediadores significativos entre perfeccionismo materno y vulnerabilidad de desarrollo de TCA. Serán necesarios estudios longitudinales adicionales para evaluar la causalidad entre perfeccionismo materno y TCA.

Palabras Clave: Perfeccionismo materno, Trastornos de la Conducta Alimentaria (TCA), Hijas Adolescentes, Modelo de mediación múltiple paralelo.

\section{ABSTRACT}

Currently $7.1 \%$ of the Lima and Callao female teenager population experience symptoms related to eating disorders. This cross-sectional study aimed at analyzing the relationship between maternal perfectionism and vulnerability to develop an ED in teenager daughters (15-22 years old) in Lima, Peru. A total of 109 mothers - daughters' pairs were assessed using the Multidimensional Perfectionism Scale (MPS) and the Eating Disorder Inventory - 2 (EDI2). The findings revealed there were no significant total mediational pathways between mother's perfectionism and ED vulnerability in their daughters. Further longitudinal studies are needed to assess causal relationship between mother's perfectionism and ED.

Keywords: Mother's perfectionism, Eating Disorders (ED), Teenagers Daughters, Parallel Multiple Mediator Model 


\section{CAPÍTULO I: PLANTEAMIENTO DEL PROBLEMA}

\subsection{Descripción del tema}

Según la Organización Mundial de la Salud (OMS) más de 70 millones de individuos en el mundo están afectados por un trastorno de la conducta alimentaria (TCA) posicionándose en tercer lugar dentro de las enfermedades crónicas sufridas por adolescentes mujeres en los países industrializados por lo que esta importante prevalencia los convierte en un tema de interés de salud pública (Organización Panamericana de la Salud [OPS], 2009). Numerosos estudios a nivel mundial reportan información acerca de la importancia de los TCA, entre los cuales resalta un estudio exploratorio apoyado en cinco años de data del U.S. Medical Expenditures Panel Survey que realiza una comparación de tres indicadores: los costos anuales de los cuidados médicos, las tasas de empleo laboral y la ganancia por ingresos en personas con o sin TCA. Reportan que las personas que padecen un TCA tienen un costo anual de salud superior en $\$ 1869$ ( $p=0.012)$, una menor tasa de empleabilidad $(\mathrm{OR}=.67$, 95\% CI [0.41-1.09]) así como una reducción en sus ingresos anuales evaluada en \$2093 que aquellas personas que no sufren un TCA. Asimismo, subrayan la alta comorbilidad del TCA con trastornos como la ansiedad, la esquizofrenia, el trastorno bipolar y la depresión mayor y reportan la contribución de esta comorbilidad al incremento de los tres índices evaluados, elevando los costos de salud anuales en $\$ 1993$ adicionales, reduciendo la probabilidad de ser empleado $(\mathrm{OR}=.41, \mathrm{CI}[0.14-1.20]$ y produciendo una reducción significante del $50 \%$ en ingresos anuales $(\$ 19,374, p<0.01)$. Estas cifras llevan a la conclusión que la prevención y el tratamiento de los TCA puede presentar un beneficio económico en términos de montos invertidos en el cuidado de la salud, posibilidad de ingresos y ahorros anuales así como en la productividad laboral, lo cual justifica realizar estudios en gran escala acerca del impacto económico y social de los TCA y su comorbilidad (Samnaliev, Leann, Sonneville, Austin, 2014).

Otro meta análisis basado en 36 estudios cuyo objetivo fue evaluar la tasa de mortalidad de los pacientes con TCA (Anorexia Nerviosa (AN), Bulimia Nerviosa (BN) y Trastorno de Alimentación No especificado (TANE)) reporta que esta es elevada en los tres trastornos mostrando mayor incidencia en la AN de 5.10 muertes por cada 1000 personas por año seguida por la incidencia del TANE de 3.31 muertes por cada 1000 pacientes y por la incidencia de mortalidad de la $\mathrm{BN}$ la cual fue menor siendo de 1.74 por 1000 pacientes 
resaltando la alta comorbilidad de los TCA con la conducta suicida ya que 1 de cada 5 individuos con AN no fallece por AN sino por suicidio (Arcelus, Mitchell Wales y Nielsen, 2011).

Otro estudio llevado a cabo en el Reino Unido revela un incremento en la incidencia de diagnósticos de trastornos de la conducta alimentaria en general durante el periodo 20002009. Refiere que si bien la incidencia de la AN y de la BN se mantiene estable en esta primera década del siglo XXI , la incidencia de los casos de Trastornos de Alimentación no especificado (TANE) se ha incrementado en la población adolescente femenina creciendo de 17.7 a 28.4 casos de incidencia por cada 100,000 mujeres entre el año 2000 y año 2009, transformándose los TANE en la incidencia de mayor diagnóstico en mujeres de 10-49 con edad pico de diagnóstico entre los 10 y 19 años colocando este problema de salud mental en segundo lugar después de la depresión (Micali, Hagberg, Petersen, y Treasure, 2013). Finalmente, un estudio australiano detalla que padecer un TCA representa una carga cada vez más creciente a nivel mundial la cual se mide utilizando la medida métrica del Global Burden of Disease (2015) basada en el Disability Adjusted Life Year (2015) que combina la mortalidad prematura y los años vividos con el trastorno. Reportan que la carga correspondiente a la combinación de sufrir anorexia y bulimia nerviosas posiciona a los TCA en el décimo segundo lugar de las enfermedades físico-mentales padecidas por las mujeres en edad entre 15 a 19 años, representando así la importancia del impacto del trastorno (Erskine, Whiteford, y Pike, 2016).

Asimismo, la quinta edición del manual diagnóstico y estadístico de los trastornos mentales DSM-5 publicada en mayo 2013 ha revisado y modificado la información categorial proponiendo innovaciones relevantes con respecto a los criterios diagnósticos de TCA hasta la fecha presentes en el DSM-4. Modifica los criterios para la Anorexia Nervosa (AN) (F50.0), la Bulimia Nerviosa (BN) (F.50.2), reconociendo al Trastorno por Atracón como un TCA especifico (F 50.8). Propone una lista de otros trastornos como el trastorno dismórfico muscular, el trastorno evitativo/restrictivo de la ingesta alimentaria, pica, rumiación, AN atípica, BN sub-umbral, trastorno por atracones sub-umbral, trastorno purgativo y síndrome del comer nocturno a ser mencionados en la categoría Trastorno de alimentación y de la ingestión no especificado (Behar y Arancibia, 2014).

A nivel mundial se observan múltiples estudios respecto de los TCA destacando una investigación española de Asuero, Avargues, Martín y Borda (2012), quienes estudiaron la 
relación existente entre la autoestima, la preocupación por la apariencia física y las alteraciones emocionales en mujeres con trastornos alimentarios comparando tres grupos de mujeres con autoestimas baja, media y alta respectivamente. Encontraron que las mujeres del grupo de autoestima baja presentan puntuaciones superiores en insatisfacción corporal, ansiedad y depresión en comparación con los otros grupos de autoestima media y alta y que las pacientes del grupo baja autoestima son aquellas que muestran desear tener un índice de masa corporal (IMC) más bajo al que tienen en la actualidad. A nivel latinoamericano se evidencia igualmente el interés por el tema de los TCA, lo que se refleja en una investigación llevada a cabo en México acerca de la asociación existente entre la triada del estrés, compuesta por el nivel de estrés, el tipo de afrontamiento y las emociones, con el Índice de Masa Corporal (IMC), en 89 adolescentes de 11 a 15 años encontrándose que el IMC se relaciona de forma positiva con el efecto mediador del estrés cotidiano $(r=.24, p<.05)$ y de la ansiedad $(r=.22$, $p<.05)$ y negativamente con la culpa $(r=-.0 .26, p<.05)$ (Muñoz, Vega, Berra, Nava y Gómez, 2015). En Colombia se halla un estudio descriptivo correlacional de HernándezCortés y Londoño (2013) sobre la relación existente entre antecedentes psicológicos familiares, género, estilo de afrontamiento, deseo de disminución de peso, depresión, satisfacción de la imagen corporal y el riesgo de padecer un TCA en 417 jóvenes estudiantes universitarios entre los 16 y 25 años. La investigación reporta una evidencia predictiva de la contribución de la depresión (32\%,) los antecedentes psicológicos familiares (22\%), el estilo de afrontamiento evitativo (14\%), la satisfacción con la imagen corporal (12\%), el deseo de disminución del peso (11\%) y el género (-16\%) en la varianza total explicada del riesgo de padecer un TCA. En el Perú, también se realizaron estudios sobre los TCA observándose uno sobre la prevalencia de riesgo de trastornos de conducta alimentaria en jóvenes preuniversitarios que indica como resultado que estos se registran con mayor frecuencia en el género femenino $(18.70 \%)$ que en el género masculino $(16.38 \%)$, desarrollándose en promedio a los 17 años de edad (Miranda, 2016).

En cuanto al perfeccionismo, definido de manera general como la combinación de excesivos elevados estándares personales y una auto sobre evaluación crítica de los desempeños (Frost, Marten, Lahart y Rosenblate, 1990), Curran y Hill (2017) realizaron un meta análisis longitudinal entre 1989 y 2016 aplicando la Escala Multidimensional del Perfeccionismo (MPS) propuesta por Hewitt y Fleet la cual considera tres dimensiones como lo son el Perfeccionismo Autoorientado (AO), el Perfeccionismo Orientado hacia los demás (OD) y el Perfeccionismo Socialmente Prescrito (SP). Los autores reportaron como resultados 
un aumento en el perfeccionismo multidimensional en los jóvenes universitarios canadienses, americanos y británicos entre 18 y 25 años de edad durante los últimos 27 años hallando un incremento en las tres dimensiones descritas con un tamaño del efecto de pequeño a moderado ( $d=.12$ (AO), $d=.19$ (OD) y $d=.40(\mathrm{SP})$ ) con un mayor aumento en el perfeccionismo socialmente prescrito. Analizan el desarrollo del concepto de la meritocracia y la consecuente necesidad de alcanzar y demostrar elevados logros personales los cuales se encuentran estrechamente ligado al perfeccionismo y atribuyen este incremento de perfeccionismo a la migración durante las últimas décadas de un modelo económico proteccionista hacia un modelo neoliberalista el cual da pie a una necesidad de desarrollo de mayor individualismo.

Adicionalmente los autores plantean la hipótesis que el desarrollo de este neoliberalismo y doctrina de meritocracia han contribuido al desarrollo de una cultura en la cual se espera que las personas perfeccionen sus estilos de vida e intenten alcanzar estándares irrealistas. Mencionan que estos cambios sociales y económicos en el tiempo han también influenciado las actitudes parentales quienes dedican en la actualidad mayor tiempo a actividades académicas en vez de actividades de entretenimiento con sus hijos, mostrando ellos mismos mayor perfeccionismo ejerciendo sobre control y presiones excesivas en arras de sus altas expectativas en cuanto al éxito de sus hijos. Curran y Hill concluyen que el aumento global del perfeccionismo en jóvenes estudiantes durante las pasadas tres décadas sea posiblemente atribuible a la evolución individualista, materialista y socialmente antagónica de la cultura así como una generación de jóvenes quienes hoy enfrentan entornos más competitivos con expectativas no realísticas así como padres ansiosos y controladores y "proponen la relación entre el incremento de perfeccionismo y psicopatología porque el perfeccionismo es una vulnerabilidad hacia el desarrollo de trastornos, síntomas y síndromes" (Curran y Hill, 2017, p. 11).

Por otro lado, en Chile también hubo interés por el estudio descriptivo de la influencia del perfeccionismo y la Imagen Corporal (IC) en el desarrollo de los TCA. Los resultados indican que el perfeccionismo y la IC son características nucleares y factores predisponentes, desencadenantes y perpetuantes en el riesgo del desarrollo, mantenimiento, tratamiento y desenlace de un TCA. Asimismo, mencionan que tanto los padres, pares y medio ambiente favorecen el desarrollo de los TCA, y reportan que la presencia de un TCA en la madre es un factor de riesgo para el desarrollo de ese tipo de patología en sus hijas (Behar y Arancibia, 2014a; Behar, Gramegna y Arancibia, 2014). 
Al revisar las investigaciones realizadas acerca del perfeccionismo y los TCA se aprecia los diversos intentos por averiguar si existe un efecto o asociación entre ambas variables y se desprende la multietiopatogenia de los TCA. Sin duda estas investigaciones contribuyen al conocimiento científico confirmando o negando la asociación existente entre las dos variables sin embargo, el establecimiento de estas asociaciones podría beneficiarse adicionalmente si se intentara responder a la pregunta adicional ¿cómo es ejercido el efecto? Hayes (2013) sugiere ir más allá del solo establecimiento del efecto de una variable sobre la otra para lo cual propone usar el modelo de mediación con el objetivo de intentar establecer cuales son los procesos biológicos o psicológicos intermediarios que intervienen adicionalmente en el establecimiento de la relación entre las variables. Propone usar el análisis de mediación múltiple paralelo tomando en consideración tanto los caminos directos entre la variable independiente y dependiente del estudio así como los caminos indirectos que son aquellos que pasan por múltiples mediadores intervinientes que en el caso de los TCA son numerosos.

Al analizar el aumento de la prevalencia de los TCA en el mundo y en nuestro medio, su elevada tasa de mortalidad y comorbilidad, la significancia de la carga por padecer un TCA en la vida de las jóvenes del género femenino específicamente en el grupo etario de la adolescencia , el incremento generado en la inversión en salud pública, la pérdida de ingresos y la reducción de empleabilidad, la importancia del crecimiento de la dimensión del perfeccionismo a través del tiempo en los jóvenes, el efecto de los antecedentes psicológicos familiares y de la influencia de la presencia de un TCA materno en la transmisión de un TCA a sus hijas, se plantea responder la siguiente interrogante: ¿Cuál es la relación entre el perfeccionismo de las madres y la presencia de rasgos predisponentes de los trastornos de la conducta alimentaria en hijas adolescentes entre 15 y 22 años en el nivel socio económico A de Lima Metropolitana? En aras de mejorar la comprensión acerca de cómo funciona el mecanismo de influencia del perfeccionismo de las madres en la vulnerabilidad de padecer un TCA en sus hijas, se plantea responder a la siguiente pregunta: ¿Cuál es el efecto mediador de los rasgos predisponentes de los trastornos de la conducta alimentaria entre el perfeccionismo de las madres y la vulnerabilidad en desarrollar un TCA en sus hijas adolescentes entre 15 y 22 años en el nivel socio económico A de Lima Metropolitana? 


\subsection{Justificación y relevancia}

Los desórdenes de la conducta alimentaria son enfermedades severas debido a su alta comorbilidad, complicaciones médicas, mortalidad y tasas de suicidio, tienen prevalencia en la población adolescente y representan un problema de salud pública a nivel mundial (Swanson, Crow, Le Grange, Swendsen, \& Merikangas, 2011). De acuerdo con el Ministerio de Salud del Perú (MINSA) se registró un aumento de casos de TCA entre los años 1998 y 2008 (Lazo, Quenaya y Mayta, 2015) y el último estudio epidemiológico realizado por el Instituto Nacional de Salud Mental (INSM) reporta que la prevalencia actual de la tendencia hacia problemas alimentarios se eleva a $7.1 \%$ de la población adolescente femenina en Lima y Callao (INSM, 2012). Adicionalmente una investigación peruana aportó evidencia acerca del creciente rol influenciador de los medios de comunicación en nuestro medio en la probabilidad de desarrollo de tal patología en las escolares mujeres en Lima (Lazo, Quenaya, Mayta, 2015) encontrando que a mayor influencia de los medios de comunicación sobre la imagen corporal de la escolar, mayor fue el riesgo de desarrollo de un TCA. En cuanto a lo que se refiere a la importancia de la influencia materna, Behar y Arancibia (2014a) reportan que existe una relación entre la presencia de un TCA materno y el desarrollo de un TCA en las hijas.

Las consecuencias de los TCA abarcan el ámbito tanto individual, familiar y social llevando a alcanzar un deterioro significativo del bienestar psicosocial del que lo padece como el de su entorno inmediato familiar y social. Asimismo, conllevan al desarrollo de un daño físico que muchas veces se convierte en crónico generando problemas desde la morbilidad médica y psiquiátrica pudiendo ocasionar complicaciones médicas e incluso llevar hasta la muerte (López y Treasure, 2010). Debido a la gravedad de las consecuencias y la importancia de los TCA en el mundo y en el Perú surge el interés de plantear una investigación que estudie el rol de la función relacional familiar y específicamente la dimensión de perfeccionismo presente en la madre en el desarrollo de los TCA en las hijas adolescentes, generando una toma de conciencia de la existencia de dicha influencia para intentar reducir la presencia de estas patologías, las cuales son hoy un tema sensible en el sector salud del Perú. Asimismo el estudio de la asociación existente entre ambas variables tendría un impacto social ya que permitiría por un lado contribuir a la evaluación de la presencia del perfeccionismo en las madres e implementar programas que revisan creencias y pensamientos perfeccionistas asociadas a trastornos alimentarios para mejorar el manejo de los mismos (Antony y Swinson, 1998). 
Asimismo resulta importante realizar este estudio usando el modelo de mediación múltiple paralelo en el caso de los TCA debido a los numerosos procesos intervinientes en la etiopatogenia del trastorno. Gracias al uso del modelo propuesto por Hayes (2013) que permite analizar dos caminos de influencia, es decir el camino desde la variable independiente hacia los múltiples mediadores y luego desde estos mediadores hacia la variable dependiente. La obtención de este desglose permitiría cuantificar los efectos directos e indirectos de las diversas modalidades del perfeccionismo materno en los mediadores así como el efecto de estos en la variable TCA y comparar la fuerza entre todos los efectos indirectos individuales. Aplicar este modelo buscaría aportar elementos adicionales en la comprensión de la influencia del perfeccionismo materno en la presencia de los rasgos predisponentes de los TCA y la posterior vulnerabilidad en desarrollar el trastorno en sus hijas adolescentes. 


\section{CAPÍTULO II: MARCO TEÓRICO}

\subsection{El perfeccionismo}

\subsubsection{Teoría de la perfección}

El perfeccionismo ha sido conceptualizado por varios autores a lo largo de la historia, entre ellos Adler (como se citó en González, Gómez y Conejeros, 2017) quien se refirió a este concepto en la teoría sobre el complejo de superioridad e inferioridad y lo definió como "una herramienta para desarrollar sentimientos de independencia y maximizar las habilidades con el fin de utilizarlo para el bien social". Asimismo, Hamachek (como se citó en Mendi y Eldeleklioglu, 2016) propuso una distinción teórica con relación al concepto de perfeccionismo distinguiendo dos tipos, por un lado, como normal y por otro lado como neurótico asociándole características negativas. Describió como normal y consideró adaptativo aquel esfuerzo y búsqueda de logros para alcanzar una satisfacción personal provocando una consiguiente alta autoestima siendo saludable en términos de funcionamiento psicológico. Al contrario, señaló como neurótico y desadaptativo aquel perfeccionismo que se caracteriza por intentar alcanzar objetivos excesivamente altos que conlleva a una elevada preocupación por la evaluación externa y miedo al fracaso. Finalmente, consideró que el perfeccionismo engendra un estilo de la personalidad relacionándose también con emociones como la culpa, la vergüenza, la duda, la frustración, la procrastinación y la baja autoestima. Los autores Rice, Ashby y Slaney (como se citaron en De Rosa, Dalla Valle, Rutsztein y Keegan, 2012) también catalogaron a sujetos como perfeccionistas adaptativos y desadaptativos como lo hizo Hamachek, basándose en los estándares de rendimiento y los altos o bajos niveles de discrepancia definiendo ésta como "la percepción de que constantemente uno no logra cumplir con los altos estándares que se han establecido para sí mismo". El análisis de esa clasificación de perfeccionismo lleva a De Rosa et al. (2012) a observar la vinculación de la autocrítica misma con el constructo perfeccionismo desadaptativo en el cual destaca el estilo cognitivo de la personalidad cuando el individuo se autoevalúa, jugando así un rol importante en el mantenimiento del perfeccionismo disfuncional. 
Al revisar la literatura sobre el perfeccionismo se constata que esta dimensión ha generado interés debido a su implicación etiológica en un conjunto amplio de trastornos mentales como son los trastornos de personalidad, los trastornos de ansiedad como el trastorno obsesivo compulsivo, algunos trastornos del desarrollo, algunas formas depresivas, así como los de la conducta alimentaria (Belloch, 2012). Burns (como se citó en García-Fernández et al., 2016) definió al individuo perfeccionista como alguien que se plantea estándares y metas inalcanzables y hasta irrazonables tratando de alcanzarlos de manera compulsiva, valorando su desempeño solamente en función de la productividad y del dominio alcanzado. Es importante resaltar que este autor se refiere al perfeccionismo como una dimensión única tomando en consideración solamente aquellos pensamientos exclusivamente auto dirigidos.

Para Frost, Marten, Lahart y Rosenblate (1990) el perfeccionismo consiste en una alta preocupación de incurrir en errores al intentar alcanzar los elevados estándares autofijados, siendo a la vez extremadamente crítico consigo mismo. Sin embargo, conforme se ha incrementado el interés científico por este constructo, resulta interesante observar cómo ya no es considerado como una dimensión única sino también como un constructo sensible a las influencias del entorno y del contexto cultural del sujeto. 3En relación con esas influencias es importante mencionar que otros autores proponen el concepto tridimensional del perfeccionismo como Fleet y Hewitt (1991) quienes plantearon que existe el perfeccionismo auto-orientado, aquel orientado hacia los demás y el perfeccionismo prescrito por la sociedad.

Hewitt y Fleet (1991) plantean que la dimensión del perfeccionismo auto-orientado consiste en implementar conductas para alcanzar objetivos auto-fijados excesivamente elevados siendo muy autocríticos en cuanto al desempeño obtenido. Si bien este perfeccionismo es considerado como una de la forma más adaptativa de perfeccionismo por lo que puede llevar a alcanzar metas y objetivos de manera proactiva y depende solamente del control de uno mismo, en ocasiones ha sido también relacionado con manifestaciones de ansiedad, presencia de anorexia nerviosa y depresión subclínica encontrándose correlaciones significativas con las emociones de culpa, ira y desencanto. Por otro lado, los autores definen la segunda dimensión del perfeccionismo como aquella orientada hacia los demás teniendo creencias y expectativas acerca de las habilidades y capacidades que se considera deberían de estar presentes en los demás, exigiendo que alcancen estándares elevados procediendo a emitir un constante juicio. Mencionan que el ejercer esta dimensión del perfeccionismo acarrea inseguridad en los demás, culpas y frustraciones interpersonales que pueden generar problemas familiares y conyugales. Finalmente, Hewitt y Fleet se refieren al tercer tipo de 
perfeccionismo como la percepción que se tiene de la prescripción de estándares exigentes o irrealistas establecidos por la sociedad en la que se vive, la cual aplica excesiva presión esperando un cumplimiento de patrones socialmente determinados. Esta tercera dimensión del perfeccionismo conlleva a la vivencia de emociones negativas debido al miedo a ser evaluados desfavorablemente por los demás por no poder alcanzar los estándares establecidos por la sociedad.

Horney (1937) aborda aspectos ligados al perfeccionismo cuando hace referencia a los pensamientos y diálogos internos presentes en personas neuróticas quienes son tiranizadas por aquellos mandatos, observando cómo esas demandas gobiernan y guían su comportamiento. En efecto en su teoría sobre las neurosis la autora presenta los trastornos neuróticos como algo continuo en la vida cotidiana y se refirió a ellos como un intento de establecer una forma de control interpersonal y una adaptación sobre aquellos aspectos a alcanzar en el diario vivir. A lo largo de su experiencia clínica distinguió diez patrones particulares de necesidades neuróticas basadas en aspectos que se desean alcanzar, sin embargo, menciona que estos se han vuelto distorsionadas por las dificultades encontradas en la vida particular de algunas personas. Con respecto a las diez necesidades descritas, la necesidad neurótica de reconocimiento o prestigio social, de admiración personal, de logro personal y de perfección son aquellas que guardan mayor relevancia con el tema de interés de este estudio. Esta última necesidad de perfección corresponde al impulso que lleva a pretender ser constantemente perfecto y no fallar queriendo estar en control todo el tiempo.

Adicionalmente Horney se refiere a la neurosis en términos de imagen del self, planteando la teoría del self actual y self ideal. Indica que aquella persona libre de neurosis tiene un concepto preciso de si mismo que le permite desarrollar su potencial para alcanzar la auto-realización, en cambio menciona que la persona con neurosis tiene un self escindido en un self ideal y un self despreciado. Esta división lo lleva a someterse al constante intento de alcanzar ciertos ideales que se encuentran fuera de sus posibilidades, acarreando consecuencias de desprecio hacia si mismo en el intento de ser perfectos. Adicionalmente Raich (2011) reporta que la reducida capacidad en reconocer los éxitos personales, el establecimiento de estándares excesivamente altos y el hábito compulsivo de evaluar el rendimiento personal son rasgos perfeccionistas presentes en personas que han desarrollado algún TCA. 
Al revisar los antecedentes acerca del perfeccionismo se encuentra que Pamies y Quiles (2014) buscaron evaluar la relación existente entre las diversas dimensiones del perfeccionismo y las conductas alimentarias de riesgo en una muestra de 2142 adolescentes españoles de ambos géneros con una edad promedio de 13.9 años para lo cual aplicaron los instrumentos Child and Adolescent Perfectionism Scale (CAPS) y EAT- 40. En ambos géneros encontraron asociaciones positivas entre las puntuaciones totales del EAT-40 y la dimensión de perfeccionismo auto orientado siendo mayor para las mujeres $(r=.29, p<.01)$ que para los varones $(r=.24, p<.01)$ así como con la dimensión del perfeccionismo socialmente prescrito encontrándose para las mujeres $(r=.26, p<.01)$ y para los varones $(r$ $=.22, p<.01)$. Concluyeron adicionalmente que, acorde a los resultados de la aplicación del instrumento EAT-40, los adolescentes ubicados en el grupo de mayor riesgo en desarrollar un TCA presentaban un mayor perfeccionismo auto-orientado y perfeccionismo socialmente prescrito que aquellos ubicado en el grupo de bajo riesgo.

Asimismo, Egan et al. (2012) realizaron otro estudio que analizó la relación entre perfeccionismo y TCA en una comunidad de mujeres en Estados Unidos. El objetivo fue evaluar cuál era el efecto mediador de la sobrevaloración del peso y forma corporal y el establecimiento de metas en la relación entre perfeccionismo y desarrollo de TCA. Los autores reportan que la sobrevaloración del peso y la forma corporal fueron los mediadores más relevantes y los resultados apoyan la hipótesis que la dimensión del perfeccionismo autoorientado acrecienta la génesis de estas psicopatologías.

Otros estudios apoyan la hipótesis de la relación existente entre perfeccionismo negativo y TCA como el estudio de Elizathe, Murawski, Custodio y Rutsztein (2012) que exploró la asociación existente entre perfeccionismo y riesgo de desarrollo de TCA en niños de ambos sexos de 9-13 años, observando una asociación significativa entre ambas variables $(\mathrm{r}=.41, \mathrm{p}<.001)$ concluyendo que el perfeccionismo constituye una variable asociada al riesgo de TCA en niños. Asimismo, Schappatura, Arana, Elizathe y Rutsztein (2011) llevaron a cabo un estudio de revisión sobre diez trabajos empíricos publicados desde el año 1991 hasta el año 2011 sobre el perfeccionismo adaptativo y desadaptativo y la relación de ambas dimensiones con los TCA y/o sintomatología de dichos trastornos con la finalidad de aportar a la discusión sobre la multidimensionalidad del perfeccionismo en el campo de los TCA. Los autores ponen de manifiesto una falta de concordancia entre las distintas investigaciones sobre el rol de dichas dimensiones en los TCA: en efecto, los resultados encontrados muestran que algunos estudios hallan una asociación entre la sintomatología de TCA y la dimensión 
desadaptativa del perfeccionismo (Ashby, Kottmam \& Schoen, 1998; Davis, 1997; Dour \& Teran, 2011; Pearson \& Gleaves, 2006, Soenens, 2008; Terry-Short, Owens, Slade \& Dewey, 1995) y otros señalan que serian ambas dimensiones, adaptativa y desadaptativa, las que están asociados a la patología alimentaria (Bardone-Cone, 2007; Bardo-Cone et al., 2008; Bastiana, Rao, Weltzin \& Kaye, 1995; Hewitt, Flett \& Ediger, 1995). Estos hallazgos indican la necesidad de continuar estudiando ambas dimensiones del perfeccionismo en el campo de los trastornos de la conducta alimentaria. Finalmente, Cortés (2016) evaluó la relación existente entre la conducta auto restrictiva de dieta, el perfeccionismo negativo y las actitudes de riesgo ante la alimentación en una muestra subclínica de 100 mujeres entre los 18 y 23 años concluyendo que si bien se encontró un efecto significativo de la variable "dieta" en la variable dependiente "actitudes de riesgo ante la alimentación" [T (68) = -3.5; p <.05], no se halló influencia del perfeccionismo negativo [F $(1,97), \mathrm{p}>.05]$.

\subsubsection{Teoría del aprendizaje vicario e influencia del perfeccionismo.}

Distintas teorías del aprendizaje han contribuido a la comprensión de la conducta humana, pero resulta de fundamental importancia en el caso específico de los TCA revisar aquella planteada por Antonio Bandura (1990) denominada teoría del aprendizaje social o vicario que estipula que la conducta es aprendida y que el ambiente influye en su desarrollo. Hace hincapié en la importancia de la influencia ambiental y la conducta de los modelos en la transmisión de pautas sociales en el desarrollo y, advierte que el aprendizaje de los niños se genera observando la conducta modelada por los demás. La investigación sobre el tema refiere que se adquiere mayor cantidad de pautas de conducta cuando se suministra un modelo que mediante una enseñanza impartida durante un proceso lento y gradual. Refiere que luego de visualizar las demostraciones del modelo, aquel que aprende suele reproducir la pauta de respuesta más o menos en su totalidad pudiendo ya sea proceder ejecutándolas inmediatamente o, adquiriéndolas en su reportorio llevándolas a cabo más adelante. Asimismo, es importante señalar que los observadores tenderán a imitar aquellas respuestas reforzadas positivamente y aprenderán más de los modelos competentes, atractivos, agradables y prestigiosos (Chance, 1995).

Rice (1997) menciona que los padres, maestros y personas significativas en el cuidado del niño son directamente responsables de moldear patrones de conducta adecuadas al ejercer una influencia favorable para el desarrollo de los niños. Con relación a este tema de influencia social, Losada, Leonardelli y Magliolia (2015) evaluaron la relación existente entre la 
influencia ejercida por agentes y situaciones sociales en el modelo estético corporal y las conductas de riesgo correspondientes a TCA en 71 mujeres adolescentes escolarizadas de 13 a 18 años de colegios secundarios de Buenos Aires. Reportaron que el riesgo de padecer un TCA estaba positivamente asociado a una mayor sensibilidad a la influencia de las situaciones sociales. Asimismo, Cooley, Toray, Chuan y Valdez (2008) estudiaron el rol de las actitudes y comportamientos alimentarios maternos en la percepción de imagen corporal y las patologías alimentarias desarrolladas por sus hijas en una muestra apareada de 91 madres e hijas en edad adolescente, evaluando la importancia del aprendizaje vicario y su posible implicancia en el desarrollo de TCA. Apreciaron variables como la percepción de los patrones alimentarios de las madres por sus hijas, la retroalimentación negativa y desaprobatoria de las madres acerca de la figura corporal y los patrones alimentarios de sus hijas, la internalización materna de los mensajes acerca de la delgadez provistos por los medios concluyendo que estas incrementan significativamente la predicción de desarrollo de un TCA en las hijas adolescentes.

\subsection{Trastornos de la conducta alimentaria (TCA)}

Durante la segunda mitad del siglo XX y hasta la actualidad, los medios de comunicación y las redes sociales han propagado mensajes ligados a los estándares de belleza que promueven la delgadez extrema. La oferta de ropa en tallas reducidas, la constante promoción de los alimentos bajos en calorías por la industria alimentaria y la necesidad de realizar entrenamiento físico son temas recurrentes que contribuyen al desarrollo de trastornos alimentarios que se encuentran ligados a una alteración de la percepción de la imagen corporal (IC) (Poulisis, 2011). Méndez, Vásquez y García (2008) definen los TCA como “alteraciones específicas y severas en la ingesta de los alimentos en personas que presentan patrones distorsionados en el acto de comer y que se caracterizan bien sea por comer en exceso o por dejar de hacerlo en respuesta a un impulso psíquico y no por una necesidad metabólica o biológica” (Méndez, Vásquez y García, 2008, p. 580).

\subsubsection{Imagen Corporal}

Para poder entender adecuadamente la psicopatología de un TCA es necesario revisar lo que se entiende por el término Imagen corporal (IC), ya que este es el denominador común de los 
TCA. Schilder (como se citó en Baile, 2003) quien es conocido como el padre del concepto lo define como "la figura de nuestro propio cuerpo que formamos en nuestra mente, es decir la forma en la cual nuestro cuerpo se nos representa a nosotros mismos" (p.3) la cual no tiene coincidencia con la apariencia física real. Asimismo, Raich, Perpiña y Botella y Baños (como se citaron en Quiroga, 2006) consideran la importancia de la contribución del IC en la génesis y el mantenimiento de los TCA por lo que debe efectuarse un apropiado diagnóstico de las alteraciones que constituyen la formación de la IC. Refieren que la IC es un concepto multifacético en el cual intervienen percepciones, actitudes, pensamientos, valoraciones y comportamientos provenientes de las cogniciones y sentimientos que se experimenta acerca del propio cuerpo. Indican que existen alteraciones tanto a nivel perceptivo, cognitivo y conductual. En cuanto a lo perceptivo refieren que, a pesar de las evidencias contrarias, se aprecia una sobre o sub-evaluación del tamaño corporal. En segundo lugar, en el aspecto cognitivo se vivencian sentimientos de insatisfacción corporal como el asco generándose pensamientos automáticos acerca del cuerpo que conllevan a una desvalorización personal al prestar atención en forma selectiva solo a los defectos corporales que se piensa tener. Finalmente interviene el factor conductual soliendo pasar tiempo en registrar aquellas imperfecciones corporales que estiman tener y llevar a cabo conductas restrictivas en relación con el patrón de alimentación, cambios de postura y de vestuarios intentando esconder los defectos que piensan tener.

En relación con este tema de fundamental importancia para los TCA, García, Ortiz, Salazar, Martino y Vergara (2015) estudiaron la percepción y satisfacción de la imagen corporal en una comunidad universitaria mixta de 211 estudiantes y docentes en México. El objetivo del estudio fue evaluar las actitudes y valoraciones de la persona con respecto a su propio cuerpo para lo cual aplicaron cuestionarios sobre satisfacción y percepción de la imagen corporal. Se observó que para ambos géneros existe una distorsión de la imagen corporal y de la percepción de sí mismo reportando que el $71 \%$ de la población estudiada no estaba satisfecha con su IC creyendo tener un peso mayor al real con lo cual se comprobó la existencia de una distorsión de la IC en relación con el IMC. 


\subsubsection{Rasgos predisponentes de los Trastornos de la Conducta Alimentaria (TCA)}

Acorde a Garner, Olmstead y Polivy, (1983), existen actitudes y conductas relacionadas con la comida, peso y tipo, así como rasgos psicológicos que son clínicamente relevantes en el caso de los TCA los cuales son la obsesión por la delgadez, la bulimia, la insatisfacción corporal, la ineficacia, el perfeccionismo, la desconfianza interpersonal, la conciencia interoceptiva, el miedo a la madurez, el ascetismo, la impulsividad y la inseguridad social (véase en Tabla 3). De ser descubierta en individuos fuera del ámbito clínico la presencia de esta sintomatología asociada a los TCA, esta permitiría elaborar un perfil de aquellas personas que tendrían riesgo de desarrollar este tipo de conductas en el futuro.

Bruch (1973) describió el rasgo de obsesión por la delgadez como la característica esencial de los trastornos de la conducta alimentaria siendo un intenso impulso de estar más delgado o tener un fuerte temor a la gordura. En cuanto al rasgo referente a la bulimia, se refiere a este como aquella conducta que consiste en la tendencia a tener pensamientos o conductas asociadas al poco control al momento de comer, lo que conlleva a que la persona sienta culpa, ansiedad o tristeza (Manzaneque, 2013). Con respecto a la insatisfacción corporal, la cual se considera uno de los aspectos de la perturbación de la imagen corporal característica de los pacientes con TCA, se refiere al disgusto con la forma general de su cuerpo o con alguna parte de este como son el estómago, caderas, muslos, nalgas etc. generando preocupación mayor en aquellas personas que sufren de un TCA. Asimismo, esta puede calificarse como uno de los factores responsables de la génesis y del mantenimiento de conductas relacionadas al control del peso en presencia de un TCA (Garner y Garfinkel, 1981).

Acorde a Bruch (1962) la ineficacia se refiere a vivenciar sentimientos de incapacidad general, inseguridad, vacío, auto desprecio y falta de control relacionándose con un déficit significativo de autoestima por experimentar sentimientos fuertes de falta de adecuación. En cuanto al rasgo de perfeccionismo, Bruch (1978) indica que los pacientes con trastornos de la conducta alimentaria luchan por alcanzar excesivos niveles de rendimiento y Slade (1892) refiere que esta característica facilita el desarrollo de un TCA ya que se considera que el rendimiento personal excepcional es esperado por los otros. Acorde a Selvini-Palazzoli (1974), Story (1976) y Strober (1981) la necesidad de permanecer alejado de los demás y el desinterés por desarrollar relaciones íntimas manteniéndose aislado constituye un rasgo 
psicológico llamado desconfianza interpersonal que guarda relación con la aparición y persistencia de ciertos TCA.

Adicionalmente Garner y Bemis (1985) se refirieron a la conciencia interoceptiva como la dificultad para reconocer estados emocionales ligados a la inseguridad, así como sensaciones viscerales relacionadas con el hambre y la saciedad los cuales son un factor importante en el desarrollo y mantenimiento de los TCA. Asimismo, el miedo a crecer consiste en una característica nuclear en pacientes portadoras de Anorexia Nervosa (AN) quienes presentan un temor a la madurez deseando regresar a la seguridad de los años de la pre-adolescencia por no querer afrontar las demandas de la adultez. Crisp (1980) relaciona la inmadurez psicosexual en la anorexia Nervosa (AN) con la regresión a un cuerpo prepuberal como un mecanismo maladaptativo para enfrentar los cambios biopsicosociales inherentes a la transición hacia la adultez. Con respecto al ascetismo Bell (1985), Casper (1983) y Rampling (1985) consideraron que el hacer dieta se acerca a un estado de purificación, siendo la búsqueda de la delgadez una virtud y el ayuno penitencia por lo que este rasgo se refiere a alcanzar ideales espirituales a través del sacrificio, restricción y control corporal. Con relación a la impulsividad, Casper (1990) la define como la imposibilidad de regular adecuadamente los propios impulsos lo cual es considerado como un elemento predictor de los TCA. Finalmente, en lo que se refiere a la inseguridad social, esta se relaciona con la observación de la dificultad experimentada por los pacientes con TCA en establecer relaciones sociales de calidad con su entorno (Bruch ,1973).

\subsubsection{Trastornos de la Conducta Alimentaria (TCA)}

El DSM-5(APA,2014) describe cuatro trastornos alimentarios que se desarrollan mayormente en la adolescencia o adultez y se reporta que se suele dar migraciones entre ellos (Morrison, 2014). El primero de ellos es la Anorexia Nerviosa (AN) que se caracteriza por la restricción del consumo de alimentos ejerciendo un excesivo control en arras de reducir el peso corporal y mantener el mismo a pesar de encontrarse excesivamente delgada, tener una fijación en cuanto al peso y miedo a engordar y, poseer una autopercepción distorsionada con respecto a la imagen corporal percibiéndose con sobrepeso. Este trastorno afecta al 1\% de la población mundial y se presenta tres veces más en mujeres que en varones. La Anorexia nerviosa puede presentarse en dos modalidades distintas, sea restrictiva o purgativa. La anorexia de tipo restrictiva consiste en la restricción extrema de ingestas en cambio la anorexia de tipo 
purgativa conjuga conductas de atracones seguidas de purgas auto inducidas o uso de laxantes o diuréticos con la finalidad de mantener un reducido peso corporal. Ambos tipos acarrean consecuencias peligrosas para la salud debido a la falta de nutrientes indispensables para el normal funcionamiento del organismo conllevando a la absorción de recursos de otros órganos como los huesos o músculos para suplir esas carencias ocasionando un debilitamiento general del cuerpo y hasta peligros de fracturas óseas. Así mismo se presentan síntomas paralelos como el disfuncionamiento de la hormona tiroidea, alteración de la menstruación, del ritmo cardiaco, de la presión sanguínea, alteraciones renales e intestinales, así como problemas a nivel de procesos cognitivos superiores como la concentración, atención y memoria. Este trastorno tiene una alta comorbilidad con otros trastornos como los trastornos del ánimo y en especial la depresión mayor, los trastornos de ansiedad como el trastorno de ansiedad generalizada, los ataques de pánico, la agorafobia y el trastorno obsesivo compulsivo así como el trastorno del control de impulsos y guarda relación con rasgos de personalidad rígidos y perfeccionistas. Para poder establecer el diagnóstico de AN es importante tomar en consideración la duración de las conductas propias de la AN debiendo estas presentarse durante un lapso de tiempo superior a los tres meses y la determinación de la gravedad del estadio del trastorno se mide mediante la evaluación del nivel de IMC (IMC: $\mathrm{Kg} / \mathrm{m} 2$ ) pudiéndose ser extremo si este es inferior a 15, grave cuando se encuentra entre 15 y 16 , moderado entre 16 y 17 y leve cuando el IMC es superior a 17 (Quiroga, 2006).

La bulimia nerviosa (BN) es otro TCA que se presenta también mayormente en mujeres y con mayor frecuencia que la $\mathrm{AN}$ afectando entre $1 \%$ y $2 \%$ de las mujeres a nivel mundial. Sus consecuencias son menos mortales y se diferencia de la AN ya que no experimentan autopercepción equivocada de su imagen corporal ni tampoco ejercen el control excesivo sobre la ingestión de alimentos. En este trastorno la paciente se caracteriza por experimentar dificultad en cuanto a poder limitar la cantidad de las ingestas procediendo a incurrir en conductas impulsivas de atracones alimentarios a pesar de encontrarse saciada e inducirse a los vómitos. Adicionalmente implementan conductas compensatorias como la realización de ejercicio excesivo y prácticas purgativas recurriendo al uso de laxantes y/o diuréticos como las prácticas implementadas en la anorexia purgativa para equilibrar el índice ponderal. A diferencia de la AN estas pacientes no muestran una drástica reducción del IMC, más bien tienden a tener un peso normal o sobrepeso sin alcanzar niveles de obesidad y para efectos de diagnóstico no se recurre al índice de IMC sino a la duración y la frecuencia semanal de los episodios de conductas compensatorias calificándolas como leves si se 
presentan de una a tres veces por semana, moderada si se implementan de cuatro a siete veces por semana, grave cuando supera ocho episodios semanales y extremo al realizarse más de 14 veces por semana por un lapso de tiempo de tres meses o más. Existe una comorbilidad de la BN con los trastornos del ánimo, de ansiedad y de control de impulsos (Morrison, 2014).

Asimismo, se registra otro TCA llamado Trastorno de Atracones (APA, 2014) que se caracteriza por una pérdida de control con respecto al consumo, muchas veces de manera solitaria y a escondidas, de grandes cantidades de alimentos en un tiempo bastante corto a pesar de ya no percibir hambre, alcanzando un incómodo nivel de plenitud. A diferencia de la Bulimia Nerviosa (BN) este consumo excesivo no da origen a la aplicación de técnicas compensatorias para reducir el excedente de peso, por lo que la paciente presenta niveles de sobrepeso u obesidad. Este tipo de conductas suele iniciarse cuando la persona experimenta sentimientos de soledad, ansiedad o tristeza encontrando un alivio en la ingesta de alimentos y guarda relación con trastornos depresivos y ansiosos, así como con trastornos del control de los impulsos. El diagnóstico de gravedad de este trastorno se establece en función de la frecuencia de los episodios de atracones guardando los mismos rangos diagnósticos considerados en el caso de la bulimia nerviosa (Morrison, 2014).

Finalmente se conoce otro TCA llamado Trastorno de la Conducta Alimentaria No Especificada (TANE) (APA, 2014) en el cual son agrupados todos aquellos trastornos que si bien resultan ser una alteración de la conducta alimentaria no pueden ser diagnosticados como tales debido a que son un cuadro incompleto y no cumplen con los suficientes criterios para recibir un diagnóstico formal y categorial, sin embargo, son de igual importancia y ameritan tratamiento.

\subsubsection{La génesis y mantenimiento de los TCA}

Al investigar sobre la génesis de los TCA se observa que la etiopatogenia resulta en una red compleja que engloba factores biológicos, ambientales, individuales y comportamentales cuya combinación puede influenciar el desarrollo de un TCA (Ruiz, Vásquez, Mancilla, Viladrich, \& Halley, 2013; Trace, Baker, Peñas, \& Bulik, 2013). En lo que se refiere a los aspectos individuales presentes en personas que desarrollan un TCA, Camarillo (2015) menciona una serie de características personales como son la baja autoestima, la dificultad para tolerar la frustración, la impulsividad, los rasgos de personalidad obsesiva y perfeccionista, los rasgos de personalidad ansioso-depresivos, la dificultad en la aceptación 
de la necesidad de otro, las dificultades en el manejo de la dependencia, aspectos en la organización del narcicismo no resueltos así como la dificultad para establecer vínculos íntimos y mantenerlos. Asimismo, la autora evoca la asociación de personalidades más impulsivas e inestables emocionalmente, menos perfeccionistas y con una dificultad en reconocer la necesidad del otro en sus relaciones interpersonales a rasgos característicos de la bulimia y por el contrario asocia rasgos de personalidad narcisistas, perfeccionistas, controladoras, así como una dificultad en establecer un vínculo con el otro a rasgos característicos de la anorexia.

Adicionalmente en cuanto a la posible contribución de las características personales de tipo perfeccionista en el aumento del riesgo de presentar un TCA, Verstuyf, Patrick, Vansteenkiste y Teixeira (2012) refieren que el mostrar rasgos de personalidad perfeccionista lleva a desarrollar una mayor cantidad de frustración al no poder alcanzar los estándares personales generando por lo tanto una emoción negativa. En ese contexto, refieren que el ejercer un control sobre las conductas alimentarias permitiría sobrellevar la experiencia de aquella emoción negativa restableciendo un bienestar el cual es alcanzado mediante el acto de control ejercido sobre la comida. Adicionalmente se encuentran investigaciones que estudian la relación existente entre el perfeccionismo y los cinco grandes rasgos de la personalidad desarrollados por Costa y McRae (1992) encontrándose una asociación positiva entre el perfeccionismo y el neuroticismo (Sherry, Hewitt, Fleet, Lee-Baggley y Hall, 2007) así como una relación entre el neuroticismo y el padecer un TCA puntuando más alto en dicha dimensión de la personalidad aquellas personas con un TCA (Sanchez, 2013).

En nuestro medio se encuentra un estudio que detalla la lectura psicoanalítica de los TCA (Zusman, 2004) refiriéndose a su complejidad debido a la presencia de síntomas físicos evidentes a pesar de no encontrar ninguna causa orgánica. La autora menciona que los TCA, a diferencia de la histeria, no imitan una enfermedad física sino que expresan, a través de la manipulación de la ingesta de la comida, las dificultades de asumir el cuerpo y sus necesidades descargando el dolor emocional y las experiencias afectivas de la psique. Indica que el cuerpo se torna en un significante que emite un mensaje concreto y superficial que esconde afectos exentos de representación mental que no han podido expresarse a través del lenguaje y menciona que los desórdenes de la conducta alimentaria son esfuerzos llevados a cabo por jóvenes adolescentes en aras de resolver o esconder un problema vital al cual no encuentran solución, haciéndolo a través del control sobre la comida. Asimismo, refiere que para intentar comprender la etiopatogenia del TCA resulta importante revisar los aportes acerca de la teoría 
del vínculo (Bowlby,1988) y la teoría de las relaciones objetales aportados por Melanie Klein (Ramírez, 2010) en relación con las organizaciones patológicas por su importancia en explicar el proceso de formación y mantenimiento de los TCA. Menciona que cuando se presenta un maternaje de tipo errático y un vínculo temprano insatisfactorio, estos favorecen el desarrollo de un self no integrado y la aparición de un TCA asociado a un comportamiento de aislamiento y oposición al medio. En la etapa de la adolescencia se produce un quiebre (Laufer, 1997) el cual seria una segunda significancia de la falla temprana y del trauma original presentándose como un espacio de reedificación del conflicto original negando la comida como si se negara la madre. Asimismo, en relación con la particularidad del vinculo materno y su rol en la etiopatogenia del TCA, Zuzman (2009) indica que por lo general las madres de los pacientes con TCA son mujeres eficientes, de tipo ansioso y preocupado que suelen generar relaciones de dependencia con sus hijos. Se caracterizan por atender a sus necesidades antes que estos las hayan podido manifestar anulando así la capacidad del hijo en detectar sus propias necesidades y diferenciarlas del ofrecimiento exterior. Este tipo de comportamiento acarrea una falta de autonomía e independencia en los hijos limitando su posibilidad de autocontrol en sus vidas. Esto se traduce luego, en la etapa de la adolescencia, en una tendencia a demarcar sus limites reduciendo las intervenciones de la madre y ejerciendo entonces el control que se les negó en la niñez. El periodo de la pubertad y adolescencia consiste en una transición tanto a nivel corporal como psíquico hacia la adultez que involucra cambios sustantivos propios del ciclo del desarrollo y madurez con respecto del crecimiento físico, sexual y afectivo, la separación e individuación de las figuras parentales y la consolidación de la identidad de género. Por lo tanto este periodo resulta ser el momento propicio para que las jóvenes afirmen su autonomía convirtiendo su cuerpo en el lugar ideal para ejercer el control a través de la alimentación y manejo del peso corporal. Zuzman (2009) subraya que la literatura contemporánea referente a los TCA hace alusión al rol predisponente ejercido por la madre ligado a su presencia activa desde el embarazo y durante la crianza, convirtiendo al padre en un "segundo mejor", lo cual la responsabilizaría de la génesis y mantenimiento del problema familiar. Refiere que si en la niñez la ecuación madre - comida fue vivida de manera dolorosa, interrumpida o inconstante, esta puede ocasionar el establecimiento de una relación perturbada con la comida en la adolescencia, sin embargo, indica que atribuir toda la responsabilidad a la madre sería cuestionable y sugiere que se debe de priorizar adoptar un enfoque transgeneracional tomando en cuenta el aporte de ambos padres y sus familias al desarrollo y mantenimiento del trastorno. Por lo tanto, resulta necesario analizar los aspectos 
del vínculo temprano, el self, la relación y la comunicación familiar, así como las experiencias intersubjetivas de la infancia debido a que estos juegan un rol importante en el desarrollo de los TCA y que acarrean experimentación de dolor psíquico y vacío emocional a estos pacientes.

Asimismo, Zusman (2009) propone una descripción de los factores de riesgo hacia los TCA clasificándolos en factores de predisposición, precipitantes y de mantenimiento los cuales intervienen, asociados con la vulnerabilidad personal en el marco de la sociedad, en el desarrollo de la patología. La autora refiere que los factores predisponentes emanan de un fondo emocional y están relacionados con el miedo a crecer y asumir la madurez femenina, la inseguridad personal, las aspiraciones de logro y el temor a ser incompetente, la ausencia de autonomía, los patrones disfuncionales de la interacción familiar y la influencia sociocultural promotora del patrón de la delgadez. En cuanto a los posibles factores precipitantes menciona algunos como la tendencia hacia los conflictos interpersonales y la dificultad en resolverlos, el incremento de conductas de logro, la búsqueda de aceptación social y satisfacción de la necesidad de pertenencia por medio de la apariencia, la llegada de la menstruación vivida como una intrusión, los cambios corporales perturbadores, la disrupción en el equilibrio familiar, los cambios de nivel socioeconómico, las experiencias sexuales anticipadas o displacenteras y los comentarios reforzadores por el entorno acerca de la importancia de la delgadez, entre otros. Finalmente, en cuanto a los factores de mantenimiento, Zusman menciona el rol ejercido por la cultura occidental la cual asocia la restricción alimentaria y la delgadez al éxito, a la capacidad de control y a la valía personal. El ser capaz de desarrollar y mantener un control estricto sobre el peso y la alimentación se convierte en un reforzador positivo creando un sentido de efectividad y una consiguiente buena autoestima, y se convierte en una solución al conflicto emocional vivenciado por la adolescente.

Adicionalmente el estudio de Zusman (2004) hace referencia al aporte de la terapia de familia en cuanto a la génesis de los TCA, cuestionando si la génesis del TCA es exclusivamente individual o si involucra al sistema familiar. Minuchin (1978) y Selvini Pallazolli (1974) se refieren a la enfermedad como un síntoma familiar y como una enfermedad individual que afecta a todo el sistema familiar. Indican que el síntoma alimenticio es un tipo de barrera implementado para regular la estabilidad familiar cuando los problemas se mantienen y amenazan al equilibrio familiar. Llaman "familia psicosomática" a aquellos sistemas familiares en los cuales se desarrolla un TCA y refieren que estos suelen 
ser de tipo disfuncional, bloqueando la individuación y la evolución saludable de sus miembros desconociendo la existencia de un problema propio al sistema familiar salvo aquel que aqueja al paciente indicado. En general la familia psicosomática se caracteriza por ejercer sobreprotección intensificando la proximidad e intensidad de las interacciones familiares en todos los niveles del sistema retardando el proceso de autonomía, competencia y desarrollo de intereses personales en sus miembros. Asimismo suelen tener limites difusos entre sus subsistemas, pobre diferenciación interpersonal y mostrar rigidez experimentando dificultades en los periodos de cambio.

Al igual que Minuchin (1978) y Selvini Pallazolli (1974), Quiroga (2006) reporta que en los hogares en los cuales se desarrolla un TCA se observa la presencia de una disfunción familiar ya sea a nivel de conflicto entre padres e hijos y/o también en la relación de pareja siendo el TCA un síntoma de una disfunción familiar preexistente. En cuanto a la contribución de variables familiares al desarrollo de un TCA, indica que suele encontrarse presencia de antecedentes de anorexia y/o trastornos psiquiátricos en algún miembro de la familia. Asimismo, atribuye la responsabilidad de la génesis y el mantenimiento de los TCA al ejercicio de un estilo parental autoritario, una pobre comunicación intrafamiliar, un historial de refuerzos y castigos desadaptativos, poca manifestación de afecto, patrón de alimentación inapropiado, así como una presión por la delgadez.

Al continuar revisando la literatura nacional, se encuentra el aporte de De Las Casas (2008) quien realiza una descripción de la relación existente entre las propuestas freudianas en cuanto al desarrollo psicosexual y la incidencia de la presentación de los TCA en la adolescencia femenina. Describe la complejidad de la estructuración de la zona erógena oral compuesto por el impulso que equivale al hambre, la boca como zona erógena de placer, el comer que viene a ser la incorporación, el alimento como sinónimo de la satisfacción, el pecho materno productor del alimento y la madre como objeto proveedor de alimento y afecto. Se refiere al establecimiento del vínculo entre esta zona erógena oral y la madre como objeto proveedor pudiendo explicar, en el caso de una fijación en la etapa oral, la aparición de síntomas y perturbaciones alimentarias. De las Casas también hace mención de la alteración de la percepción corporal por la joven con TCA al mirarse en el espejo haciéndolo de manera distorsionada, e indica que este hecho podría atribuirse a que la adolescente no encuentra la aprobación de afecto ni aceptación que requiere en la mirada materna. Lo anterior trae como consecuencia que la joven se descalifique y se desapruebe. Finalmente, al igual que Zusman (2009), De las Casas (2008) hace referencia a la figura paterna distante o ausente y a una 
madre omnipresente coincidiendo con la asociación de la constelación parental de la familia disfuncional con los cuadros de TCA.

Bruch (1973) atribuye el origen de un TCA a la calidad de las relaciones tempranas entre las madres y sus hijas en las cuales la madre no está en capacidad de atender las necesidades de su hija asumiendo un comportamiento controlador. Menciona la importancia de la calidad de las dinámicas familiares y en particular la calidad de la relación madre hija, subrayando como influencian la aparición de caminos mal adaptativos que conllevan a una pobre percepción de la imagen corporal precursora de patologías alimentarias. Se refiere al comer como una actividad que conjuga simultáneamente experiencias fisiológicas, psicológicas y afectivas las cuales están ligadas al vinculo temprano con la madre y subraya la importancia del papel del hogar en los aprendizajes tempranos con respecto a aspectos ligados al estilo de alimentación y la relación con la comida, las estrategias de control personal y las pautas de interacción social ya que todas se aprenden en los primeros años de vida.

Adicionalmente se encuentra en nuestro medio un estudio de Borrego (2010) que consiste en correlacionar los factores de riesgo psicológicos, familiares y socioculturales con los indicadores clínicos asociados a los TCA en una muestra no-clínica de 355 mujeres estudiantes entre los 16 y 20 años. El autor realizó una correlación de Pearson entre los instrumentos Cuestionario de Factores de Riesgo de Trastornos de la Conducta Alimentaria (Borrego, 2010) y el Inventario de Trastornos de la Conducta Alimentaria EDI-2 (Garner, $1998)$ encontrándose una correlación fuerte $(r=.60, p<.01)$ entre los totales de los factores de riesgo y los totales de los indicadores clínicos asociados a los trastornos de la conducta alimentaria. En lo que se refiere específicamente a la relación entre el factor de riesgo familiar descrito por el autor como un desencadenante de TCA debido a la presión ejercida por la familia, subraya el rol de la influencia materna en la génesis de estos TCA debido a que las madres han sufrido en su juventud un cuadro ligado a un TCA con una valoración positiva de bajo peso, hábitos dietéticos, hiperactividad, pudiendo transmitir estos a sus hijas. El autor reporta una correlación positiva de ese factor de riesgo familiar con 8 de las 11 dimensiones del EDI-2. En efecto se observa una relación altamente significativa entre el factor familiar y las tres dimensiones principales de las actitudes relacionadas con las conductas, el tipo y el peso del EDI-2: Obsesión por la Delgadez (DT) $(r=.43, p<.01)$, Bulimia (B) $(r=.36, p$ $<.01)$, e Insatisfacción Corporal (DB) $(r=.39, p<.01)$, así como con las dimensiones más generales referidas a los siguientes rasgos psicológicos clínicamente relevantes en TCA: Ineficacia (I) $(r=.38, p<.01)$, Conciencia Interoceptiva (IA) $(p=.38, p<.01)$, Impulsividad 
(IR) $(r=.31, p<.01)$ e Inseguridad Social (SI) $(r=.35, p<.01)$, evidenciando así que la familia se constituye en un factor desencadenante con altas posibilidades de predisponer a un TCA.

\subsection{Relación entre el rasgo perfeccionismo en madres y el desarrollo de trastornos de la conducta alimentaria en hijas adolescentes escolares}

Debido a que el objetivo principal de la presente investigación es determinar la relación existente entre el perfeccionismo de las madres y los rasgos predisponentes de los trastornos de la conducta alimentaria en las hijas adolescentes, resulta importante mencionar el estudio de Vásquez y Reidl (2013) quienes evaluaron el papel de la madre en la génesis y el mantenimiento de las conductas alimentarias desadaptadas así como la insatisfacción corporal en sus hijas, los cuales son aspectos presentes en los TCA. El objetivo de dicho estudio fue analizar siete publicaciones sobre el tema y desde allí comprender y establecer si las conductas de las madres se relacionan con las alteraciones en la conducta alimentaria de las hijas. Tomaron en cuenta factores de riesgo como el IMC de las madres, su hábito de seguir dietas restrictivas, la importancia que atribuyen a la imagen corporal con relación a los patrones dictados por la sociedad, sus conductas compulsivas con la alimentación, la insistencia en la importancia del control del peso, así como las restricciones que imponen sobre la alimentación de sus hijas. Concluyeron que el papel de la madre contribuye en el desarrollo de actitudes y conductas alimentarias desadaptadas en las hijas, no solo por modelamiento de las conductas sean estas de tipo restrictivas o de descontrol, sino también imponiendo restricciones en la alimentación de sus hijos, y transmitiéndoles la internalización de los estándares de belleza impuestos por la sociedad.

El estudio que sigue a continuación tiene como objetivo analizar la relación existente entre el perfeccionismo materno y la vulnerabilidad en desarrollar un TCA en sus hijas adolescentes e indagar cuáles son los mediadores que intervienen en el desarrollo de un TCA en sus hijas adolescentes. Se procedió a evaluar una muestra apareada de 109 madres-hijas adolescentes entre 15 y 22 años del sector socio económico A de la ciudad de Lima Metropolitana utilizando la Escala Multidimensional del Perfeccionismo (EMP) y el Eating Disorder Inventory-2 (EDI-2). 


\section{CAPÍTULO III: OBJETIVOS, HIPÓTESIS Y DEFINICIÓN DE VARIABLES}

\subsection{Objetivos}

1. Analizar la relación entre el perfeccionismo auto-orientado (AO), el perfeccionismo orientado a los demás (OD) y el perfeccionismo socialmente prescrito (SP) de las madres y la vulnerabilidad en presentar un TCA: anorexia (obsesión por la delgadez -DT) y bulimia (bulimia - B) en sus hijas adolescentes de 15 a 22 años en la ciudad de Lima Metropolitana.

2. Analizar el efecto mediador de los rasgos predictores de TCA tales como la insatisfacción corporal (BD), la ineficacia (I), el perfeccionismo (P), la desconfianza interpersonal (ID), la conciencia interoceptiva (IA), el miedo a la madurez (MF), el ascetismo (A), la impulsividad (IR) y la inseguridad social (IS) entre el perfeccionismo auto orientado (AO), el perfeccionismo orientado a los demás (OD) y el perfeccionismo socialmente prescrito (SP) de las madres y la vulnerabilidad en desarrollar un TCA en sus hijas adolescentes de 15 a 22 años en la ciudad de Lima Metropolitana.

\subsection{Hipótesis}

$\mathrm{H}_{1}$ : Las dimensiones de perfeccionismo auto-orientado (AO), orientado a los demás (OD) y socialmente prescrito (SP) de las madres se asociarán de manera positiva con la vulnerabilidad a desarrollar un TCA: anorexia (obsesión por la delgadez -DT) y bulimia (bulimia - B) en sus hijas adolescentes de 15 a 22 años en la ciudad de Lima Metropolitana.

$\mathrm{H}_{2}$ : La relación entre las dimensiones perfeccionismo auto orientado (AO), perfeccionismo orientado a los demás (OD) y perfeccionismo socialmente prescrito (SP) de las madres y la vulnerabilidad a desarrollar un TCA en sus hijas adolescentes de 15 a 22 años en la ciudad de Lima Metropolitana estará mediada por los rasgos predictores de TCA como la insatisfacción corporal (BD), la ineficacia (I), el perfeccionismo (P), la desconfianza interpersonal (ID), la conciencia interoceptiva (IA), el miedo a la madurez (MF), el ascetismo (A), la impulsividad (IR) y la inseguridad social (IS). 


\subsection{Variables}

\subsubsection{Perfeccionismo}

Los autores Fleet y Hewitt (1991) avanzan que el perfeccionismo está constituido por tres dimensiones: el perfeccionismo auto orientado (AO), el perfeccionismo orientado hacia los demás (OD) y el perfeccionismo socialmente prescrito (SP). Los autores mencionan que "el perfeccionismo auto orientado (AO) consiste en adoptar comportamientos en los cuales se auto-fijan estándares de exactitud, procediendo a evaluar constantemente y censurar rigurosamente su comportamiento". Asimismo, definen al perfeccionismo orientado hacia los demás (OD) como "un perfeccionismo parecido al perfeccionismo auto orientado con la diferencia que este comportamiento es orientado hacia el exterior, estableciendo estándares irrealistas para las personas significativas del entorno esperando perfección y procediendo a evaluarlos rigurosamente". En cuanto al perfeccionismo socialmente prescrito (SP) los autores lo describen como "la percepción de tener que alcanzar estándares y expectativas no realísticos prescritos por los demás quienes ejercen presión esperando perfección y los evalúan de manera rigurosa" (Hewitt y Fleet, 1991, p. 457).

Operacionalmente se obtendrán los valores de perfeccionismo a través de las puntuaciones en el instrumento Escala Multidimensional del Perfeccionismo (EMP) (Rodríguez, Rojo, Ortega, y Sepúlveda, 2009) en cada una de las tres dimensiones del perfeccionismo: perfeccionismo auto orientado $(\mathrm{AO})$, perfeccionismo orientado a los demás (OD) y perfeccionismo socialmente prescrito (SP).

\subsubsection{Trastornos de la Conducta Alimentaria}

Conceptualmente los TCA se definen como "alteraciones específicas y severas en la ingesta de los alimentos, observadas en personas que presentan patrones distorsionados en el acto de comer y que se caracterizan bien sea por comer en exceso o por dejar de hacerlo en respuesta a un impulso psíquico y no por una necesidad metabólica o biológica" (Méndez, Vásquez, y García, 2008, p. 580). Debido a que el interés del presente estudio es evaluar el riesgo de desarrollar un TCA en las adolescentes frente al perfeccionismo de las madres, éste se medirá operacionalmente a través de las medias aritméticas de las puntuaciones alcanzadas en las dimensiones obsesión por la delgadez (DT) y bulimia (B) del Inventario de Trastornos de la Conducta Alimentaria - EDI-2 (Garner, 1991) combinando ambas dimensiones en una única variable dependiente solo si se encuentra una consistencia interna alta $(\omega>.70)$. 


\subsubsection{Mediadores - rasgos predisponentes de los trastornos de la conducta alimentaria}

(TCA)

Los rasgos predisponentes de los TCA son definidos conceptualmente por diversos autores. Garner y Gafinkel (1981) consideran la insatisfacción corporal (BD) como la perturbación de la imagen corporal referida al disgusto con la forma general de su cuerpo o aquella parte de él que puede considerarse como factor responsable del inicio y persistencia de TCA. Bruch (1978) define la ineficacia (I) como el sentimiento de incapacidad general, inseguridad, vacío, auto desprecio y falta de control sobre la vida. Asimismo, Bruch (1978) se refiere al perfeccionismo $(\mathrm{P})$ como la lucha por alcanzar altos niveles de rendimiento personal.

Selvini-Palazzoli (1974), Story (1976) y Strober (1981) describen la desconfianza interpersonal (ID) como la necesidad de permanecer alejado de los demás y el desinterés por desarrollar relaciones íntimas manteniéndose aislado. Acorde a Garner y Bemis (1985), la conciencia interoceptiva (IA) es la dificultad para reconocer estados emocionales ligados a la inseguridad, así como sensaciones viscerales relacionados con el hambre y la saciedad. Crisp (1980) define el miedo a la Madurez (MF) como el temor a la madurez psico-biológica relacionada con el peso de la adultez y el deseo por conservar una apariencia prepuberal.

Bell (1985), Casper (1983) y Rampling (1985) se refieren al ascetismo (A) como una virtud cuyo fin es la búsqueda de la delgadez y una purificación siendo el ayuno un acto de penitencia por lo que este rasgo se refiere a alcanzar ideales espirituales a través del sacrificio, restricción y control de las necesidades corporales. En cuanto a la impulsividad (IR), Casper (1990) la define como la incapacidad de regular adecuadamente los propios impulsos. Finalmente, Bruch (1973) define la inseguridad social (IS) como la creencia de que las relaciones sociales son tensas, inseguras, incómodas, insatisfactorias y generalmente de escasa calidad. Operacionalmente se medirán los mediadores hacia el desarrollo de un TCA a través de las puntuaciones alcanzadas en cada una de las dimensiones del Inventario de Trastornos de la Conducta Alimentaria - EDI-2 (Garner, 1991) referidas a estos rasgos. 


\section{CAPÍTULO IV: MÉTODO}

\subsection{Tipo y Diseño de Investigación}

El alcance de la investigación es de tipo cuantitativo por lo que los datos son procesados y analizados de forma estadística y es transversal por recoger la información en un momento único (Hernández, Fernández y Baptista, 2014). Asimismo, la investigación es de tipo no experimental al no manipularse ninguna variable y sólo es una búsqueda empírica y sistemática en la que el investigador no posee control sobre ninguna variable debido a que sus manifestaciones ya han ocurrido (Kerlinger y Lee, 2002). Finalmente, este estudio es de diseño correlacional por lo que tiene como propósito medir el grado de relación entre las variables sin evaluar la causalidad entre la variable perfeccionismo en las madres y la presencia de rasgos de vulnerabilidad a presentar algún TCA en las hijas (Díaz, 2009).

En cuanto al diseño de investigación se utiliza el modelo mediacional paralelo múltiple (Hayes, 2013) el cual se ejemplifica en la siguiente figura 4.1.

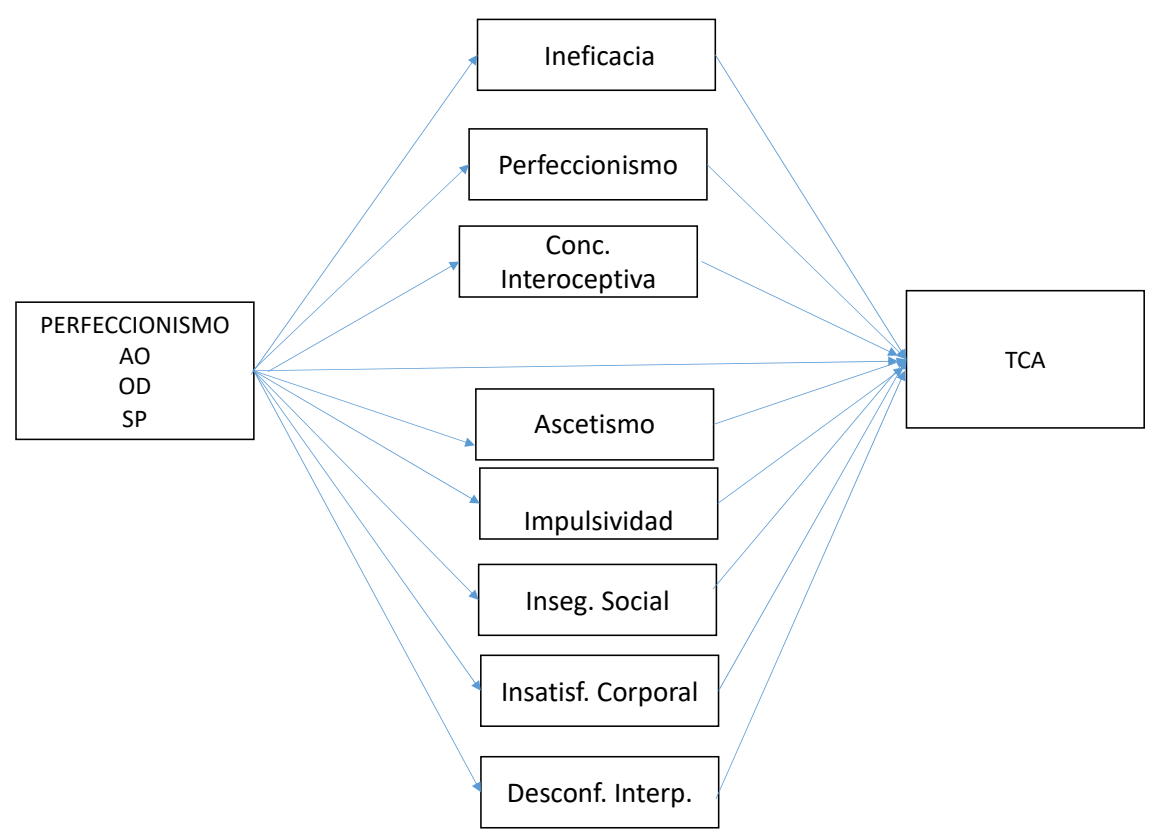

Figura 4.1. Modelo de mediación múltiple paralelo 


\subsection{Participantes}

Los participantes de esta investigación fueron estudiantes del género femenino en edad adolescente entre 15 y 22 años $(\mathrm{M}=18,47, \mathrm{DE}=1,99)$ y sus madres pertenecientes al nivel socioeconómico A de la ciudad de Lima metropolitana. Acorde a la Encuesta Nacional de Hogares sobre condiciones de vida y pobreza- ENAHO-2016- realizada por el Instituto Nacional de Estadística e Informática (INEI, 2016) para elaborar los indicadores de pobreza del país, este nivel socioeconómico corresponde al nivel que dispone de mayores recursos en el país. Como criterio de exclusión se decidió incluir solamente una hija entre 15 y 22 años por cada madre a pesar de que esta tuviera otras hijas en ese rango de edad, y se excluyen aquellas adolescentes que tuvieran un diagnóstico de TCA. La participación fue voluntaria y la aplicación tardó un mes para poder recabar la información necesaria.

La muestra fue reclutada de manera no probabilística intencional ya que la selección de los elementos no depende del uso de fórmulas probabilísticas en el que todos los integrantes tienen la misma probabilidad de ser elegidos, sino de causas ligadas a las características de la investigación, de la toma de decisión del investigador y por el hecho que esta investigación no busca generalizar resultados ni que los casos sean estadísticamente representativos de la población (Hernández et al., 2014). El tipo de muestra fue por conveniencia porque los sujetos fueron seleccionados por la fácil disponibilidad, accesibilidad y proximidad para el investigador, y se reclutó también algunos sujetos mediante la técnica en cadena o también llamada por redes o bola de nieve debido a que los sujetos inicialmente seleccionados por el investigador fueron a su vez refiriendo otros sujetos con características similares las cuales son acorde a los criterios de selección planteadas para el estudio (Del Cid, Méndez y Sandoval, 2011). Es importante señalar que la realización de los cuestionarios se llevó a cabo de manera independiente, en diferente momentos y espacios por las participantes al recibir cada una, madres o hijas un enlace directo por vía electrónica para efectuar el llenado del cuestionario en la plataforma virtual.

Para efectos del cálculo del tamaño de la muestra, este se realizó a través del programa estadístico MedPower (Kenny, 2017). Se consideró una potencia de .90 para el "camino a" de la variable perfeccionismo hacia los mediadores , una potencia de .88 para el camino "b" de los mediadores hacia la variable dependiente, una potencia de $.51 \mathrm{del}$ "camino c" que une la variable perfeccionismo hacia la variable TCA sin tomar en cuenta la acción de los 
mediadores, y una potencia de .79 para los "caminos ab" que enlaza indirectamente la variable perfeccionismo con la variable TCA tomando en cuenta los mediadores. Se obtuvo una cantidad de $\mathrm{n}=109$ participantes, es decir 109 binomios madres e hijas adolescentes entre 15 y 22 años.

\subsection{Técnicas de recolección de información}

La información de las variables se recogió a partir de dos fichas sociodemográficas (consultar anexos 1 y 2) y la aplicación de dos instrumentos psicométricos: la Escala Multidimensional de Perfeccionismo (EMP) (consultar anexo 3) y el Inventario de Trastornos de la Conducta Alimentaria - Eating Disorder Inventory 2- (EDI-2) (consultar anexo 4).

\section{Fichas sociodemográficas}

Las fichas socio demográficas desarrolladas específicamente para esta investigación incluyeron información sobre edad, estado civil, cantidad de hijos, cantidad de personas que viven en el hogar, situación laboral, lugar de nacimiento, peso y talla.

\section{Escala Multidimensional de Perfeccionismo (EMP)}

Para la medición de la variable perfeccionismo se empleó la Escala Multidimensional de Perfeccionismo (EMP) la cual es una adaptación al castellano de la Multidimensional Perfectionism Scale (MPS) (Rodríguez, Rojo, Ortega y Sepúlveda, 2009) basada en la teoría del perfeccionismo de Hewitt \& Fleet quienes consideran tres tipos de perfeccionismo: El auto orientado (AO), el orientado a los demás (OD) y el socialmente prescrito (SP). Esta escala está compuesta por 45 ítems agrupados en tres dimensiones mencionadas anteriormente (véase en tabla 1) puntuándose 26 de ellos en forma directa en una escala likert de 7 puntos que se escalonan desde totalmente en desacuerdo (1), muy en descuerdo (2), bastante en desacuerdo (3), ni de acuerdo ni en desacuerdo (4), bastante de acuerdo (5), muy de acuerdo (6) y totalmente de acuerdo (7), y 19 ítem en forma inversa, es decir del 7 al 1. El ítem número 6 de la EMP es representativo del perfeccionismo auto orientado (AO) ("uno de mis objetivos es ser perfecta en todo lo que hago", $\omega=.93$ ), el ítem número 04 de la EMP es representativo del perfeccionismo orientado hacia los demás (OD): ("rara vez critico a mis amigos, cuando se contentan con poca calidad , $\omega=.65$ ) “y el ítem 5 de la EMP es representativo del 
perfeccionismo socialmente prescrito (SP) ("tengo dificultades en satisfacer las expectativas que los demás tienen sobre mí”, $\omega=.78)$. Los autores originales del instrumento sugieren no sumar las tres dimensiones para obtener una puntuación global, sino que, acorde al planteamiento de la teoría multidimensional, debe mantenerse las tres puntuaciones por separado. El uso de dicha prueba fue autorizado mediante una comunicación electrónica de Rodríguez (consultar en anexo 7), investigadora principal a cargo de la adaptación de la MPS al castellano (M.A. Rodríguez, comunicación personal, 31 de agosto 2017).

Los autores Rodríguez, Rojo, Ortega y Sepúlveda (2009) adaptaron y validaron el instrumento original llamado Multidimensional Perfecionism Scale (MPS) luego de recibir la autorización formal de la empresa Multi-Health Systems Incorporated quien tiene los derechos de autores del instrumento original, llamando a la nueva versión del instrumento Escala Multidimensional del Perfeccionsimo (EMP). Juzgaron necesario realizar la adaptación lingüística de la redacción de los ítems originales de la prueba para lo cual la cual se solicitó la colaboración de cinco profesionales expertos en textos de contenido psicológico quienes acordaron sobre las frases que mejor coincidían con el instrumento original, decidiendo utilizar el total de ítems del cuestionario original quedando conformado el instrumento adaptado por 45 ítems los cuales tienen por objetivo medir el comportamiento perfeccionista propuesto por Hewitt y Fleet: el perfeccionismo auto orientado, el perfeccionismo orientado hacia los demás y el perfeccionismo socialmente prescrito. Según lo reportado por Rodríguez et al., (2009) la adaptación española fue realizada con una muestra compuesta por 356 sujetos, 132 varones (38\%) y 224 mujeres (62\%), cuyas edades fluctuaban entre 17 y 42 años.

Para obtener evidencias de validez vinculadas a la estructura interna de las puntuaciones derivadas de aplicar este instrumento Rodríguez, Rojo, Ortega y Sepúlveda, (2009) utilizaron un análisis factorial con rotación varimax como fue realizada para la versión original Multidimensional Perfectionism Scale (MPS) (AERA, APA Y NCME, 2014) y comprobaron la existencia de los tres factores: el factor $\mathrm{N}^{\circ} 1$ (AO) agrupa 20 ítems, el factor $\mathrm{N}^{\circ} 2$ (SP) agrupa 14 ítems y el factor $\mathrm{N}^{\circ} 3$ (OD) agrupa 11 ítems. Los pesos factoriales correspondientes a los veinte ítems del primer factor fluctúan entre .78 y .25; los catorce ítems correspondientes al segundo factor varían entre .62 y .22 y, finalmente los once ítems del factor 3 se ubican entre .58 y .31 lo cual permite concluir que la adaptación del instrumento MPS al castellano presenta adecuada evidencia de validez vinculada a la estructura interna. 
En cuanto a la evidencia de validez vinculada a las relaciones con otras variables, observaron la existencia de una relación entre la Escala Multidimensional de Perfeccionismo (EMP) y la subescala de perfeccionismo (P) del EDI-2 (Garner, Olmsted y Polivy, 1983) al encontrarse una relación estadísticamente significativa entre dichas dimensiones, siendo la más elevada con la dimensión AO $(r=.61 ; p<.01)$, seguida de la dimensión $\operatorname{SP}(r=.57 ; p<.01)$.

Con relación a la estimación de las puntuaciones de confiabilidad resultantes de aplicar la Escala Multidimensional de Perfeccionismo (EMP) los estudios utilizados se centraron en la consistencia interna y la confiabilidad test-retest. En el primer estudio, los autores obtuvieron el resultado del alfa de cronbach fue $(\alpha=.86)$ para la escala total, y coeficiente de $(\alpha=.87)$ para la sub-escala perfeccionismo auto orientado (AO), $(\alpha=.66)$ para la sub-escala perfeccionismo orientado hacia los demás (OD) y $(\alpha=.76)$ para la sub-escala perfeccionismo socialmente prescrito (SP), presentando evidencia de puntaciones confiables. En relación al estudio de la temporalidad del instrumento Escala Multidimensional de Perfeccionismo (EMP) se utilizó el método Test- Retest mediante el cálculo del coeficiente de correlación intraclase con cinco semanas de diferencia para el cual se obtuvo un resultado de $(\alpha=.78)$ para la escala total y un coeficiente de $(\alpha=.82)$ en la dimensión de perfeccionismo auto orientado (AO), $(\alpha=.63)$ en la dimensión de perfeccionismo socialmente prescrito (SP) y $(\alpha=.72)$ en la dimensión del perfeccionismo orientado hacia los demás (OD). En base a los análisis obtenidos y expresados anteriormente Rodríguez et al. (2009) refirieron que las puntuaciones derivadas de la aplicación la Escala Multidimensional de Perfeccionismo (EMP) son válidas y confiables para evaluar el perfeccionismo en la población universitaria española.

En el año 2013, debido a que aún no se habían realizado estudios en Latinoamérica de la versión española del EMP, Tataje (2013) realizó una aplicación piloto de la prueba en Lima - Perú en un grupo de 285 jóvenes estudiantes con características similares a la muestra española con la finalidad de comprobar la correcta comprensión de la escala Likert así como de los ítems del instrumento y validar las propiedades psicométricas del instrumento. A ese efecto se replicó en la población local los análisis estadísticos realizados por los autores españoles calculando los estimadores Kaiser Meyer-Olkin (KMO; rango entre 0-1) y de designación de Bartlett y se llevó a cabo el análisis factorial mediante la extracción de componentes principales con rotación Varimax. Se obtuvo las evidencias de validez referidas a la estructura interna obteniendo un KMO de .87, un estimado de esfericidad de Bartlett que resultó estadísticamente significativo $(p<.01)$ y el análisis factorial exploratorio correspondió 
al establecimiento de los tres factores como señalado en la adaptación española. Los ítems incluidos en cada una de las tres dimensiones del instrumento Escala Multidimensional de Perfeccionismo (EMP) fueron los siguientes (véase en tabla 1).

\section{Tabla 1}

Distribución de Ítems directos e inversos del instrumento EMP

\begin{tabular}{lcc}
\hline Dimensión & Ítems directos & \multicolumn{1}{c}{ Ítems inversos } \\
\hline $\begin{array}{l}\text { Auto } \\
\text { Orientado }\end{array}$ & $1,6,7,11,14,15,17,18,20,23$, & 08 y 12 \\
$\begin{array}{l}\text { Orientado a } \\
\text { los Demás }\end{array}$ & $4,28,29,31,32,35,40,42$ & \\
Socialmente & & $2,3,10,19,24,36,37,43,45$ \\
Prescrito & $5,13,25,27,33,39,41$ & $9,21,22,30,34,38,44$ \\
\end{tabular}

Asimismo, en cuanto al estudio de confiabilidad vinculado a la consistencia interna de cada una de las tres dimensiones del instrumento Escala Multidimensional de Perfeccionismo (EMP) aplicadas al grupo de estudio de 285 jóvenes, Tataje (2013) reportó una alta consistencia interna para la dimensión perfeccionismo auto orientado $(\mathrm{AO})(\alpha=.91)$ con unas correlaciones ítem/ test que oscilaron entre $(r=.27)$ para el ítem $29 \mathrm{y}(r=.82)$ para el ítem 15; para la dimensión orientado hacia los demás (OD) $(\alpha=.66)$ con unas correlaciones ítem/test que fluctuaron desde $(r=.24)$, para el ítem 37, hasta $(r=.42)$, para el ítem $10 \mathrm{y}$ finalmente para la dimensión socialmente prescrito (SP) $(\alpha=.86)$ y correlaciones desde $(r=$ .38) para el ítem 44 y hasta $(r=.63)$ para el ítem 13. Acorde a los puntajes obtenidos de la aplicación del EMP, se observa que los ítems de las tres dimensiones de la Escala Multidimensional del Perfeccionismo (EMP) obtuvieron puntaciones confiables. 


\section{Inventario de Trastornos de la Conducta Alimentaria - Eating Disorder Inventory 2- EDI-2}

Para la medición de la variable de TCA, se utilizó el instrumento de tamizaje Inventario de Trastornos de la Conducta Alimentaria - Eating Disorder Inventory 2- EDI-2 (Garner, 1991). La finalidad de este instrumento no es llegar a un diagnóstico específico de TCA sino realizar la observación y evaluación de ciertos rasgos psicológicos que tienen relevancia y que normalmente acompañan un TCA lo cual permite obtener un perfil psicológico para así identificar posibles casos vulnerables en desarrollar un TCA. Esta versión EDI-2 es una versión revisada del EDI, instrumento original que data del 1983.

El EDI-2 es un inventario de auto-reporte que se dirige a una población de 12 años en adelante, consta de 91 ítems incluyendo 27 ítems inversos, los cuales evalúan síntomas conductuales, emocionales y cognitivos que podrían resultar en una vulnerabilidad a desarrollar trastornos de la conducta alimentaria. Los ítems son afirmaciones en formato Likert de 6 puntos que se escalonan desde siempre a nunca calificando los ítems directos con valores de siempre (3), casi siempre (2), a menudo (1), a veces (0), pocas veces (0) y nunca (0) y los ítems indirectos con valores de nunca (3), pocas veces (2), a veces (1), a menudo (0), casi siempre (0) y siempre (0). El instrumento tiene tres dimensiones principales de las actitudes relacionadas con las conductas, el tipo y el peso, las cuales son la obsesión por la delgadez (DT) representada por el ítem n³2 (“estoy preocupada porque querría ser una persona más delgada", $\omega=.83$ ), la bulimia (B) representada por el ítem no 38 ("suelo pensar en darme un atracón", $\omega=.58$ ) y la insatisfacción corporal (BD) representada por el ítem $\mathrm{n}^{\circ}$ 9 ("pienso que mis muslos son demasiado gruesos", $\omega=.83$ ). Asimismo, contiene ocho dimensiones más generales referidas a rasgos psicológicos que son clínicamente relevantes en este tipo de trastorno los cuales son la ineficacia (I) representada por el ítem n ${ }^{\circ} 10$ ("me considero una persona poco eficaz", $\omega=.85$ ), el perfeccionismo $(\mathrm{P})$ representado por el ítem $\mathrm{n}^{\mathrm{o}} 52$ ("creo que debo hacer las cosas perfectamente o no hacerlas", $\omega=.65$ ), la desconfianza interpersonal (ID) representada por el ítem no 57 ("soy incapaz de hablar sobre aspectos personales y sentimientos", $\omega=.78$ ), la conciencia interoceptiva (IA) representada por el ítem n $\mathrm{n}^{\mathrm{o}} 33$ ("no sé lo que ocurre en mi interior", $\omega=.80$ ), el miedo a la madurez $(\mathrm{MF})$ representado por el ítem n 3 (“me gustaría volver a ser niño para sentirme seguro”, $\omega=.15$ ) , el ascetismo (A) representado por el ítem n 66 ("me avergüenzo de mis debilidades humanas", $\omega=.64$ ), la impulsividad (IR) representada por el ítem $\mathrm{n}^{\circ} 79$, (“soy propensa a 
tener ataque de rabia o de ira", $\omega=.72$ ) y la inseguridad social (SI) representada por el ítem n 87 ("prefiero pasar el tempo sola que estar con los demás", $\omega=.82$ ). Las once dimensiones del EDI-2 (véase en tabla 2) fueron diseñadas para medir rasgos independientes por lo que se debe de considerar los puntajes obtenidos en cada escala de manera independiente y no obtener una puntuación global (Garner, 1998).

En el año 1998, Corral, González, Pereña y Seisdedos (1998) realizaron la adaptación española del EDI-2. Las puntuaciones obtenidas de la aplicación del instrumento original evidencian una alta confiabilidad test-retest $(r=.75$ a .94) y buena consistencia interna $(\alpha=$ .73 a. .93) (Hamel, Zaitsoff, Taylor, Menna y Legrange, 2012). En cuanto a la evidencia de validez relacionada con otras variables, se obtiene correlación con la sub-escala de motivación para adelgazar del Test de Actitudes hacia la Comida (EAT): $(r=.71)$; correlación de la subescala de Restricciones Alimentarias y el EAT: $(r=.61)$; sub-escala de bulimia con las dimensiones de bulimia y preocupación por la comida: $(r=.68)$ y también discrimina pacientes con trastornos de alimentación de personas libres de patología (Pérez, 2018). Según lo reportado por Guerrero (2008) el instrumento empleado en esta investigación fue adaptado a la población peruana, sometiéndolo a análisis estadístico reportándose puntuaciones confiables resultantes de su aplicación, así como evidencias de validez vinculadas a la estructura interna al analizar las puntuaciones obtenidas al aplicar el instrumento. El uso de este instrumento fue autorizado (consultar en anexo 7) mediante una comunicación electrónica de Guerrero (D. Guerrero, comunicación personal, 1 de setiembre 2017).

Para llevar a cabo la adaptación de la prueba a la realidad nacional, Guerrero trabajó con una muestra compuesta por 393 estudiantes entre los 16 y los 20 años de ambos sexos quienes cursaban los primeros años de pregrado en una universidad particular o cursos de preparación en una academia preuniversitaria de Lima Metropolitana. Al estar usando la versión española del instrumento buscó obtener la evidencia de validez vinculada al contenido, juzgó conveniente evaluar el estilo de redacción de los ítems de la prueba por posibles problemas de comprensión ligados a diferencias culturales. Procedió a someter esta versión a dos psicólogos jueces, los cuales no juzgaron necesario realizar modificación lingüística de dicha versión. Posteriormente entregó el instrumento a un juicio de expertos constituido por 10 jueces siendo nueve psicólogos y uno psiquiatra, para la evaluación final de los ítems e inclusión de cada ítem en su escala original. El análisis de los resultados mostró 
una concordancia de opinión igual o superior al $80 \%$ en el $97.8 \%$ de los ítems, observándose un acuerdo del 99\% de la totalidad de los ítems.

\section{Tabla 2}

Distribución de ítems directos e inversos del Instrumento EDI-2

\begin{tabular}{|c|c|c|}
\hline Dimensión & Ítems directos & Ítems inversos \\
\hline Obsesión por la Delgadez (DT) & $7,11,16,25,32,49$ & 1 \\
\hline Bulimia (B) & $4,5,28,38,46,53,61$ & \\
\hline Insatisfacción Corporal (BD) & $2,9,45,59$ & $12,19,31,55,62$ \\
\hline Ineficacia (I) & $10,18,24,27,37,41$ & $20,42,50$ \\
\hline Perfeccionismo $(\mathrm{P})$ & $13,29,36,43,52,63$ & \\
\hline Desconfianza Interpersonal (ID) & 34,54 & $15,17,23,30,57$ \\
\hline Conciencia Interoceptiva (IA) & $\begin{array}{l}8,21,33,40,44,47, \\
51,60,64\end{array}$ & 26 \\
\hline Miedo a la madurez (MF) & $3,6,14,35,48$ & $22,39,58$ \\
\hline Ascetismo (A) & $\begin{array}{c}66,68,75,78,82,86 \\
88\end{array}$ & 71 \\
\hline Impulsividad (IR) & $\begin{array}{l}65,67,70,72,74,77, \\
79,8183,85,90\end{array}$ & \\
\hline Inseguridad Social (IS) & 84,87 & $69,73,76,80,89,91$ \\
\hline
\end{tabular}

\subsection{Procedimiento de recolección de datos}

Para recoger los datos se procedió inicialmente al establecimiento de un contacto por vía electrónico con dos centros de educación escolar del nivel socio económico A de la ciudad de Lima Metropolitana. Se solicitó acceso a la muestra anexando una carta de presentación de la Universidad de Lima en la cual se encontraban detallados los objetivos de la investigación y los instrumentos a aplicar, sin embargo, no se consiguió las aprobaciones deseadas. Debido a este contratiempo se procedió a crear ambos instrumentos en una plataforma virtual lo cual permite obtener datos que guardan consistencia con los datos obtenidos de manera tradicional 
(Gosling, Vazire, Srivastava y John, 2004). Se inició luego el proceso de reclutamiento de la muestra de las madres e hijas adolescentes entre 15 y 22 años aplicando la técnica de bola de nieve, en cadena o por redes (Del cid, Méndez y Sandoval, 2011). En un primer momento se procedió a contactar de manera individual a cada madre mediante llamada telefónica, envío de mensaje por correo electrónico y mensajería instantánea explicando el objetivo de la investigación, solicitándole su acuerdo en participar y su autorización para la participación de su hija si esta fuera menor de edad. Luego se prosiguió a contactar directamente a la hija solicitando su participación en el estudio. Posteriormente se enviaron dos enlaces distintos de manera paralela, uno para la madre y otro para la hija, en los cuales se encontraban el consentimiento informado para las madres y su hija menor de edad y para las adolescentes mayores de edad (consultar en anexos 5 y 6) así como el instrumento EDI 2 para las adolescentes y el instrumento EMP para las madres. Se solicitó a las participantes llenar los cuestionarios de manera independiente, y la aplicación se realizó de forma anónima atribuyendo un mismo código a cada binomio madre-hija a colocar en la pregunta $\mathrm{N}^{\mathrm{o}} 2 \mathrm{de}$ ambos cuestionarios para posibilitar su posterior apareamiento. Los cuestionarios fueron recopilados durante el espacio de dos meses y luego importados y procesados. 


\section{CAPÍTULO V: RESULTADOS}

Acorde a los objetivos planteados se procederá en un primer momento a reportar los resultados del cálculo de los estadísticos psicométricos relacionados al análisis de las evidencias de confiabilidad de la consistencia interna de ambos instrumentos utilizando el coeficiente omega $(\omega)$ de McDonald tomando en cuenta la naturaleza ordinal de los datos (Dunn, Baguley y Brunsden, 2014). En un segundo momento se procederá a reportar las características del perfeccionismo de las madres obteniendo estadísticos descriptivos de las tres dimensiones evaluadas (AO, SP, OD) en el instrumento EMP y se procederá de la misma manera para describir las características de los rasgos asociados al riesgo de presentar un TCA con cada una las dimensiones del instrumento EDI- 2. Luego se procederá a reportar los estadísticos inferenciales de las correlaciones existentes entre las dimensiones de los instrumentos EMP y EDI-2. Posteriormente, con la finalidad de mejorar la comprensión de la etiopatogenia del TCA, se reportarán los resultados obtenidos de la aplicación del modelo mediador múltiple paralelo (Hayes, 2013), modelo de estudio propuesto en el cual la variable TCA es modelada directamente por la variable perfeccionismo en sus tres modalidades e indirectamente por los ocho mediadores que corresponden a los rasgos usualmente presentes en pacientes con TCA.

El modelo propuesto considera el efecto de la variable perfeccionismo en la variable TCA a través de $k+1$ caminos siendo un camino directo del perfeccionismo hacia el TCA sin pasar por ninguno de los mediadores y los otros caminos $k$ siendo indirectos, cada uno a través de un mediador único, teniendo así $k$ efectos indirectos específicos a través de cada uno de los mediadores contemplados (Hayes, 2013). Se analizarán los efectos directos, indirectos y totales a través del estudio de cuatro caminos distintos: el camino a que examina la correlación existente entre la variable perfeccionismo en sus tres modalidades y cada uno de los ocho mediadores; el camino b el cual analiza la correlación existente entre los mediadores y la variable TCA; el camino $\mathrm{c}$ que establece el efecto total existente entre la variable perfeccionismo y la variable TCA sin el efecto de los mediadores y finalmente se analiza el camino c' que consiste en el efecto de los mediadores en la relación entre el perfeccionismo y la variable TCA. Con la finalidad de medir el efecto indirecto de los mediadores se utiliza la Macro Process (V.3) (Hayes, 2013) en SPSS (versión 22) el cual es un método basado en 
el sistema de remplazo en el remuestreo aleatorio realizando cinco mil réplicas con el método bootstrap.

Tomando en consideración por un lado la teoría tridimensional del perfeccionismo avanzada por Hewitt y Fleet (1991) que contempla el perfeccionismo Auto Orientado (AO), el perfeccionismo Orientado a los Demás (OD) y el perfeccionismo Socialmente Prescrito (SP) que se midió con el instrumento EMP y por otro lado la posición de Garner, Olmstead y Polivy, (1983) que plantean la evaluación de los TCA con el instrumento EDI-2 a través de la medición de once dimensiones, siendo dos de ellas dimensiones centrales : obsesión por la delgadez (DT) y la bulimia (B) representativas de las patologías anorexia nervosa y bulimia respectivamente, y las nueve otras dimensiones adicionales representativas de rasgos psicológicos que suelen acompañar la presencia de los trastornos TCA en los individuos, se planteó el siguiente modelo : Una variable independiente bajo tres modalidades es decir una por cada dimensión de perfeccionismo (AO) (OD) y (SP), múltiples mediadores paralelos correspondientes a los rasgos de personalidad usualmente presentes en un TCA y una variable dependiente global llamada TCA la cual combina las dimensiones (DT) y (B) debido a que el promedio de los 12 ítems correspondientes a los ítems de ambas dimensiones tiene una alta consistencia interna $(\omega=.71)$ y al momento de verificar el efecto de los caminos mediacionales de tipo "b" para cada una de las dos dimensiones por separado, (DT) y (B) en paralelo, se obtuvo que los mediadores insatisfacción Corporal (BD), ascetismo (A) y conciencia interoceptiva (IA) son aquellos que resultan estadísticamente significativos.

\subsection{Análisis psicométricos}

\subsubsection{Instrumento EMP}

\subsubsection{Evidencias de confiabilidad del instrumento EMP.}

Se realizó el estudio de la confiabilidad por consistencia interna de las puntuaciones de las dimensiones de la prueba EMP mediante el coeficiente omega de McDonald ( $\omega)$. En un primer análisis se halló que algunos ítems de las dimensiones SP y OD presentaban una correlación ítem-test bajo por lo que se decidió retirarlos siendo el listado de ítems retirados el siguiente: Para la dimensión SP se eliminó el ítem 22 mientras que para la dimensión OD se retiraron los ítems 2 y 19, es así que en un segundo análisis se obtuvo los siguientes resultados (véase en tabla 3) quedando 42 ítems en total correspondiendo 20 ítems a la dimensión AO, 13 ítems 
a la dimensión SP y 9 ítems a la dimensión OD. De esa manera las tres dimensiones del EMP contaron con el siguiente coeficiente omega de McDonald ( $\omega)$ :

\section{Tabla 3}

Confiabilidad de las dimensiones del instrumento EMP

\begin{tabular}{ccc} 
& Omega & $\mathrm{N}^{\mathrm{a}}$ de Ítems \\
Dimensiones & $\operatorname{McDonald}(\omega)$ & \\
\hline
\end{tabular}

$\mathrm{AO}$

SP

OD
.93

.81

.66
20

13

9

\subsubsection{Instrumento EDI-2}

\subsubsection{Evidencias de confiabilidad del instrumento EDI-2.}

Se estimó la confiabilidad por consistencia interna de los puntajes obtenidos de la aplicación de las dimensiones del instrumento EDI-2 mediante el coeficiente omega de McDonald ( $\omega)$ hallando que algunos ítems de las dimensiones B, I, P, ID, A e IR presentaban una correlación ítem-test baja por lo que se tomó la decisión de eliminar los ítems 5 y 53 de la dimensión (B), ítem 37 de la dimensión (I), ítem 13 de la dimensión (P), ítem 30 de la dimensión (ID), ítem 71 de la dimensión (A) y finalmente los ítems 72 y 90 de la dimensión (IR) y eliminar la totalidad de la dimensión (MF) que resultó ser de magnitud muy baja $(\omega=.15)$. Es así que luego de un segundo análisis quedaron ubicándose en un rango de magnitud muy alta $(\omega=.81$ a .91) las dimensiones (DT), (B), (BD), (I), (ID), (IA) e (IS) y en un rango de magnitud alta $(\omega=.67$ a .79) las dimensiones (P), (A), (IR) conservándose un total de 77 ítems repartidos en 7 ítems para la dimensión Obsesión por la Delgadez (DT), 5 ítems para Bulimia (B), 9 ítems para Disconformidad corporal (BD), 9 para Ineficacia (I), 5 ítems para Perfeccionismo (P), 6 ítems para Desconfianza Interpersonal (ID), 10 ítems para Conciencia Interoceptiva 
(IA), 7 ítems para Ascetismo (A), 9 ítems para Impulsividad (IR) y 8 ítems para Inseguridad social (IS) (véase en tabla 4).

\section{Tabla 4}

Confiabilidad de las dimensiones del Instrumento EDI-2

\begin{tabular}{ccc}
\hline & OmegaMcDonald & N de Ítems \\
\hline DT & .91 & 7 \\
B & .71 & 5 \\
BD & .83 & 9 \\
I & .89 & 9 \\
P & .69 & 5 \\
ID & .81 & 6 \\
IA & .80 & 10 \\
A & .72 & 7 \\
IR & .76 & 9 \\
IS & .82 & 8 \\
\hline
\end{tabular}

\subsection{Estadísticos descriptivos}

Se calcularon los estadísticos descriptivos de los puntajes de cada dimensión de las variables de estudio a saber el perfeccionismo en las madres, la vulnerabilidad a desarrollar un TCA (véase en tablas 5 y 6 ). 


\section{Tabla 5}

Estadísticos descriptivos de los puntajes de las dimensiones de la prueba EMP

\begin{tabular}{cccccc}
\hline Variables & N & $M$ & $D E$ & Min. & Max. \\
\hline AO & 109 & 80.17 & 25.36 & 29 & 140 \\
SP & 109 & 26.55 & 10.40 & 13 & 57 \\
OD & 109 & 35.71 & 8.19 & 17 & 55 \\
\hline
\end{tabular}

En la población investigada la dimensión AO presentó una media de 80.17 y una desviación estándar de 25.36 mostrando un puntaje mínimo de 29 y máximo de 140. Asimismo, la dimensión SP ostentó una media de 26.55 y una desviación estándar de 10.40 con un puntaje mínimo de 13 y máximo de 57. Finalmente, la dimensión OD obtuvo una media de 35.71 y una desviación estándar de 8.19 con un puntaje mínimo de 17 y máximo de 55. Asimismo, se calcularon las medias, desviaciones estándares, mínimos y máximos para los puntajes de las dimensiones de la prueba EDI-2 (véase en la tabla 6) observándose que en todas las dimensiones el puntaje mínimo fue cero y los puntajes máximos se ubicaron en las dimensiones de Ineficacia (I) con 25 seguida de las dimensiones Insatisfacción Corporal (BD) y conciencia interoceptiva (IA) con 24 respectivamente. 


\section{Tabla 6}

Estadísticos descriptivos de los puntajes de las dimensiones de la prueba EDI-2

\begin{tabular}{cccccc}
\hline Variables & $\mathrm{N}$ & $M$ & $D E$ & Min. & Max. \\
\hline DT & 109 & 5.63 & 5.98 & 0 & 21 \\
B & 109 & 1.5 & 2.3 & 0 & 11 \\
BD & 109 & 6.9 & 5.94 & 0 & 24 \\
I & 109 & 1.6 & 3.35 & 0 & 25 \\
P & 109 & 4.76 & 3.60 & 0 & 15 \\
ID & 109 & 2.51 & 3.08 & 0 & 17 \\
IA & 109 & 5.01 & 5.07 & 0 & 24 \\
A & 109 & 2.82 & 3.41 & 0 & 19 \\
IR & 109 & 2.72 & 3.74 & 0 & 21 \\
IS & 109 & 2.83 & 3.37 & 0 & 16 \\
\hline
\end{tabular}

\subsection{Estadísticos inferenciales}

\subsubsection{Instrumento EMP}

\subsubsection{Evidencias de correlación entre las dimensiones del instrumento EMP}

Para estimar la existencia de correlaciones entre los puntajes obtenidos de la aplicación de las dimensiones del instrumento EMP se llevó primero a cabo el análisis de la prueba de normalidad para comprobar si los puntajes de las variables perfeccionismo auto orientado (AO), orientado hacia los demás (OD) y socialmente prescrito (SP) obtenidos de la aplicación del instrumento EMP se distribuyen de acuerdo a la curva normal de población, usando el estadístico descriptivo Shapiro-Wilk debido a que actualmente es considerado una de las pruebas con mayor potencia (Razali y Wah, 2011). Al hallar que no hay evidencia suficiente para señalar que los puntajes provenientes de la dimensión SP se distribuyen normalmente a nivel de la muestra (véase en tabla 5) se realizó el análisis de los datos a través de una prueba no paramétrica utilizando el coeficiente Spearman $(r s)$ para el análisis de la correlación de los puntajes de las dimensiones SP con las dimensiones AO y OD de la prueba EMP, en cambio 
debido a que las dimensiones AO y OD se distribuyen normalmente a nivel de la muestra, se usó una prueba paramétrica aplicando el coeficiente Pearson $(r)$ para el análisis de la correlación de los puntajes de las dimensiones AO y OD del instrumento EMP.

\section{Tabla 7}

Prueba de Normalidad Shapiro- Wilk para los puntajes de las variables del instrumento EMP

\begin{tabular}{|c|c|c|c|}
\hline \multicolumn{4}{|c|}{ Shapiro-Wilk } \\
\hline \multicolumn{2}{|c|}{ Estadístico } & $\mathrm{df}$ & Sig. \\
\hline $\mathrm{AO}$ & .98 & 109 & .133 \\
\hline SP & .94 & 109 & .001 \\
\hline OD & .99 & 109 & .59 \\
\hline
\end{tabular}

Luego realizados los análisis de correlación, se encontró que las tres dimensiones del instrumento EMP presentaron correlaciones estadísticamente significativas observándose una relación fuerte para la asociación entre las dimensiones AO y SP $(r s=.64, p<.001)$ mientras que las asociaciones entre AO y OD $(r=.44, p<.001)$ y OD y $\mathrm{SP}(r s=.39, p<.001)$ mostraron una relación moderada.

\subsubsection{Instrumento EDI-2}

\subsubsection{Evidencias de correlación entre dimensiones del instrumento EDI-2}

Para estimar la existencia de correlaciones entre los puntajes obtenidos de la aplicación de las dimensiones del instrumento EDI-2 se llevó primero a cabo el análisis de la normalidad usando el estadístico descriptivo Shapiro-Wilk debido a que actualmente es considerada una de las pruebas con mayor potencia (Razali y Wah, 2011). Se halló que las once dimensiones del EDI-2 presentaban una distribución que se diferencia de forma estadísticamente significativa a una distribución normal $(p<.01)$ por lo que se realizó el análisis de los datos a través del uso de una prueba no paramétrica usando el coeficiente Spearman Brown ( $r s$ ) para el análisis de la correlación de los puntajes de las dimensiones de la prueba EDI-2. 
Al realizar el análisis de las correlaciones de los puntajes de las dimensiones del EDI-2 (rs), a pesar que el autor del instrumento realiza la diferenciación entre las 11 dimensiones, se observó que en la muestra estudiada existía una correlación significativa entre los puntajes de algunas dimensiones lo que resultó en una limitación en la tentativa del uso del modelo explicativo propuesto acerca del camino causal existente entre las variables perfeccionismo materno y TCA que contempla que los mediadores deberían de ser independientes (consultar anexo 10).

\subsection{Modelo de Mediación múltiple paralelo}

5.4.1. Análisis del modelo múltiple paralelo para la modalidad perfeccionismo auto orientado (AO)

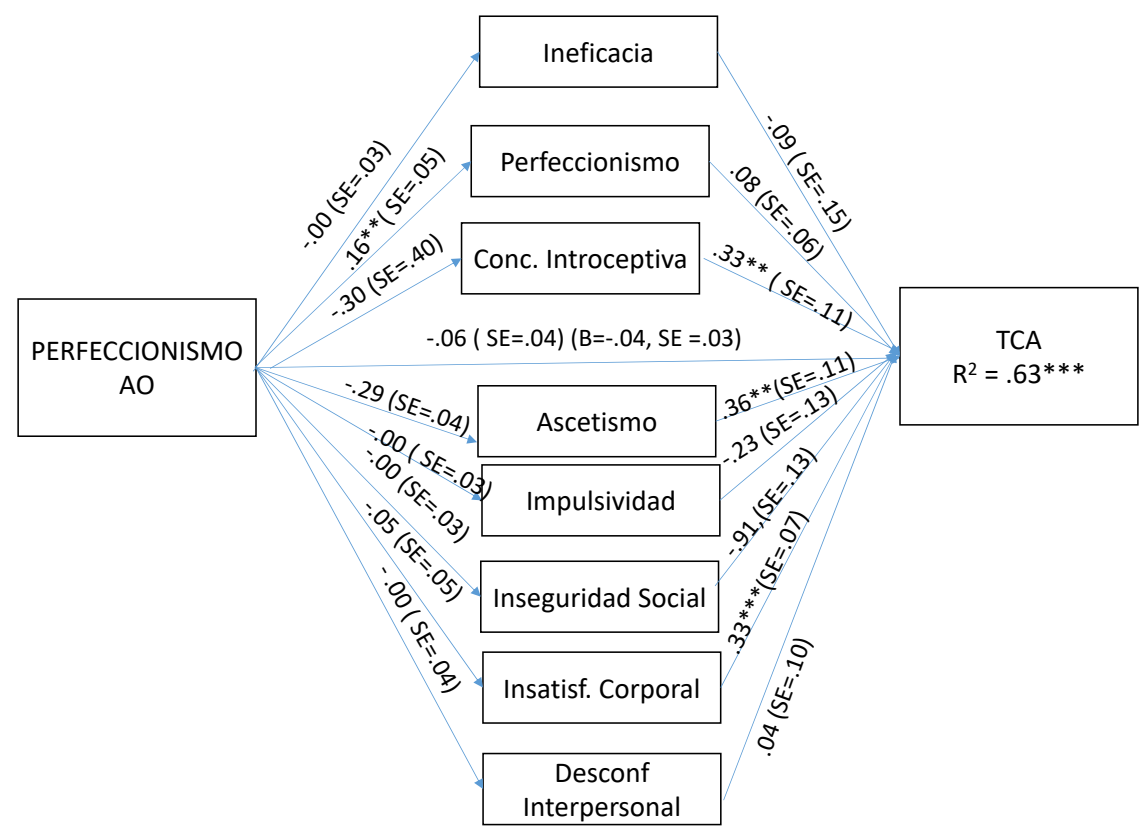

Figura 5.4.1. Nota: Mediación de la relación entre perfeccionismo auto orientado y TCA por ineficacia, perfeccionismo, conciencia interoceptiva, ascetismo, impulsividad, inseguridad social, insatisfacción corporal y desconfianza interpersonal $-* * p<.01 . * * * p<.001$.

En la figura 5.4.1. se observa que, de todos los caminos "a" que enlazaron la variable perfeccionismo AO hacia cada uno de los mediadores, solamente el camino "a" de AO hacia Perfeccionismo fue significativo $B=.16, \mathrm{SE}=.05(p<.01)$, sin embargo los caminos "b" que parten desde los mediadores conciencia interoceptiva, ascetismo e insatisfacción corporal 
hacia la variable TCA fueron significativos resultando en una varianza total $\mathrm{R}^{2}=.63$, $(p<$ $.001)$.

\section{Tabla 8}

Resultados bootstrap para efectos mediación- perfeccionismo AO

Resultados Bootstrap para Efectos Mediación

$95 \%$ IC

Efecto

Modalidad Perfeccionismo

$\mathrm{AO}$

Mediador (ES)

Inferior

Superior

Mediadores

Efecto Total Mediación

$-.02(.04)$

$-.09$

.05

Ineficacia

$-.00(.00)$

$-.02$

.01

Perfeccionismo

$.01(.01)$

$-.02$

.04

Conciencia Interoceptiva

$-.01(.14)$

$-.04$

.02

Ascetismo

$-.01(.13)$

$-.04$

.01

Impulsividad

$.00(.00)$

$-.01$

.01

Inseguridad Social

$-.00(.01)$

$-.02$

.01

Insatisfacción Corporal

$-.02(.02)$

$-.06$

.02

Desconfianza Interpersonal

$-.00(.00)$

$-.01$

.01

Nota: Resultados de efecto de un bootstrap percentilar con un IC al 95\% (5000 réplicas con el método bootstrap). Errores estándares reportados entre paréntesis. IC = Intervalo de confianza 
En la tabla 8 se reporta el efecto total de la mediación, así como los efectos individuales de cada mediador. Se realizaron 5000 réplicas con el método bootstrap estableciendo el intervalo de confianza con el bootstrap percentilar (IC 95\%), obteniendo como resultado que ningún camino mediador completo "ab", es decir desde el perfeccionismo en su modalidad AO hacia el TCA tomando en cuenta el efecto de los mediadores, fue significativo.

5.4.2. Análisis del modelo múltiple paralelo para la modalidad perfeccionismo orientado a los demás (OD)

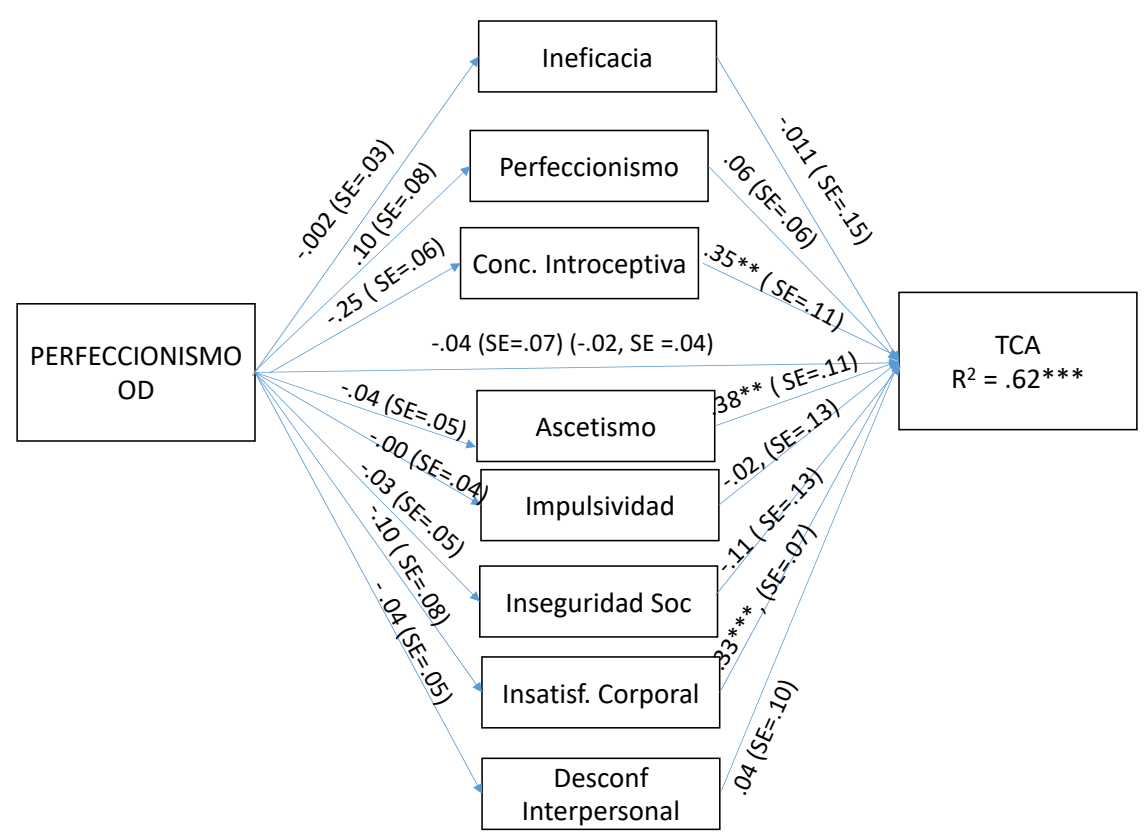

Figura 5.4.2. Nota: Mediación de la relación entre perfeccionismo orientado a los demás y TCA por ineficacia, perfeccionismo, conciencia interoceptiva, ascetismo, impulsividad, inseguridad social, insatisfacción corporal y desconfianza interpersonal $-* * p<.01 . * * * p<.001$

En la figura 5.4.2 se observa que ninguno de los caminos "a" que relacionaron perfeccionismo OD hacia los mediadores fueron significativos, sin embargo, los caminos " $b$ " que parten desde los mediadores conciencia interoceptiva, ascetismo e insatisfacción corporal hacia la variable TCA fueron significativos resultando en una varianza $\mathrm{R}^{2}=.62,(p<.001)$ 


\section{Tabla 9}

Resultados Bootstrap para efecto mediación - perfeccionismo OD

Resultados Bootstrap para Efectos Mediación

$95 \%$

CI

Efecto

Modalidad

Perfeccionismo OD

Mediador (ES)

Inferior

Superior

Mediadores

Efecto Total Mediación

Ineficacia

Perfeccionismo

Conciencia Interoceptiva

Ascetismo

Impulsividad

Inseguridad Social

Insatisfacción Corporal

Desconfianza Interpersonal
$-.02(.05)$

$.00(.01)$

$.00(.09)$

$-.01(.02)$

$.01(.02)$

$.00(.01)$

$.01(.01)$

$.03(.03)$

$.00(.01)$
$-.13$

$-.001$

$-.01$

$-.05$

$-.02$

$-.015$

$-.01$

$-.01$

$-.02$

\section{.08}

.03

.03

.06

.01

.04

.01

.00

Nota: $\quad$ Resultados de efecto de un bootstrap percentilar con un IC al 95\% (5000 réplicas con el método bootstrap). Errores estándares reportados entre paréntesis. IC = Intervalo de confianza

En la tabla 9 se reporta el efecto total de la mediación, así como los efectos individuales de cada mediador. Se realizaron 5000 réplicas con el método bootstrap obteniendo como resultado que ningún camino mediador completo "ab", es decir desde el perfeccionismo en su modalidad OD hacia el TCA tomando en cuenta el efecto de los mediadores, fue significativo. 
5.4.3 Análisis del modelo múltiple paralelo para la modalidad perfeccionismo socialmente prescrito (SP).

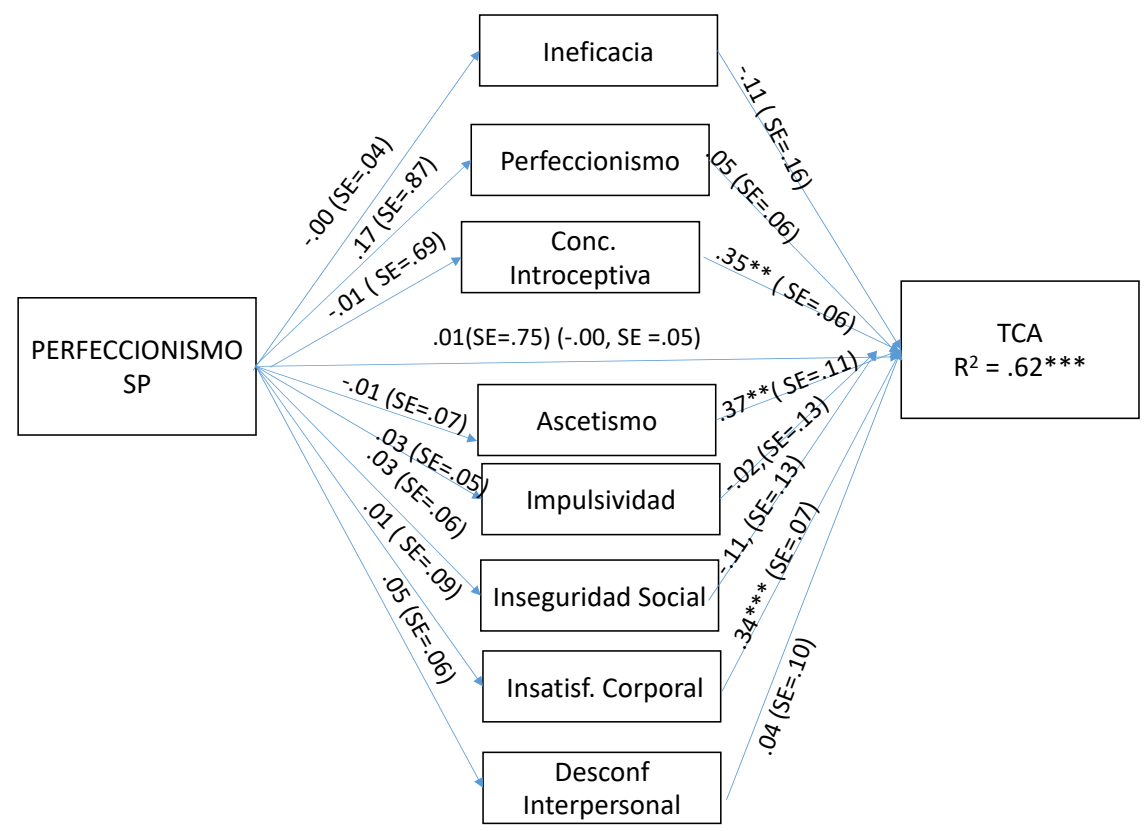

Figura 5.4.3. Nota: Mediación de la relación entre perfeccionismo socialmente prescrito y TCA por ineficacia, perfeccionismo, conciencia interoceptiva, ascetismo, impulsividad, inseguridad social, insatisfacción corporal y desconfianza interpersonal $-* * p<.01 .{ }^{* * *} p<.001$

Al observar los resultados en la figura 5.4.3, se visualiza que ningún camino "a" desde la variable perfeccionismo (SP) hacia los mediadores fue significativo, sin embargo, los caminos "b" que parten desde los mediadores conciencia interoceptiva, ascetismo e insatisfacción corporal hacia la variable TCA fueron significativos, obteniendo una varianza $\mathrm{R}^{2}=.62 * * *$; $(p<.001)$. 


\section{Tabla 10}

Resultados Bootstrap para efecto mediación - perfeccionismo SP

Resultados Bootstrap para Efectos Mediación

$95 \%$

CI

Efecto

Modalidad Perfeccionismo

SP

Mediador (ES)

Inferior

Superior

\section{Mediadores}

Efecto Total Mediación
$.02(.06)$

$.00(.07)$

$.00(.01)$

$-.00(.03)$

$.00(.02)$

$.00(.01)$

$.00(.01)$

$.01(.03)$

$.00(.01)$
$-.11$

.14

$-.01$

.02

$-.01$

.05

$-.05$

.05

$-.04$

.05

$-.03$

.01

$-.05$

.00

Insatisfacción Corporal

Desconfianza Interpersonal
$-.05$

.07

$-.01$

Nota: Resultados de efecto de un bootstrap percentilar con un IC al 95\% (5000 réplicas con el método bootstrap). Errores estándares reportados entre paréntesis. IC = Intervalo de confianza

En la tabla 10 se reporta el efecto total de la mediación, así como los efectos individuales de cada mediador. Se realizaron 5000 réplicas con el método bootstrap obteniendo como resultado que ningún camino mediador completo "ab", es decir desde el perfeccionismo en su modalidad SP hacia el TCA tomando en cuenta el efecto de los mediadores, fue significativo. 


\section{CAPITULO VI: DISCUSION}

El objetivo de la presente investigación consistió en analizar la relación entre los niveles de las tres dimensiones del perfeccionismo (AO, OD y SP) presentes en las madres y la vulnerabilidad en desarrollar un TCA en sus hijas adolescentes de 15 a 22 años y analizar cómo este efecto es mediado por los rasgos predisponentes al desarrollo de un TCA en las hijas adolescentes de 15 a 22 años en el sector socioeconómico A de la ciudad de Lima Metropolitana. Es de importancia señalar que numerosos estudios muestran la importancia de la relación entre ambas variables. En efecto Behar, Gramegna y Arancibia (2014) concluyen que existe un modelo de la influencia tripartita compuesto por padres, pares y medio que contribuye al desarrollo de TCA y en otro estudio Behar y Arancibia (2014) reportan la existencia de una particular relación entre la presencia de un TCA en la madre y su ocurrencia en sus hijas siendo ese un factor de riesgo para su desarrollo.

Otros resultados avanzados por Egan, Watson, Kane, Mc Evoy, Fursland, y Nathan (2012) confirman la hipótesis de que el perfeccionismo auto orientado acrecienta el desarrollo de TCA siendo la sobrevaloración de la forma e IMC agentes mediadores importantes. De la misma manera Cooley, Toray, Chuan y Valdez (2008) concluyen que las actitudes y los comportamientos alimentarios de las madres tienden a incrementar significativamente la vulnerabilidad de las hijas en presentar un TCA. Asimismo, Vásquez y Reidl (2013) reportan que el papel de la madre contribuye en el desarrollo de actitudes y conductas alimentarias desadaptadas en las hijas, no solo por aprendizaje vicario de conductas restrictivas o de descontrol, sino también debido al control impuesto sobre la alimentación de sus hijos y la transmisión de conductas de tipo perfeccionistas ligadas a la internalización de los estándares de belleza socialmente prescritos.

Adicionalmente Borrego (2010) encuentra una correlación positiva entre los factores de riesgo familiar y los indicadores clínicos asociados a los TCA y Hernández - Cortés y Londoño (2013) hacen referencia a la importancia de los antecedentes psicológicos familiares en la contribución al riesgo de padecer un TCA. Asimismo, los resultados de Pamies y Quiles (2014) evidencian que un mayor perfeccionismo auto-orientado y prescrito socialmente estaban asociados positivamente con un mayor riesgo de desarrollar un trastorno alimentario y Egan, Watson, Kane, Mc Evoy, Fursland, y Nathan (2012) confirman la hipótesis de que el perfeccionismo auto orientado acrecienta el desarrollo de TCA siendo la sobrevaloración de 
la forma e IMC agentes mediadores importantes. Sin embargo, se debe de señalar que Cortés (2016) no halla influencia del perfeccionismo negativo en las actitudes de riesgo ante la alimentación.

En cuanto a los análisis realizados a los puntajes obtenidos de la aplicación del instrumento EMP, los resultados indican evidencias de confiabilidad relacionadas a la consistencia interna. Esta fue reportada mediante el omega de McDonald para las dimensiones auto orientado (AO) $(\omega=.93)$, socialmente Prescrito (SP) $(\omega=.81)$ y Orientado a los demás (OD) $(\omega=.66)$ respectivamente luego de haber retirado los ítems 2 y 19 de la dimensión Orientado a los demás (OD) y 22 de la dimensión Socialmente Prescrito (SP). El elevado resultado del índice $(\omega)$ en la modalidad AO podría atribuirse al hecho que la carga factorial de la dimensión AO es superior a la de las otras dimensiones, teniendo esto un efecto en el resultado obtenido al aplicar la fórmula de confiabilidad del $(\omega)$ de McDonald.

Al realizar los análisis de correlaciones de Spearman-Brown Rho $(r s)$ y Pearson $(r)$ a los puntajes obtenidos en las tres dimensiones de la aplicación del EMP, estos evidenciaron una relación fuerte para la asociación entre las dimensiones perfeccionismo socialmente prescrito (SP) y perfeccionismo auto orientado (AO) mientras que las asociaciones entre las dimensiones perfeccionismo orientado hacia los demás (OD) - perfeccionismo auto orientado (AO) y perfeccionismo socialmente prescrito (SP) - perfeccionismo orientado hacia los demás (OD) se consideran moderadas. En cuanto al resultado de la asociación fuerte entre las dimensiones SP y AO en la muestra analizada, este podría indicar un sesgo de la muestra. En efecto el hallazgo de esta correlación entre SP y AO podría atribuirse al hecho de que los miembros de la muestra elegida pertenecieron al sector socio económico A de Lima Metropolitano los cuales están más expuestos a demandas de altos estándares y por lo tanto podrían resultar fuertemente influenciados por aquellos mandatos impuestos por la sociedad llevándolos a incorporar esos altos estándares transformándolos en una auto exigencia de cumplimiento, es decir en un perfeccionismo auto orientado. Adicionalmente los resultados obtenidos en las correlaciones SP-AO realizadas en esta muestra podrían llevar a pensar que los sujetos no disciernen adecuadamente entre las modalidades SP y AO, uniéndolas en una misma categoría por lo que el constructo perfeccionismo en esta muestra podría ser bidimensional con una única modalidad OD y la conjunción de las otras dos modalidades SPAO, y no tridimensional como lo proponen los autores Fleet y Hewitt (1991).

Igualmente, en cuanto al análisis realizado a los puntajes obtenidos de la aplicación 
del instrumento EDI-2, estos indican evidencias de confiabilidad relacionada a la consistencia interna la cual fue reportada mediante el omega de McDonald $(\omega)$ sin embargo, se tuvo que decidir por el retiro total de la dimensión MF (miedo a crecer) debido a que arrojaba una magnitud muy baja $(\omega=.15)$. Se considera que este bajo valor podría atribuirse al hecho que los ítems incluidos en dicha dimensión obtienen respuestas sesgadas por referirse a que las participantes desearían tener una menor edad en la actualidad. Este anhelo no resulta ser una característica de las jóvenes de la muestra de este estudio debido a no ser una muestra clínica, y estas afirmaciones parecen diferir de su pensamiento actual por encontrarse a gusto de poder vivenciar y valorar los comportamientos característicos que le confieren su edad actual

Al realizar los análisis de las correlaciones Spearman-Brown Rho ( $r s)$ a los puntajes obtenidos de las diez dimensiones de la aplicación del instrumento EDI-2, se observa una relación positiva significativa entre dichas dimensiones salvo entre las dimensiones Ineficacia (I) y Perfeccionismo (P) ( $r s=.16)$ lo cual guarda lógica por el antagonismo del contenido mismo de los ítems de cada una de esas dos dimensiones. Adicionalmente, si bien estos resultados positivos contradicen las instrucciones de uso del modelo múltiple mediador paralelo, la decisión de uso de tal modelo fue anterior a los resultados obtenidos en la muestra estudiada.

Con respecto a la primera hipótesis planteada acerca de la asociación significativa entre las dimensiones de perfeccionismo auto-orientado (AO), orientado a los demás (OD) y socialmente prescrito (SP) de las madres con la vulnerabilidad a desarrollar un TCA representada por las dimensiones Anorexia (Obsesión por la Delgadez -DT) y Bulimia (Bulimia - B) en sus hijas adolescentes de 15 a 22 años en la ciudad de Lima Metropolitana, los resultados del modelo de mediación múltiple paralelo aplicado que intenta encontrar la explicación causal entre las tres modalidades del perfeccionismo materno y el posible desarrollo de un TCA evaluado en sus hijas rechazan la hipótesis al no encontrarse, en ninguna de las tres modalidades del perfeccionismo materno, un camino "c" (efecto directo) significativo : $\mathrm{AO}(B=-.06, S E=.04, p>.10), \mathrm{OD}(B=-.04, S E=.07, p>.10)$ y $\mathrm{SP}(B=$ $.01, S E=.08, p>.10)$ con el desarrollo de un TCA. Debido a que no se encuentran estudios anteriores relacionando específicamente el perfeccionismo de las madres con la presencia de TCA en sus hijas, no se puede establecer una comparación directa con otros resultados. En efecto el estudio más próximo a este análisis es aquel realizado por Behar y Arancibia (2014) que investiga la relación entre un TCA materno y la conducta alimentaria de los hijos(a)s y 
concluyen que existe una particular relación entre la presencia de un TCA materno y su ocurrencia en hijo(a)s considerándose este como un factor de riesgo. A lo largo de este estudio se ha revisado en varias oportunidades el aporte de distintos autores en cuanto a considerar el perfeccionismo como un rasgo predisponente a los TCA lo que permite considerar que probablemente esas madres con historia de TCA muestren conductas perfeccionistas adscritas en su reportorio que, acorde a Behar y Arancibia (2014) se traducen en un elevado control del consumo de las hijas así como la expresión de la preferencia por la delgadez, transfiriendo estos patrones a las adolescentes. Sin embargo los resultados del análisis de los caminos "c" del modelo propuesto en este estudio difieren de estas premisas al no encontrar ninguna asociación significativa entre las tres modalidades del perfeccionismo materno y el desarrollo de TCA en hijas adolescentes.

Siguiendo con los objetivos del estudio, los resultados obtenidos rechazan parcialmente la segunda hipótesis planteada la cual sugiere que las dimensiones perfeccionismo auto orientado (AO), orientado a los demás (OD) y socialmente prescrito (SP) de las madres y el desarrollo de un TCA en sus hijas adolescentes de 15 a 22 años en la ciudad de Lima Metropolitana están mediadas por los rasgos predictores de TCA como la Insatisfacción Corporal (BD), la ineficacia (I), el perfeccionismo (P), la desconfianza interpersonal (ID), la conciencia interoceptiva (IA), el Ascetismo (A), la impulsividad (IR) y la inseguridad Social (IS). En efecto en cuanto al análisis de la contribución del efecto de los ocho mediadores en la variable TCA, los resultados indican que no se encuentran ningún camino mediacional "ab" completo en ninguna de las tres modalidades del perfeccionismo en las madres hacia la variable TCA, sin embargo se encuentra un único camino mediacional de tipo "a" significativo entre la dimensión del perfeccionismo auto orientado de las madres y el mediador perfeccionismo $(B=.16, S E=05, p<.01)$ en las hijas lo cual no sucede para las otras dos modalidades de perfeccionismo orientado a los demás $(B=.10, S E=.08, \mathrm{p}>.10)$ y socialmente prescrito $(B=.17, S E=.87, \mathrm{p}>.10)$.

Con respecto a este primer resultado parcial de asociación significativa entre el perfeccionismo auto orientado al mediador perfeccionismo presente en las hijas, este guarda relación con los hallazgos del estudio de Vásquez y Reidl (2013) en cuanto al papel de la madre en el desarrollo y transmisión de conductas de tipo perfeccionistas. Enmarcándose dentro de la teoría de aprendizaje vicario avanzada por Bandura (1990), resultaría pensable atribuir esta asociación significativa a un aprendizaje vía modelamiento por parte de las hijas adolescentes de las conductas de perfeccionismo auto-orientado presentes en las madres, es 
decir las adolescentes estudiadas en la muestra tienden a emular las conductas de perfeccionismo auto-orientado presentes en los comportamientos maternos visualizadas en el seno familiar, adquiriéndolos inconscientemente en su reportorio debido a su naturaleza sutil y no impuesta por las madres, reproduciéndolas luego en la etapa de la adolescencia debido a que estas muy posiblemente hayan sido reforzadas positivamente por la madre (Chance, 1995).

Este resultado significativo del camino "a" entre la modalidad de perfeccionismo AO y el mediador perfeccionismo en las hijas también guarda relación con el resultado del análisis de la consistencia interna de la dimensión AO en el instrumento EMP ( $\omega=.93)$ el cual es superior a los resultados de OD $(\omega=.66)$ y $\mathrm{SP}(\omega=.81)$ respectivamente.

Adicionalmente, en cuanto al hecho que no existen relaciones significativas entre las modalidades de Perfeccionismo OD y SP y el perfeccionismo en las hijas, este resultado no guarda relación con los hallazgos avanzados por Cooley, Toray, Chaun y Valdez (2008) quienes se interesaron por los efectos maternos en los trastornos alimentarios e imagen corporal de sus hijas y concluyeron que los comentarios negativos de las madres acerca de las figuras corporales y patrones alimentarios de sus hijas generaron un incremento significativo en las dificultades de sus hijas en esas áreas y que aquellas madres que mostraban una mayor internalización de los mensajes difundidos en medios sociales acerca de la delgadez eran más propensas a tener hijas con patologías alimentarias. Con respecto a la divergencia entre los resultados negativos obtenidos en los caminos "a" de las dimensiones perfeccionismo orientado a los demás y socialmente prescrito y los resultados del estudio de Cooley, Toray, Chaun y Valdez (2008), se considera que estos se podrían atribuir a una actitud de reactancia propia de la etapa evolutiva de la adolescencia y el posible rechazo que tienden a manifestar las jóvenes hacia las imposiciones practicadas por la madre es decir tanto hacia el perfeccionismo modalidad orientado hacia los demás (OD) así como la modalidad socialmente prescrita (SP) la cual es vivenciada por la madre y luego orientada por esta hacia la hija. Asimismo, resulta interesante observar la limitada eficacia del camino "a" en la modalidad del perfeccionismo orientado hacia los demás (OD) de las madres en la muestra estudiada, pudiéndose tal vez atribuir al hecho que la madre realiza comentarios o críticas hacia la hija sin acompañar sus comentarios de estrategias de eficacia, limitando así el impacto en las hijas (Tannenbaum et al., 2015). Finalmente, en cuanto a la ausencia de asociación significativa de la modalidad socialmente prescrita (SP), este se podría imputar al hecho que 
son las madres quienes resienten la prescripción social y no la hija directamente y por lo tanto no existe una proximidad causal y el impacto del modelamiento resulta débil (Bandura, 1990).

Si bien el perfeccionismo presente en las hijas se asocia positivamente con la modalidad AO del perfeccionismo de la madre, es decir en el camino "a", sin embargo, el camino " $b$ " de este mismo mediador hacia la variable TCA no es significativo $(B=.08, S E=$ $.06, p>.10$ ). Por un lado, este hallazgo apoya lo reportado por Cortés (2016) quien no encontró asociación significativa entre el perfeccionismo negativo y un mayor riesgo de padecer un TCA en una muestra sub-clínica de 100 adolescentes, pero por otro lado, contradice los resultados obtenidos tanto en el estudio de Pamies y Quiles (2014) quienes se refieren a la presencia de perfeccionismo auto-orientado y socialmente prescrito como factor predisponente para el desarrollo de TCA. Asimismo se opone a los resultados aportados por Schappatura et al. (2011) que informan haber encontrado en la revisión de diversos estudios que tanto la dimensión desadaptativa y adaptativa del perfeccionismo están asociados con los TCA y a lo manifestado por Raich (2011) quién avanza que los rasgos perfeccionistas como la dificultad para reconocer los propios logros, la fijación de metas sumamente elevadas, y la revisión compulsiva del rendimiento personal se hallan en sujetos que han desarrollado algún TCA. Resulta importante mencionar que esta contradicción podría explicarse por una conceptualización unidimensional del perfeccionismo en el instrumento EDI-2. En efecto este instrumento no realiza la distinción en cuanto a las diversas sub-dimensiones de la variable que menciona Fleet y Hewitt en su teoría multidimensional, ya que agrupa bajo una única categoría al perfeccionismo con ítems que evalúan tanto el perfeccionismo AO, (ítems 29, 36, 52, 63) como Perfeccionismo SP (ítem 43, 13) y no se encuentran ítems relacionados al perfeccionismo OD, resultando así difícil coincidir con Pamies y Quiles (2014) quienes consideran la separación entre perfeccionismo auto-orientado y socialmente prescrito los cuales consideran ambos como precursores de un TCA.

Por otro lado en cuanto a los caminos "b" adicionales hacia la variable TCA se encuentra que los caminos " $\mathrm{b}$ " de los mediadores conciencia interoceptiva $(\mathrm{B}=.33, \mathrm{SE}=.11$, $p<.01)$, ascetismo $(B=.36, S E=.11, p<.01)$ e insatisfacción corporal $(\mathrm{B}=.33, S E=.07$, $p<.001)$ hacia la variable TCA son significativos en cada uno de las tres modalidades del perfeccionismo. En lo referido a la insatisfacción corporal que se refiere a la perturbación de la imagen corporal referida al disgusto con la forma general de su cuerpo o alguna parte de él, los resultados altamente significativos del camino "b" hacia la variable TCA concuerdan con los resultados avanzados por Hernández-Cortés y Londoño (2013) que reportan, en el 
planteo de su Modelo Predictivo del Riesgo de Padecer un TCA, que la variable satisfacción con la imagen corporal explica en $12 \%$ la varianza total explicada la cual fue del $34 \%$ en dicho modelo predictor. Asimismo resulta interesante que los autores mencionan que la insatisfacción con la imagen corporal se asemeja a una tendencia al perfeccionismo en la cual la joven adolescente se encuentra en una batalla por intentar acercarse a los arquetipos inalcanzables. La mención de estas características compartidas entre el perfeccionismo y la inconformidad corporal deja pensar que el mediador perfeccionismo del modelo avanzado en este estudio está estrechamente ligado al mediador insatisfacción corporal el cual sí se asocia significativamente al TCA.

En cuanto al mediador conciencia interoceptiva que se refiere a la dificultad para reconocer estados emocionales así como sentir confusión acerca de las sensaciones viscerales ligadas a la sensación de hambre y a la saciedad, se aproxima a distorsiones perceptivas acerca de los procesos biológicos del cuerpo y a la desconfianza acerca de que el organismo pueda realizar los procesos regulatorios automáticos sin control consciente. La dificultad en la conciencia interoceptiva produce sensaciones parecidas a la alexitimia, trastorno en el cual se tiene poca capacidad para entender, identificar, describir y comunicar sus propias sensaciones, presentando mayor importancia a lo que sucede en el exterior, una actitud negativa hacia la expresión emocional y un bajo nivel de autoconciencia (Pinaquy, Charol, Simon, Louvet, y Barbe, 2003). Los resultados obtenidos en este estudio en el camino "b" desde el mediador conciencia interoceptiva hacia la variable TCA concuerdan con lo avanzado por Pérez Luna (2014) que reporta que los pacientes con TCA obtienen un puntaje mayor en la aplicación de la Escala de Alexitimia de Toronto (TAS-20) que aquellas personas que no sufren de TCA en la evaluación de los factores referidos a la dificultad para identificar sentimientos y diferenciarlos de las sensaciones corporales o fisiológicas que acompañan la activación emocional, la dificultad para describir los sentimientos a los demás y tener un estilo de pensamiento orientado hacia lo externo.

El mediador ascetismo considera la búsqueda de la delgadez como una virtud y una purificación y la auto restricción oral como un acto de penitencia en búsqueda de alcanzar ideales espirituales a través del sacrificio y el control de las necesidades corporales (Bell, 1985). Considera la abstinencia voluntaria del alimento en el seguimiento de un ritual prescrito en numerosas tradiciones religiosas como un esfuerzo para alcanzar la pureza del cuerpo y del alma (Bruch 1974). El haber encontrado en este estudio una asociación significativa en el camino "b" desde el mediador ascetismo hacia el TCA concuerda con lo 
avanzado por Behar (2012) en su revisión de evidencia de rasgos espirituales y ascéticos en mujeres portadoras de un TCA, donde menciona que el ascetismo se correlaciona con el desenlace de TCA y constituye un obstáculo en la adherencia al tratamiento. La autora avanza una posible asociación entre el ascetismo y el perfeccionismo debido a los aspectos de ritualismo, disciplina y autocontrol absoluto presente en el ascetismo, calificando a ambos rasgos como precursores de los TCA.

El hecho de que los valores de varianza explicada obtenidos en este estudio sean elevados lleva al análisis de dicha inflación siendo esta posiblemente causada por el efecto de la presencia de numerosos parámetros en el modelo propuesto los cuales podrían no ser forzosamente importantes en la contribución de dicha varianza. Para responder a esta problemática se podría utilizar el Índice AIC (Akaike Infomation Criteria) el cual consiste en penalizar el modelo por tener numerosos parámetros o en su defecto considerar eliminar algunos mediadores conservando los mediadores insatisfacción corporal, ascetismo y conciencia interoceptiva los cuales son los que obtienen resultados significativos en el camino "b" hacia la variable TCA. Al retirar aquellos mediadores no significativos en el camino "b" y reduciendo la cantidad de mediadores, se podría tal vez observar una modificación en la varianza, pudiendo así confirmar el grado de contribución de los mediadores hacia la varianza total obtenida.

Por otro lado, es importante señalar que si bien la propuesta de este modelo mediacional predictor de TCA pretende contribuir a un mayor análisis y comprensión del rol del perfeccionismo materno en la vulnerabilidad en desarrollar un TCA en sus hijas adolescentes entre 15 y 22 años en el nivel socio-económico A de Lima Metropolitana, esta investigación contó también con ciertas limitaciones. Un primer tipo de limitación está relacionado con las características de la muestra. Debido al hecho que las gestiones realizadas para obtener los permisos correspondientes en las instituciones educativas no tuvieron respuesta favorable y no se pudo recabar datos de manera grupal, se decidió proceder a la elección del tipo de muestro no probabilístico intencional aplicando ambos instrumentos a adolescentes y madres por medio de la técnica de bola de nieve usando las plataformas virtuales lo cual demandó un seguimiento personalizado. Esto dificultó la obtención de gran cantidad de participantes afectando el tamaño de la muestra y por ende la posibilidad de generalizar los resultados obtenidos. Si bien este sistema virtual ofrece ventajas permitiendo ahorrar tiempo y desplazamiento físico, también presentó ciertos inconvenientes como son las fallas en grabar las encuestas al finalizarlas en la plataforma virtual teniendo que eliminar 
algunos cuestionarios y ampliar la muestra continuando aplicando ambos instrumentos a participantes adicionales. Adicionalmente, se debe mencionar la dificultad en la recolección de la muestra debido al hecho que fue una muestra apareada y por lo tanto se requirió obtener resultados válidos de la aplicación de los instrumentos al binomio madre-hija, teniendo que desechar numerosas encuestas a pesar de estar adecuadamente realizadas por una de las dos participantes mas no por la otra, imposibilitando la correlación entre ambas puntuaciones. Otra limitación de este estudio reside en la dificultad de tener acceso a una muestra clínica de pacientes diagnosticados con TCA debido a la sensibilidad del tema. Asimismo, consiste en una limitación el hecho que este estudio es de corte transversal por lo que no permite realizar un seguimiento a la evolución de la muestra investigada imposibilitándose la comprobación del efecto del perfeccionismo materno a largo plazo en la manifestación de TCA en sus hijas.

Una limitación adicional que representó un sesgo a nivel de muestra residió en el hecho que el estudio fue limitado a un solo estrato socioeconómico oriundo de una misma ciudad por lo que la muestra no resulta representativa a nivel nacional. Adicionalmente el no haber contado con información más detallada referente a características genéticas y emocionales de las madres e hijas adolescentes constituyó en una limitación en cuanto a posibles factores adicionales que podrían intervenir en el riesgo de desarrollar un TCA. Finalmente se podría considerar como otra limitación el grado de validez del auto reporte en la aplicación de los instrumentos EMP y EDI -2, pudiendo incurrir en sesgos respondiendo inadecuadamente a las preguntas ya sea por la búsqueda de deseabilidad social, una mala comprensión de las preguntas o una ausencia de flexibilidad en las opciones de respuestas propuestas para lo cual resultaría importante desarrollar una medida comportamental alimentaria que permite reforzar la confianza en los datos auto reportados en el tema de trastornos alimenticios. 


\section{CONCLUSIONES}

A continuación, se presentan las conclusiones del presente estudio:

- En cuanto a la propuesta del modelo de mediación múltiple paralelo para alcanzar una mejor comprensión de la etiopatogenia de los TCA, los resultados de la aplicación del modelo no revelan caminos mediadores completos significativos entre el perfeccionismo materno y la vulnerabilidad al desarrollo de TCA en sus hijas.

- Se encontró que existe una asociación estadísticamente significativa entre los niveles de la dimensión perfeccionismo auto orientado en las madres y los niveles de la dimensión perfeccionismo presente en sus hijas adolescentes entre 15 y 22 años, el cual es considerado como un factor predisponente a desarrollar un TCA.

- La incorporación del rasgo perfeccionismo auto orientado presente en las madres por sus hijas adolescentes apoya la influencia de la teoría de aprendizaje social (Bandura,1990) siendo la conducta materna en un primer momento aprendida por modelamiento, incorporándose al reportorio de la hija para luego ser reproducida por la misma en la edad de la adolescencia.

- Con relación a las dimensiones perfeccionismo orientado a los demás y perfeccionismo socialmente prescrito de las madres, no se halló asociaciones significativas con los mediadores presentes en la condición de vulnerabilidad en desarrollar un TCA en sus hijas adolescentes.

- Con relación al efecto de los mediadores en el desarrollo de TCA en jóvenes adolescentes, se encontraron asociaciones significativas parciales en los caminos " $b$ " desde los mediadores conciencia interoceptiva, ascetismo y disconformidad corporal en cada una las tres modalidades del perfeccionismo (AO, OD, SP).

- En cuanto al efecto directo del perfeccionismo en sus tres modalidades en el desarrollo de un TCA en sus hijas adolescentes no se halló ninguna asociación significativa. 


\section{RECOMENDACIONES}

A continuación se sugieren algunas recomendaciones:

- En cuanto a no haber encontrado la explicación causal luego de la implementación del modelo mediacional múltiple paralelo en cuanto a la etiopatogenia de los TCA, se recomienda realizar otro estudio similar reduciendo la cantidad de parámetros priorizando aquellos que dieron resultados significativos

- A partir del resultado de no encontrar ninguna asociación estadísticamente significativa entre la modalidad de perfeccionismo orientado hacia los demás (OD) y los mediadores ni tampoco encontrar efecto hacia la vulnerabilidad en desarrollar un TCA en sus hijas adolescentes, resultaría interesante proponer la realización de un estudio de tipo cualitativo para analizar si la ausencia de esa asociación podría atribuirse a la tendencia a presentar actitudes de reactancia durante la etapa de la adolescencia resistiéndose las hijas adolescentes a recoger indicaciones o comentarios prescritos por sus madres.

- En cuanto a futuras investigaciones, se recomendaría replicar dicha investigación ampliando el tamaño de la muestra así como extenderla a otros niveles socioeconómicos a nivel nacional para poder obtener mayor heterogeneidad y poder generalizar los resultados obtenidos.

- Con respecto a la muestra estudiada resultaría interesante realizar un estudio longitudinal para evaluar la evolución de los niveles obtenidos en las dimensiones vinculadas a la vulnerabilidad a desarrollar un TCA en las jóvenes participantes del estudio actual en arras de evaluar la influencia del perfeccionismo materno en esas adolescentes.

- Asimismo se recomendaría incluir una muestra adicional constituida por una población clínica para poder así establecer comparaciones en la influencia del perfeccionismo materno y evaluar la importancia del rol de los mediadores propuestos en el modelo de este estudio en el desarrollo del TCA en las hijas diagnosticadas con un TCA. 
- Con lo que concierne al aspecto de la posible desconfianza de los datos auto reportados, se sugiere reflexionar en el desarrollo de una medida comportamental alimentaria que permite reforzar la confianza en los datos auto reportados en el tema de trastornos alimenticios.

- En relación con la sensibilización de las madres hacia sus patrones de perfeccionismo auto orientado (AO), se recomendaría diseñar un programa dirigido a la concientización de este por las madres, evaluando los niveles de perfeccionismo antes y después de la aplicación del programa psico-educativo y comprobar si se observa una disminución en la transmisión de conductas perfeccionistas y una reducción en los efectos de la auto exigencia emulada por sus hijas en la etapa de la adolescencia. 


\section{REFERENCIAS}

American Educational Research Association, American Psychological Association, \& National Council on Measurement in Education. (2014). Standards for educational and psychological testing. Washington, D.C.: AERA

American Psychiatric Association (APA). (2014). DSM-5: Manual diagnóstico y estadístico de los trastornos mentales. Buenos Aires: Editorial Médica Panamericana.

Antony, M., y Swinson, P. (1998). Cuando lo perfecto no es suficiente: Estrategias para hacer frente al perfeccionismo. Bilbao: Desclée de Brouwer.

Arcelus, J., Mitchell, A., Wales, J., \& Nielsen, S. (2011). Mortality rates in patients with anorexia nervosa and other eating disorders. A meta-analysis of 36 studies. Archives of General Psychiatry, 68(7), 724-731. http://dx.doi.org/10.1001/ archgenpsychiatry.2011.74

Asuero, R., Avargues, M., Martín, B., y Borda, M. (2012). Preocupación por la apariencia física y alteraciones emocionales en mujeres con trastornos alimentarios con autoestima baja. Escritos de Psicología, 5(2), 39-45. http://dx.doi.org/ 10.5231/psy.writ.2012.1007

Baile, J. (2003). ¿Qué es la imagen corporal? Revista de Humanidades “Cuadernos del Marqués de San Adrián, 2, 53-70. Recuperado de https://www.researchgate.net/ publication/28112716

Bandura, A. (1990). Aprendizaje social y desarrollo de la personalidad (2 ${ }^{\mathrm{a}}$ ed.). Madrid: Alianza Editorial.

Behar, R. (2012). Espiritualidad y ascetismo en la anorexia nerviosa. Revista Chilena Neuro-Psiquiátrica, 50(2), 117-129. http://dx.doi.org/10.4067/S0717 92272012000200006

Behar, R., y Arancibia, M. (2014a). Trastornos alimentarios maternos y su influencia en la conducta alimentaria de sus hijas(os). Revista Chilena de Pediatría, 85(6), 731739. http://dx.doi.org/10.4067/S0370-41062014000600012

Behar, R., y Arancibia, M. (2014b). DSM-V y los trastornos de la conducta alimentaria. Revista Chilena de Neuro-Psiquiatria, 52(1), 22-33. Recuperado de https://www.researchgate.net/publication/265729323_DSM-5_y_los_ 
trastornos_de_la_conducta_alimentaria

Behar, R., Gramegna, G., y Arancibia, M. (2014). Perfeccionismo e insatisfacción corporal en los trastornos de la conducta alimentaria. Revista Chilena de Neuropsiquiatría, 52(2), 103-114. http://dx.doi.org/10.4067/S0717

Bell, R. (1985). Holy anorexia. Chicago: University of Chicago Press.

Belloch, A. (2012). Propuestas para un enfoque transdiagnóstico de los trastornos mentales y del comportamiento: Evidencia, utilidad y limitaciones. Revista de Psicopatología y Psicología Clínica, 17(3), 295-311. Recuperado de http://www.aepcp.net/arc/08_2012_n3_belloch.pdf

Borrego, C. (2010). Factores de riesgo e indicadores clínicos asociados a los trastornos de la conducta alimentaria. Revista Psicológica, 12(1), 13-50. Recuperado de http:// revistas.ucv.edu.pe/index.php/R_PSI/.article/view/328/217.

Bowlby, J. (1988). A secure base: parent-child attachment and healthy Human development. Londres: Routledge

Bruch, H. (1962). Perceptual and conceptual disturbances in anorexia nervosa.

Psychosomatic Medicine, 24(2), 187-194. Recuperado de https://pdfs. semanticscholar.org/3306/964babd970a2de5911db7fbd11564a790c85.pdf

Bruch, H. (1973). Eating disorders: obesity, anorexia and the person within. Estados Unidos: Basic Books.

Bruch, H. (1978). The golden cage. Estados Unidos: Harvard University Press.

Camarillo, L. (2015). Rasgos de personalidad en trastornos de la conducta alimentaria, evolución y gravedad de los síntomas (Tesis doctoral). Recuperado de https://eprints.ucm.es/33297/1/T36423.pdf

Casper, R. (1983). On the emergence of bulimia nervosa as a syndrome: A historical view. International Journal of Eating Disorders, 2(3), 3-16. http:// dx.doi.org/ 10.1002/1098-108x(198321)2:3<3::aid-eat2260020302>3.0.co;2-d

Casper, R. (1990). Personality features of women with good outcome from restricting anorexia nervosa. Psychosomatic Medicine, 52, 156-170. Recuperado de https://www.ncbi.nlm.nih.gov/pubmed/2330389 
Chance, P. (1995). Aprendizaje y conducta. México, D.F: El Manual Moderno.

Cooley, E., Toray, T., Chuan, M., \& Valdez, N. (2008). Maternal effects on daughters' eating pathology and body image. Eating Behaviors, 9(1), 52-61. https://dx.doi.org/10.1016/j.eatbeh.2007.03.001

Cortés, L. (2016). Tipo de perfeccionismo, dieta y conductas de riesgo hacia la alimentación (Tesis de maestría). Recuperado de https://repositorio.comillas.edu/rest/bitstreams/30206/retrieve

Crisp, A. (1980). Anorexia nervosa. New York: Grune \& Stratton.

Curran, T., \& Hill, A. P. (2019). Perfectionism is increasing over time: A meta-analysis of birth cohort differences from 1989 to 2016. Psychological Bulletin, 145(4), 410-429. http://dx.doi.org/10.1037/bul0000138

De las Casas, P. (2008). Un cuerpo sin sombras; Anorexia y bulimia; una relectura en Freud. Lima: UNMSM - Fondo Editorial

Del Cid, A., Méndez, R. y Sandoval, F. (2011). Investigación, fundamentos y metodología ( $2^{\mathrm{a}}$ ed.). México: Pearson Educación

De Rosa, L., Dalla Valle, A., Rutsztein, G., y Keegan, E. (2012). Perfeccionismo y autocrítica: Consideraciones clínicas. Revista Argentina de Clínica Psicológica, 21(3), 209-215. Recuperado de http://www.redalyc.org/articulo. oa? id=281929021003

Díaz, V. (2009). Metodología de la investigación científica y bioestadística: para médicos, odontólogos y estudiantes de ciencias de salud. Santiago de Chile: RIL Editores.

Dunn, T. J., Baguley, T., \& Brunsden, V. (2014). From alpha to omega: A practical solution to the pervasive problem of internal consistency estimation. British Journal of Psychology, 105(3), 399-412. http://dx.doi.org/10.1111.bjop.12046

Egan, S., Watson, H., Kane, R., \& Joyce, F. (2012). Mediators between perfectionism and eating disorder psychopathology in a community sample. Eating Behaviors, 13(4), 361-365. http:// dx.doi.org/ 10.1016/j.eatbeh.2012.07.002

Elizathe, L., Murawski, B., Custodio, J., y Rutsztein, G. (2012). Riesgo de trastorno alimentario en niños escolarizados de Buenos Aires: su asociación con 
perfeccionismo. Revista Mexicana de Trastornos Alimentarios, 3(2), 106-120. Recuperado de http://www.redalyc.org/pdf/4257/425741618004.pdf

Erskine, H., Whiteford, H., \& Pike, K. (2016). The global burden of eating disorders. Current Opinion in Psychiatry, 29(6), 346-353. http://dx.doi.org/10.1097/YCO. 0000000000000276

Fleet, G., \& Hewitt, P. (1991). Perfectionism in the self and social contexts:

Conceptualization, Assesment and Association with pshychopathology. Journal of Personality and Social Psychology, 60(3), 456-470. http://dx.doi.org/10.1.1037/ $0022-3514.60 .3 .456$

Frost, R., Marten, P., Lahart, C., \& Rosenblate, R. (1990). The dimensions of perfectionism. Cognitive Therapy and Research, 14(5), 449-468. http://dx.doi.org/10.1007/BF01172967

García, B., Ortiz, M., Salazar, G., Martino, L., y Vergara, A. (2014). Percepción y satisfacción de la imagen corporal en una comunidad universitaria. Memorias del XVI Concurso Lasallista de Investigación, Desarrollo e innovación, 1,19-22. Recuperado de https://studylib.es/doc/8156691/percepción-y-satisfacción-de-la-imagen-corporal-enuna-co...

García-Fernandez, J., Inglés, C., Vicent, M., Gonzálvez, C., Gómez-Nuñez, M., y PovedraSerra, P. (2016). Perfeccionismo Durante la Infancia y la Adolescencia. Análisis Bilbliométrico y Temático. Revista Iberoamericana de Psicología y Salud, 7,79-88. http://dx.doi.org/10.1016/j.rips.2016.02.001.

Garner, D., y Bemis, K. (1985). Cognitive therapy for anorexia nervosa. En D. M. Garner y P. E. Garfinkel (Eds.), Handbook of pshychotherapy for anorexia nervosa and bulimia (pp. 107 - 146). New York: Guilford Press.

Garner, D. (1991). Eating Disorder Inventory-2 Professional Manual. Odessa: Psychological Assesment Ressources.

Garner, D. (1998). Inventario de Trastornos de la Conducta Alimentaria. Madrid: TEA Ediciones. 
Garner, D., \& Garfinkel, P. (1981). Body image in anorexia nervosa: Measurement, theory and clinical implications. International Journal of Psychiatry in Medicine, 11(3), 263-284. Recuperado de https://www.researchgate./publication/15890496_Body_ Image_in_Anorexia_Nervosa_Measurement_Theory_and_Clinical_Implications

Garner, D., Olmstead, M., \& Polivy, J. (1983). Development and validation of a multidimensional eating disorder inventory for anorexia nervosa and bulimia. International Journal of Eating Disorders, 2(2), 15-34. https://dx.doi.org /10.1002/1098-108X(198321)2:2\%3C15::AID-EAT2260020203\%3E3.0.CO;2-6

González, A., Gómez, M., y Conejeros, M. (2017). Caracterización del perfeccionismo en estudiantes con alta capacidad: un estudio de casos exploratorio. Revista de Psicología, 35(2), 605-640. http://dx.doi.org/10.18800/psico.201702.008.

Gosling, S., Vazire, S., Srivastava, S., \& John, O. (2004). Should we trust Web-based Studies? American Psychologist, 59(2), 93-104. http://dx.doi.org/ 10.1037/ 0003066X.59.2.93

Guerrero, D. (2008). Adaptación del Inventario de Trastornos de la Conducta Alimentaria (EDI-2) en una muestra de adolescentes de 16 a 20 años de Lima Metropolitana (Tesis de licenciatura). Recuperada de http://tesis.pucp.edu.pe/repositorio/handle /123456789/631

Hamel, A., Zaitsoff, S., Taylor, A., Menna, R., \& Legrange, D. (2012). Body-Related Social Comparison and Disordered Eating among Adolescent Females with an Eating Disorder, Depressive Disorder, and Healthy Controls. Nutrients, 4(9), 1260-1272. https://dx.doi.org/10.3390/nu4091260

Hayes, A. (2013). Introduction to mediation, moderation, and conditional process analysis: a regression-based approach. New York: The Guilford Press

Hernández-Cortés, L., y Londoño, C. (2013). Imagen corporal, IMC, afrontamiento, depresión y riesgo de TCA en jóvenes universitarios. Anales de Psicología, 29(3), 748-761. https://dx.doi.org/10.6018/analesps.29.3.175711

Hernández, S., Fernández, C., y Baptista, L. (2014). Metodología de la investigación (6 $6^{\mathrm{a}}$ ed.). México D.F.: McGraw-Hill Education. 
Hewitt, P., \& Fleet, G. (1991). Perfectionism in the self and social contexts: conceptualization, assessment and association with psychopathology. Journal of Personality and Social Psychology, 60(3), 456-470. Recuperado de http://citeseerx.ist.psu.edu/viewdoc/download?doi=10.1.1.320.1494\&rep=rep1\&type $=$ pdf

Horney, K. (1937). The neurotic personality of our time. New York: Norton \& Company.

Instituto Nacional de Estadística e Informática (INEN). (2016). Encuesta Nacional de Hogares Sobre Condiciones de Vida y Pobreza - ENAHO. Recuperado de https://webinei.inei.gob.pe/anda_inei/index.php/catalog/543

Instituto Nacional de Salud mental (INSM). (2013). Estudio Epidemiológico de salud mental en Lima Metropolitana y Callao - Replicación 2012. Informe General - Anales de Salud Mental, 29(1). Recuperado dehttp://www.insm.gob.pe/investigacion /archivos/estudios/2012\%20ASM\%20-EESM\%20-LM.pdf

Kenny, A. (2017). MedPower: An interactive tool for the estimation of power in tests of mediation [Software de computación]. Recuperado de https://davidakenny.shinyapps.io/PowerMed/.

Kerlinger, F., \& Lee, H. (2002). Investigación del comportamiento. Métodos de investigación en ciencias sociales ( $4^{\mathrm{a}}$ ed.). México: McGraw-Hill.

Laufer, M. (1997). Adolescent breakdown and beyond. Londres: Karnac

Lazo,Y., Quenaya, A., \& Mayta, P. (2015). Mass media influence and risk of developing eating disorders in female students from Lima, Peru. Archivos Argentinos de Pediatría, 113(6), 519-525. http://dx.doi.org./10.5546/aap.2015.519

López, C., y Treasure, J. (2010). Trastornos de la conducta alimentaria en adolescentes: descripción y manejo. Revista Médica Clínica Las Condes, 22(1), 85-97. https://dx.doi.org/10.1016/S0716-8640(11)70396

Losada, A., Leonardelli, E., y Magliolia, M. (2015). Influencia sociocultural y los trastornos de la conducta alimentaria en adolescente. Revista electrónica de Psicología Iztacala, 18(1), 380-416. Recuperado de http://www.medigraphic.com/pdfs/epsicologia/epi2015/epi151s.pdf 
Lucas, A., Beard, C., O’Fallon, W., \& Kurland, L. (1991). 50-year trends in the incidence of anorexia nervosa in Rochester, Minnesota: a population-based-study. American Journal of Psychiatry, 148(7), 917-022. http://dx.doi.org /10.1176/ajp.148.7.917

Manzaneque, B. (2013). Contribución de la personalidad, variables clínicas y disfunciones ejecutivas a la distorsión de la imagen corporal en estudiantes universitarios (Tesis doctoral) Recuperada de https://ruidera.uclm.es/xmlui/bitstream/handle/ 10578/3620/TESIS\%20Manzaneque\%20Pérez.pdf?sequence=1

Méndez, J., Vásquez, V., y García, E. (2008). Los trastornos de la conducta alimentaria. Boletín médico del Hospital Infantil de México, 65(6), 579-592.

Recuperado de http://www.scielo.org.mx /scielo.php?script=sci_arttext\&pid= S1665-11462008000600014

Mendi, E., \& Eldeleklioglu, J. (2016). Parental conditional regard, subjective well-being and self-esteem: The mediating role of perfectionism. Psychology, 7(10), 1276-1295. http://dx.doi.org/10.4236/psych.2016.710130

Micali, N., Hagberg, K., Petersen, I., \& Treasure, J. (2013). The incidence of eating disorders in the UK in 2000-2009: Findings from the General Practice Research Database. BMJ Publishing Group Limited, 3(5). http://dx.doi.org/ 10.1136/ bmjopen-2013-002646

Minuchin, S. (1978). Psychosomatic Families: Anorexia Nervosa in Context. Harvard: University Press

Miranda, L. (2016). Prevalencia de riesgo de trastornos de conducta alimentaria en estudiantes preuniversitarios de la Academia Aduni-Cesar Vallejo en enero del 2016 (Tesis de licenciatura). Recuperado de http://cybertesis.unmsm.edu.pe/handle/cybertesis/4708

Morrison, J. (2014). DSM-5, Guía para el diagnóstico clínico. México: Manual Moderno.

Muñoz, S., Vega, Z., Berra, E., Nava, C., y Gómez., G. (2015). Asociación entre estrés, afrontamiento, emociones e IMC en adolescentes. Revista Intercontinental de Psicología y Educación, 17(1), 11-29. Recuperado de http://www.redalyc. org/pdf/802/80242935002.pdf 
Organización Panamericana de la Salud (2009). Trastornos alimentarios en la adolescencia: ¿Cuál es la influencia de los medios de comunicación? Recuperado de https://www.rima.org/Noticia.Aspx?IdNota=3502

Pamies, L., y Quiles, Y. (2014). Perfeccionismo y factores de riesgo para el desarrollo de trastornos alimentarios en adolescentes españoles de ambos géneros. Anales de Psicología, 30(2), 620-626. https://dx.doi.org/10.6018/analesps.30.2.158441

Pérez, A. (2018). Trastornos de la conducta alimentaria: estudio de variables clínicas y propuesta de una tipología. (Tesis doctoral). Universidad Complutense de Madrid. Recuperada de http://eprints.ucm.es/46697/1/T39643.pdf

Pérez Luna, P. (2014). Alexitimia en Trastornos alimenticios (Tesis de licenciatura). Recuperada de http://tesis.pucp.edu.pe/repositorio/bitstream/handle/123456789 15548/

Pinaquy, S., Charol, H., Simon, C., Louvet, J., \& Barbe,. P. (2003). Emotion Eating, Alexithymia and Binge Eating Disorder in Obese Women. Obesity Research, 11(2), 195-201. https://dx.doi.org/ 10.1038.oby.2003. 31

Poulisis, J. (2011). Los nuevos trastornos alimentarios: Alcohorexia, vigorexia, diabulimia, pregorexia, ortorexia ( $1^{\mathrm{a}}$ ed.). Buenos Aires: Paidós

Quiroga, M. (2006). Psicología de los trastornos de alimentación. Salamanca:Publicaciones Universidad Pontificia

Raich, R. (2011). Anorexia y bulimia: trastornos alimentarios. Madrid: Pirámide.

Ramirez, N. (2010). Las relaciones objetales y el desarrollo del psiquismo; Una concepción psicoanalítica. Revista de Investigación en Psicología, 13(2), 221-230.

Rampling, D. (1985). Ascetic ideals and anorexia nervosa. Journal of Psychiatric Research 19(2-3), 89-94. http://dx.doi.org/ 10.1016/0022-3956(85)90003-2

Razali, N. M., \& Wah, Y. B. (2011). Power comparisons of shapiro-wilk, kolmogorovsmirnov, lilliefors and anderson-darling tests. Journal of Statistical Modeling and Analytics, 2(1), 21-33. Recuperado de: 53https://www.Research 
gate.net/publication/267205556_Power_Comparisons_of_ShapiroWilk_Kolmogorov -Smirnov_Lilliefors_and_Anderson Darling_Tests

Rice, F. (1997). Desarrollo Humano: Estudio del ciclo vital. México: Prentice Hall.

Rodríguez, M., Rojo, L., Ortega, E., y Sepúlveda, A. (2009). Adaptación de la escala Multidimensional de Perfeccionismo a estudiantes universitarios españoles. Ansiedad y Estrés, 15(1), 13-27. Recuperado de https://www.researchgate.

net/publication/265384243_adaptacion_de_la_escala_multidimensional_de_perfec cionismo_a_estudiantes_universitarios_espanoles?

Ruiz, A., Vásquez, R., Mancilla, J., Viladrich, C., y Halley, M. (2013). Factores familiares asociados a los Trastornos Alimentarios: una revisión. Revista mexicana de trastornos alimentarios, 4(1), 45-57. Recuperado de https://www.

redalyc.org/articulo.oa?id=425741619006https://www.redalyc.org/articulo.oa?id=42 $5741619006425741619006>$

Samnaliev, M., LeAnn, H., Sonnevile, K., \& Austin, B. (2014). The economic burden of eating disorders and related mental health comorbidities: An exploratory analysis using the U.S. Medical Expenditures Panel Survey. Preventive Medicine Reports, 2, 32-34. http://dx.doi.org/10.1016/j.pmedr.2014.12.002

Sanchez, A. (2013). La personalidad y el autoconcepto en los trastornos de la conducta $\begin{array}{llll}\text { alimentaria } & \text { (Tesis dectoral). }\end{array}$ https://helvia.uco.es/xmlui/bitstream/handle/10396/10537/791.pdf?sequence=1

Schappatura, M., Arana, F., Elizathe, L., y Rutsztein, G. (2011). Perfeccionismo adaptativo y desadaptativo en trastornos alimentarios: un estudio de revisión. Anuario de Investigaciones, $\quad$ 81-88. 18 Recuperado de https://www.researchgate.net/profile/Guillermina_Rutsztein/publication/262653601_ Perfeccionismo_adaptativo_y_desadaptativo_en_trastornos_alimentarios_Un_estudi o_de_revision/links/54f625d00cf2ca5efefdce53/Perfeccionismo-adaptativo-ydesadaptativo-en-trastornos-alimentarios-Un-estudio-derevision.pdf?origin=publication_detail

Selvini-Palazzoli, M. (1974). Self-starvation. Londres: Chaucer Publishing Co.

Sherry, S., Hewitt, P., Flett, G., Lee-Baggley, D., \& Hall, P. (2007). Trait perfectionism and 
perfectionistic self-presentation in personality pathology. Personality and Individual Differences, 42(3), 477-490. http:// dx.doi.org/

10.1016/j.paid.2006.07.026

Slade, P. (1982). Towards a functional analysis of anorexia nervosa and bulimia. British Journal of Clinical Psychology, 21, 167-179. http://dx.doi.org/10.

1111/j.2044-8260.1982.tb00549.x

Stoeber, J. (2017). The psychology of perfectionism: Theory, research, applications. Nueva York: Routledge.

Story, I. (1976). Caricature and impersonating the other: Observations from the psychotherapy of anorexia nervosa. Pyschiatry, 39, 176-188. https://dx.doi.org/10.1080/00332747.1976.11023887

Strober, J. (1981). A comparative analysis of personality organization in juvenile anorexia nervosa. Journal of Youth and Adolescence, 10(4), 285-295. doi: 10.1007/ BF02088992.

Swanson, S., Crow, S., Le Grange, D., Swendsen, J., \& Kerikangas, K. (2011). Prevalence and correlates of eating disorders in adolescents. Archives General Psychiatry, 68(7). 714-723. http://dx.doi.org/10.1001/Archgenpsychiatry.2011.22

Tannebaum, M., Hepler, J., Zimmerman R., Lindsey, S., Jacobs, S., Wilson, K., \& Albarracin, D. (2015). Appealing to fear: A meta-analysis of fear appeal effectiveness and theories. Psychological Bulletin, 141(6), 1178-1204. http://dx.doi.org/10.1037/a0039729

Tataje, A. (2013). Sintomatología depresiva y dimensiones de perfeccionismo en jóvenes universitarios de Lima Metropolitana (Tesis de licenciatura). Recuperada de http://tesis.pucp.edu.pe/repositorio/handle/123456789/5080

Trace, S., Baker, J., Peñas, E., \& Bulik, C. (2013). The genetics of eating disorders. Annual Review of Clinical Psychology, 9(1), 589-620. http://dx.doi.org/ 10.1146/annurevclinpsy-050212-185546

Vásquez, V., y Reidl, L. (2013). El papel de la madre en los trastornos de la conducta alimentaria: una perspectiva psicosocial. Psicología y Salud,23(1), 15-24. 
Recuperado de https://www.uv.mx/psicysalud/psicysalud-23-1/231/Verónica\%20Vázquez\%20Velázquez.pdf

Verstuyf, J., Patrick, H., Vansteenkiste, M., \& Teixeira, P. (2012). Motivational dynamics of eating regulation: a self-determination theory perspective. International Journal of Behavioral Nutrition and Physical Activity, 9(21) http://dx.doi.org/10.1186/1479$5868-9-21$

Whiteford H., \& Weissman, R. (2017). Key factors that influence government policies and decision making about healthcare priorities: Lessons for the field of eating disorders. International Journal of Eating Disorders, 50, 315-319. https://dx.doi.org/10.1002/eat.22688 Zusman, L. (2004). Los desórdenes de la alimentación: una lectura psiconalítica. (Tesis de maestría). Pontificia Universidad Católica del Perú. Recuperado de http://tesis.pucp. edu.pe/repositorio/handle/20.500.12404/2/browse?type=author $\&$ value $=$ Zusman + Tin man\%2C+Lillyana

Zusman, L. (2009). Los desórdenes de la conducta alimentaria, anorexia y bulimia. Lima: Fondo Editorial de la Pontificia Universidad Católica del Perú. 
ANEXOS 


\section{Anexo 1: Ficha socio demográfica para madres}

1. ¿Cuántos años tiene?

30-35

$36-40$

$41-45$

$46-50$

$51-55$

2. ¿Cuál es su estado civil?

Soltera

Casada

Separada

Divorciada

Viuda

3. ¿Cuántos hijos tiene?

1

2

3

4

+ de 4

4. ¿Cuántas personas viven en su casa incluyéndola a Usted?

1

2

3

4

5

6

+ de 6

5. ¿Se encuentra trabajando actualmente?

Sí

No 


\section{Anexo 2: Ficha socio demográfica para adolescentes}

1. ¿Cuántos años tienes?

14

15

16

17

18

19

20

21

22

2. ¿Cuál es tu lugar de nacimiento?

3. ¿Con quiénes vives? Puedes marcar varias opciones

Ambos padres

Madre

Padre

Hermanos

Abuelos

4. ¿Cuál es tu peso?

5. ¿Cuál es tu talla? 


\section{Anexo 3 : Escala multidimensional del perfeccionismo EMP}

Se trata de un listado de afirmaciones referidas a características o rasgos personales. Señale con un círculo el número que mejor corresponda a su grado de acuerdo o desacuerdo con cada una de estas afirmaciones.

Utilice la escala de evaluación siguiente:

\begin{tabular}{|c|c|c|c|c|c|c|}
\hline 1 & 2 & 3 & 4 & 5 & 6 & 7 \\
\hline $\begin{array}{l}\text { Totalmente } \\
\text { en } \\
\text { desacuerdo }\end{array}$ & $\begin{array}{l}\text { Muy en } \\
\text { desacuerdo }\end{array}$ & $\begin{array}{l}\text { Bastante en } \\
\text { desacuerdo }\end{array}$ & $\begin{array}{l}\mathrm{Ni} \text { de } \\
\text { acuerdo ni } \\
\text { en } \\
\text { desacuerdo }\end{array}$ & $\begin{array}{l}\text { Bastante de } \\
\text { acuerdo }\end{array}$ & $\begin{array}{l}\text { Muy de } \\
\text { acuerdo }\end{array}$ & $\begin{array}{l}\text { Totalmente de } \\
\text { acuerdo }\end{array}$ \\
\hline
\end{tabular}

\begin{tabular}{|c|c|c|c|c|c|c|c|c|}
\hline 1 & No consigo relajarme si no está todo perfecto & 1 & 2 & 3 & 4 & 5 & 6 & 7 \\
\hline 2 & No critico a alguien que abandona con facilidad. & 1 & 2 & 3 & 4 & 5 & 6 & 7 \\
\hline 3 & No es importante que la gente que me rodea tenga éxito en todo. & 1 & 2 & 3 & 4 & 5 & 6 & 7 \\
\hline 4 & Raras veces critico a mis amigos, cuando se contentan con poca calidad. & 1 & 2 & 3 & 4 & 5 & 6 & 7 \\
\hline 5 & $\begin{array}{l}\text { Tengo dificultades en satisfacer las expectativas que los demás tienen } \\
\text { sobre mí. }\end{array}$ & 1 & 2 & 3 & 4 & 5 & 6 & 7 \\
\hline 6 & Uno de mis objetivos es ser perfecto(a) en todo lo que hago. & 1 & 2 & 3 & 4 & 5 & 6 & 7 \\
\hline 7 & Todo lo que las demás personas hacen debe ser de excelente calidad. & 1 & 2 & 3 & 4 & 5 & 6 & 7 \\
\hline 8 & Nunca tengo como objetivo la perfección. & 1 & 2 & 3 & 4 & 5 & 6 & 7 \\
\hline 9 & Los que me rodean aceptan que yo también pueda cometer errores. & 1 & 2 & 3 & 4 & 5 & 6 & 7 \\
\hline
\end{tabular}




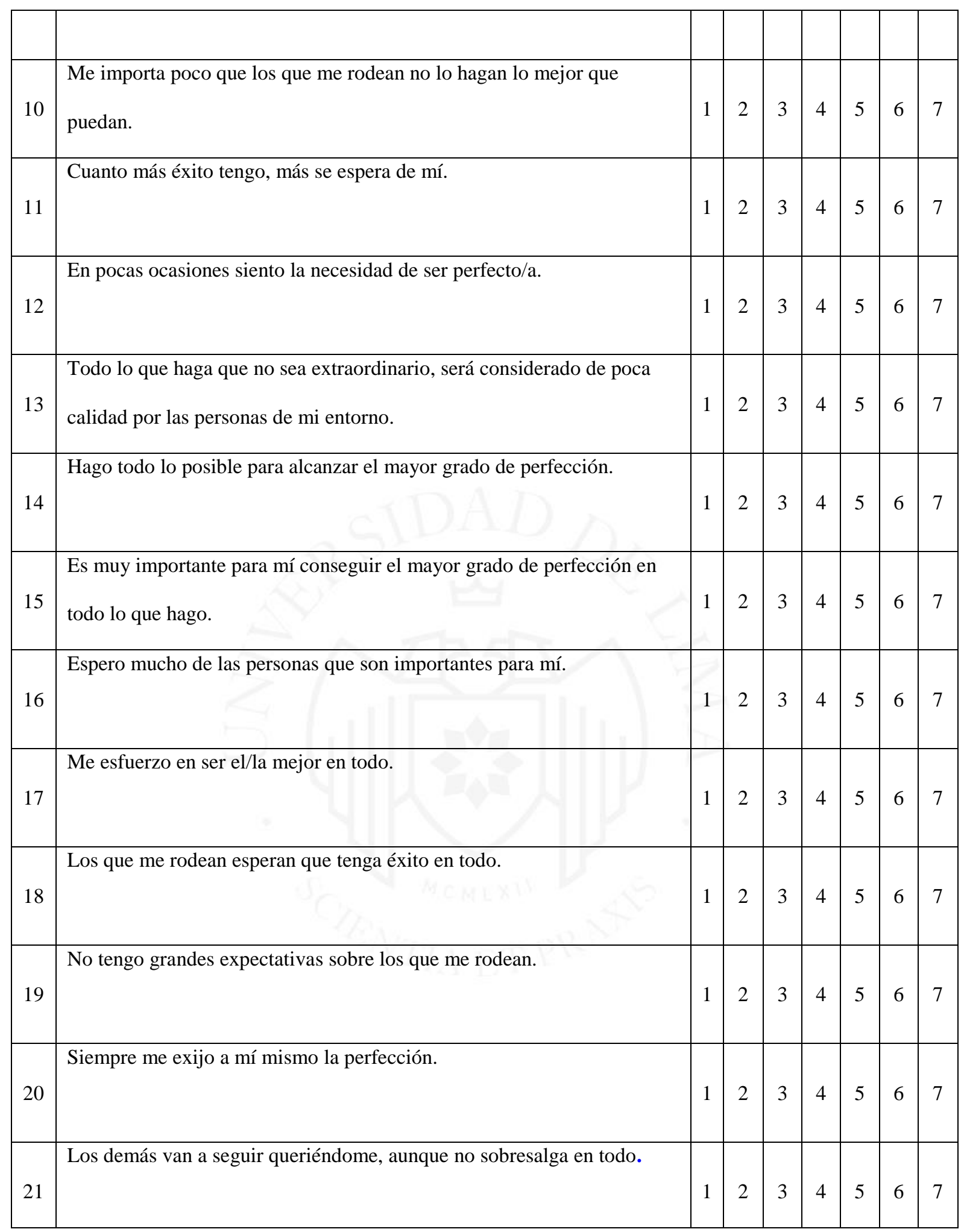




\begin{tabular}{|c|c|c|c|c|c|c|c|c|}
\hline 22 & No me interesa la gente que no se esfuerza en mejorar. & 1 & 2 & 3 & 4 & 5 & 6 & 7 \\
\hline 23 & Me siento desdichado/a cuando descubro algún error en mi trabajo. & 1 & 2 & 3 & 4 & 5 & 6 & 7 \\
\hline 24 & No espero mucho de mis amigos. & 1 & 2 & 3 & 4 & 5 & 6 & 7 \\
\hline 25 & $\begin{array}{l}\text { Tener éxito significa para mí tener que trabajar más para agradar a los } \\
\text { demás. }\end{array}$ & 1 & 2 & 3 & 4 & 5 & 6 & 7 \\
\hline 26 & Si le pido a alguien que haga algo, espero que lo haga perfectamente. & 1 & 2 & 3 & 4 & 5 & 6 & 7 \\
\hline 27 & No puedo tolerar que personas cercanas a mí cometan errores. & 1 & 2 & 3 & 4 & 5 & 6 & 7 \\
\hline 28 & Tiendo a la perfección cuando establezco mis objetivos. & 1 & 2 & 3 & 4 & 5 & 6 & 7 \\
\hline 29 & Las personas que me rodean no deberían dejar nunca de apoyarme. & 1 & 2 & 3 & 4 & 5 & 6 & 7 \\
\hline 30 & Los demás me aceptan tal como soy, incluso cuando no triunfo. & 1 & 2 & 3 & 4 & 5 & 6 & 7 \\
\hline 31 & Tengo la sensación de que la gente exige demasiado de mí. & 1 & 2 & 3 & 4 & 5 & 6 & 7 \\
\hline 32 & En todo momento debo rendir plenamente. & 1 & 2 & 3 & 4 & 5 & 6 & 7 \\
\hline 33 & $\begin{array}{l}\text { Aunque no lo manifiesten, los demás se molestan cuando fallo en lo que } \\
\text { hago. }\end{array}$ & 1 & 2 & 3 & 4 & 5 & ( & 7 \\
\hline 34 & No tengo necesidad de ser el/la mejor en todo lo que hago. & 1 & 2 & 3 & 4 & 5 & 6 & 7 \\
\hline 35 & Mi familia espera que sea perfecto/a. & 1 & 2 & 3 & 4 & 5 & $\theta$ & 7 \\
\hline
\end{tabular}




\begin{tabular}{|c|c|c|c|c|c|c|c|c|}
\hline 36 & Mis objetivos no son muy altos. & 1 & 2 & 3 & 4 & 5 & 6 & 7 \\
\hline 37 & Mis padres casi nunca esperaban que yo sobresaliera en todo en la vida. & 1 & 2 & 3 & 4 & 5 & 6 & 7 \\
\hline 38 & Respeto a la gente normal. & 1 & 2 & 3 & 4 & 5 & 6 & 7 \\
\hline 39 & Las personas no esperan de mí más que la perfección. & 1 & 2 & 3 & 4 & 5 & 6 & 7 \\
\hline 40 & Me impongo normas muy altas. & 1 & 2 & 3 & 4 & 5 & 6 & 7 \\
\hline 41 & La gente espera de mí más de lo que puedo dar. & 1 & 2 & 3 & 4 & 5 & 6 & 7 \\
\hline 42 & En la escuela o en el trabajo debo tener siempre éxito. & 1 & 2 & 3 & 4 & 5 & 6 & 7 \\
\hline 43 & $\begin{array}{l}\text { Me resulta indiferente que un buen amigo no trate de hacer las cosas } \\
\text { lo mejor posible. }\end{array}$ & 1 & 2 & 3 & 4 & 5 & 6 & 7 \\
\hline 44 & $\begin{array}{l}\text { Los que me rodean consideran que soy competente, aunque cometa un } \\
\text { error. }\end{array}$ & 1 & 2 & 3 & 4 & 5 & 6 & 7 \\
\hline 45 & Rara vez espero que los demás sobresalgan en todo. & 1 & 2 & 3 & 4 & 5 & 6 & 7 \\
\hline
\end{tabular}




\section{Anexo 4: Inventario de trastornos de la conducta alimentaria EDI-2}

Instrucciones: Debes contestar a las frases que se proponen. Algunas se refieren a la comida y otras a los sentimientos o actitudes que experimentas.

En cada frase se proponen cinco alternativas de respuestas, de las cuáles deberás elegir una que mejor te describa.

Las opciones de respuesta para cada afirmación son:

$$
\begin{gathered}
\text { Nunca }=0 \\
\text { Pocas veces }=1 \\
\text { A veces }=2 \\
\text { A menudo }=3 \\
\text { Casi siempre }=4 \\
\text { Siempre }=5
\end{gathered}
$$

En cada frase contesta si lo que se dice te ocurre y no dejes ni una en blanco.

Recuerda que no hay respuesta correcta ni incorrecta, sólo ubica lo que esté más de acuerdo con tu experiencia.

\section{Contesta a todas las frases con sinceridad}

\begin{tabular}{|c|c|c|c|c|c|}
\hline $\mathbf{0}$ & $\mathbf{1}$ & $\mathbf{2}$ & $\mathbf{3}$ & $\mathbf{4}$ & $\mathbf{5}$ \\
\hline Nunca & Pocas veces & A veces & A menudo & Casi siempre & Siempre \\
\hline
\end{tabular}

\begin{tabular}{|l|l|l|l|l|l|l|l|}
\hline 1 & Como dulces y carbohidratos sin preocuparme & 0 & 1 & 2 & 3 & 4 & 5 \\
\hline 2 & Creo que mi estómago es demasiado grande & 0 & 1 & 2 & 3 & 4 & 5 \\
\hline
\end{tabular}




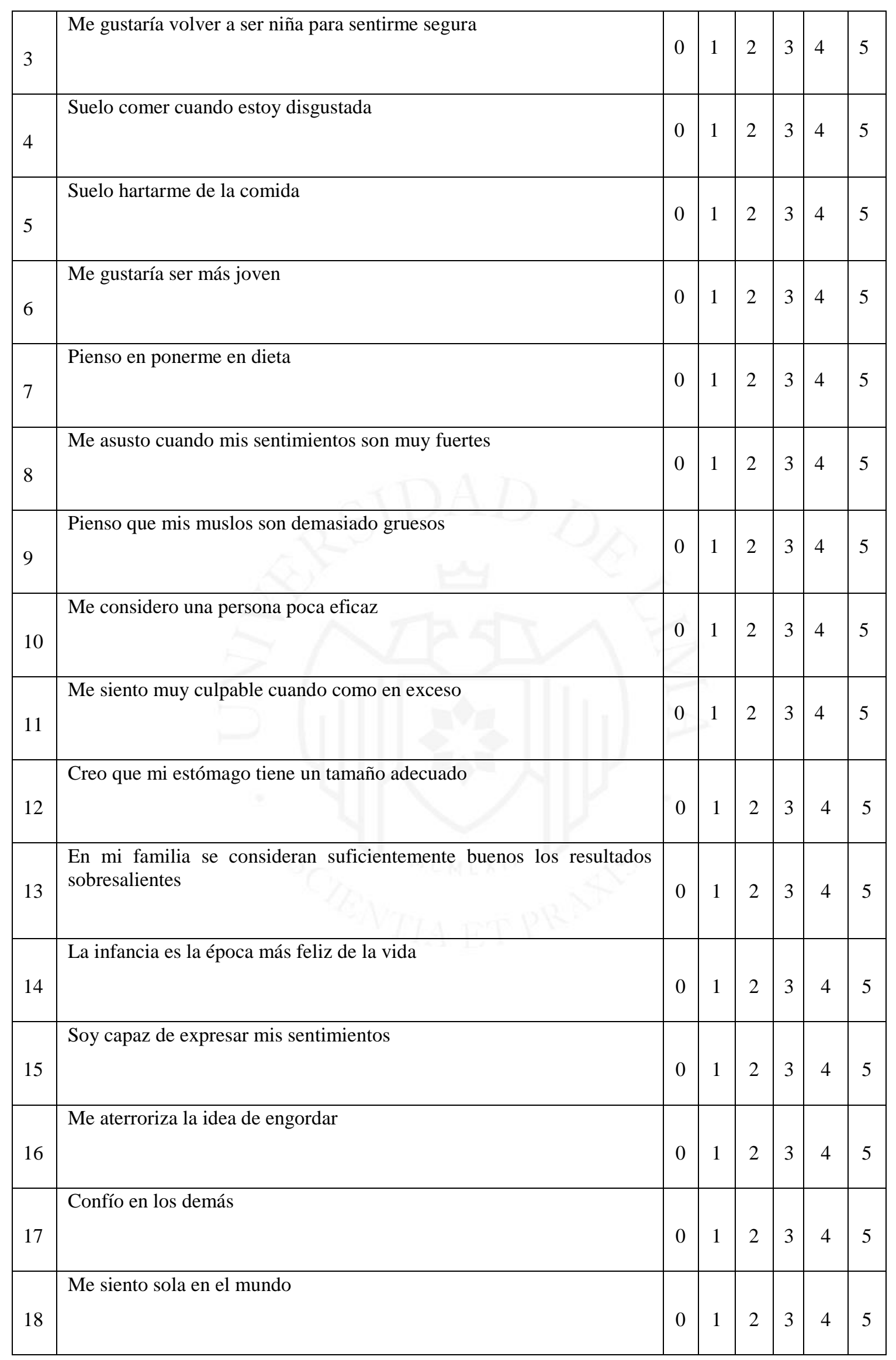




\begin{tabular}{|c|c|c|c|c|c|c|c|}
\hline 19 & Me siento satisfecha con mi figura. & 0 & 1 & 2 & 3 & 4 & 5 \\
\hline 20 & Creo que generalmente controlo las cosas que me pasan en la vida & 0 & 1 & 2 & 3 & 4 & 5 \\
\hline 21 & Suelo estar confusa sobre mis emociones & 0 & 1 & 2 & 3 & 4 & 5 \\
\hline 22 & Preferiría ser adulta a ser niña & 0 & 1 & 2 & 3 & 4 & 5 \\
\hline 23 & Me resulta fácil comunicar con los demás & 0 & 1 & 2 & 3 & 4 & 5 \\
\hline 24 & Me gustaría ser otra persona & 0 & 1 & 2 & 3 & 4 & 5 \\
\hline 25 & Exagero o doy demasiada importancia al peso & 0 & 1 & 2 & 3 & 4 & 5 \\
\hline 26 & Puedo reconocer las emociones que siento en cada momento & 0 & 1 & 2 & 3 & 4 & 5 \\
\hline 27 & Me siento incapaz & 0 & 1 & 2 & 3 & 4 & 5 \\
\hline 28 & He ido a comilonas en las que sentí que no podía dejar de comer & 0 & 1 & 2 & 3 & 4 & 5 \\
\hline 29 & $\begin{array}{l}\text { Cuando era pequeña intentaba con empeño no decepcionar a mis } \\
\text { padres y profesores }\end{array}$ & 0 & 1 & 2 & 3 & 4 & 5 \\
\hline 30 & Tengo amigos íntimos & 0 & 1 & 2 & 3 & 4 & 5 \\
\hline 31 & Me gusta la forma de mi trasero & 0 & 1 & 2 & 3 & 4 & 5 \\
\hline 32 & Estoy preocupada porque querría ser una persona más delgada & 0 & 1 & 2 & 3 & 4 & 5 \\
\hline 33 & No sé qué es lo que ocurre en mi interior & 0 & 1 & 2 & 3 & 4 & 5 \\
\hline 34 & Me cuesta expresar mis emociones a los demás & 0 & 1 & 2 & 3 & 4 & 5 \\
\hline
\end{tabular}




\begin{tabular}{|c|c|c|c|c|c|c|c|}
\hline 35 & Las exigencias de la vida adulta son excesivas & 0 & 1 & 2 & 3 & 4 & 5 \\
\hline 36 & Me fastidia no ser la mejor en todo & 0 & 1 & 2 & 3 & 4 & 5 \\
\hline 37 & Me siento segura de mí misma & 0 & 1 & 2 & 3 & 4 & 5 \\
\hline 38 & Suelo pensar en darme un atracón & 0 & 1 & 2 & 3 & 4 & 5 \\
\hline 39 & Me alegra haber dejado de ser una niña & 0 & 1 & 2 & 3 & 4 & 5 \\
\hline 40 & No sé muy bien cuando tengo hambre o no & 0 & 1 & 2 & 3 & 4 & 5 \\
\hline 41 & Tengo mala opinión de mí & 0 & 1 & 2 & 3 & 4 & 5 \\
\hline 42 & Creo que puedo conseguir mis objetivos & 0 & 1 & 2 & 3 & 4 & 5 \\
\hline 43 & Mis padres esperaban de mí resultados sobresalientes & 0 & 1 & 2 & 3 & 4 & 5 \\
\hline 44 & Temo de no poder controlar mis sentimientos & 0 & 1 & 2 & 3 & 4 & 5 \\
\hline 45 & Creo que mis caderas son demasiado anchas & 0 & 1 & 2 & 3 & 4 & 5 \\
\hline 46 & $\begin{array}{l}\text { Como con moderación delante de los demás, pero me doy un atracón } \\
\text { cuando se van }\end{array}$ & 0 & 1 & 2 & 3 & 4 & 5 \\
\hline 47 & Me siento hinchada después de una comida normal & 0 & 1 & 2 & 3 & 4 & 5 \\
\hline 48 & Creo que las personas son más felices cuando son niños & 0 & 1 & 2 & 3 & 4 & 5 \\
\hline 49 & Si engordo un kilo, me preocupa que pueda seguir ganando peso & 0 & 1 & 2 & 3 & 4 & 5 \\
\hline 50 & Me considero una persona valiosa & 0 & 1 & 2 & 3 & 4 & 5 \\
\hline
\end{tabular}




\begin{tabular}{|c|c|c|c|c|c|c|c|}
\hline 51 & Cuando estoy disgustada no sé si estoy triste, asustada o enfadada & 0 & 1 & 2 & 3 & 4 & 5 \\
\hline 52 & Creo que debo hacer la cosas perfectamente o no hacerlas & 0 & 1 & 2 & 3 & 4 & 5 \\
\hline 53 & Pienso en vomitar para perder peso & 0 & 1 & 2 & 3 & 4 & 5 \\
\hline 54 & $\begin{array}{l}\text { Necesito mantener cierta distancia con la gente, me siento incomoda } \\
\text { si alguien se acerca demasiado }\end{array}$ & 0 & 1 & 2 & 3 & 4 & 5 \\
\hline 55 & Creo que el tamaño de mis muslos es adecuado & 0 & 1 & 2 & 3 & 4 & 5 \\
\hline 56 & Me siento emocionalmente vacía en mi interior & 0 & 1 & 2 & 3 & 4 & 5 \\
\hline 57 & Soy capaz de hablar sobre aspectos personales y sentimientos & 0 & 1 & 2 & 3 & 4 & 5 \\
\hline 58 & Los mejores años de tu vida son cuando llegas a ser adulta & 0 & 1 & 2 & 3 & 4 & 5 \\
\hline 59 & Creo que mi trasero es muy grande & 0 & 1 & 2 & 3 & 4 & 5 \\
\hline 60 & Tengo sentimientos que no puedo identificar del todo & 0 & 1 & 2 & 3 & 4 & 5 \\
\hline 61 & Como o bebo a escondidas & 0 & 1 & 2 & 3 & 4 & 5 \\
\hline 62 & Creo que mis caderas tienen el tamaño adecuado & 0 & 1 & 2 & 3 & 4 & 5 \\
\hline 63 & Me fijo objetivos sumamente ambiciosos & 0 & 1 & 2 & 3 & 4 & 5 \\
\hline 64 & Cuando estoy disgustada, temo empezar a comer & 0 & 1 & 2 & 3 & 4 & 5 \\
\hline 65 & La gente que me gusta de verdad suele acabar defraudándome & 0 & 1 & 2 & 3 & 4 & 5 \\
\hline 66 & Me avergüenzo de mis debilidades humanas & 0 & 1 & 2 & 3 & 4 & 5 \\
\hline
\end{tabular}




\begin{tabular}{|c|c|c|c|c|c|c|c|}
\hline 67 & La gente dice que soy una persona emocionalmente inestable & 0 & 1 & 2 & 3 & 4 & 5 \\
\hline 68 & Me gustaría tener un control total de mis necesidades corporales & 0 & 1 & 2 & 3 & 4 & 5 \\
\hline 69 & Suelo sentirme a gusto en la mayor parte de las situaciones de grupo & 0 & 1 & 2 & 3 & 4 & 5 \\
\hline 70 & Digo impulsivamente cosas de las que después me arrepiento & 0 & 1 & 2 & 3 & 4 & 5 \\
\hline 71 & Me esfuerzo por buscar cosas que producen placer & 0 & 1 & 2 & 3 & 4 & 5 \\
\hline 72 & Debo tener cuidado con mi tendencia a consumir drogas & 0 & 1 & 2 & 3 & 4 & 5 \\
\hline 73 & Soy comunicativa con la mayor parte de la gente & 0 & 1 & 2 & 3 & 4 & 5 \\
\hline 74 & Las relaciones con los demás hacen que me siento atrapada & 0 & 1 & 2 & 3 & 4 & 5 \\
\hline 75 & La abnegación me hace sentir más fuerte espiritualmente & 0 & 1 & 2 & 3 & 4 & 5 \\
\hline 76 & La gente comprende mis verdaderos problemas & 0 & 1 & 2 & 3 & 4 & 5 \\
\hline 77 & Tengo pensamientos extraños que no puedo quitarme de la cabeza & 0 & 1 & 2 & 3 & 4 & 5 \\
\hline 78 & Comer por placer es signo de debilidad moral & 0 & 1 & 2 & 3 & 4 & 5 \\
\hline 79 & Soy propensa a tener ataques de rabia o ira & 0 & 1 & 2 & 3 & 4 & 5 \\
\hline 80 & Creo que la gente confía tanto en mí como merezco & 0 & 1 & 2 & 3 & 4 & 5 \\
\hline 81 & Debo tener cuidado con mi tendencia a beber demasiado alcohol & 0 & 1 & 2 & 3 & 4 & 5 \\
\hline 82 & Creo que estar tranquila y relajada es una pérdida de tiempo & 0 & 1 & 2 & 3 & 4 & 5 \\
\hline
\end{tabular}




\begin{tabular}{|c|c|c|c|c|c|c|c|}
\hline 83 & Los demás dicen que me irrito con facilidad & 0 & 1 & 2 & 3 & 4 & 5 \\
\hline 84 & Tengo la sensación que todo me sale mal & 0 & 1 & 2 & 3 & 4 & 5 \\
\hline 85 & Tengo cambios de humor bruscos & 0 & 1 & 2 & 3 & 4 & 5 \\
\hline 86 & Me siento incómoda por las necesidades de mi cuerpo & 0 & 1 & 2 & 3 & 4 & 5 \\
\hline 87 & Prefiero pasar el tiempo sola que estar con los demás & 0 & 1 & 2 & 3 & 4 & 5 \\
\hline 88 & El sufrimiento te convierte en una persona mejor & 0 & 1 & 2 & 3 & 4 & 5 \\
\hline 89 & Sé que la gente me aprecia & 0 & 1 & 2 & 3 & 4 & 5 \\
\hline 90 & Siento la necesidad de hacer daño a los demás o a mí misma & 0 & 1 & 2 & 3 & 4 & 5 \\
\hline 91 & Creo que realmente sé quién soy & 0 & 1 & 2 & 3 & 4 & 5 \\
\hline
\end{tabular}




\section{Anexo 5: Consentimiento informado para madres}

Yo, con DNI número de -

-----años de edad, declaro y acepto participar voluntariamente de la investigación conducida por Michele Vander Elst (Carnet de Extranjería 000290389) egresada de la Universidad de Lima como parte del Proyecto de Investigación para optar el Título de Licenciado en Piscología. He sido informada que el objetivo de este estudio es analizar el perfeccionismo de las madres e IMC y su relación con los rasgos predisponentes de los trastornos de la conducta alimentaria en hijas adolescentes. Al acceder a participar en este estudio, se me pedirá responder preguntas en un cuestionario. Esto tomará aproximadamente 25 minutos de mi tiempo.

He sido informada que la información que se recoja será estrictamente confidencial y no se usará para ningún otro propósito fuera de los de esta investigación. Sus respuestas al cuestionario y a la entrevista serán codificadas usando un número de identificación y, por lo tanto, serán anónimas. Todos los datos alcanzados serán analizados grupal y estadísticamente, los mismos que conformarán información científica importante a ser compartida de forma escrita u oral, bajo el carácter de confidencialidad de los datos.

De tener alguna duda sobre este proyecto, puedo hacer preguntas en cualquier momento durante mi participación comunicándome con Michele Vander Elst al 949288008 y/o escribir al correo electrónico michelevde@me.com. Entiendo igualmente que puedo retirarme del mismo en cualquier momento sin que eso lo perjudique en ninguna forma.

Asimismo, puedo pedir información sobre los resultados globales de este proyecto cuando el mismo haya concluido

Firma del participante DNI

Fecha 


\section{Anexo 6: Consentimiento informado para las menores de edad}

Yo, con DNI número de

años de edad, declaro y acepto que mi hija de ---años de edad participe de la investigación conducida por Michele Vander Elst (Carnet de Extranjería 000290389) egresada de la Universidad de Lima como parte del Proyecto de Investigación para optar el Titulo de Licenciada en Piscología. He sido informada que el objetivo de este estudio es analizar el perfeccionismo de las madres e IMC y su relación con los rasgos predisponentes de los trastornos de la conducta alimentaria en hijas adolescentes. Al acceder a su participación, se le pedirá responder preguntas en un cuestionario. Esto tomará aproximadamente 25 minutos de mi tiempo.

He sido informada que la información que se recoja será estrictamente confidencial y no se usará para ningún otro propósito fuera de los de esta investigación. Las respuestas al cuestionario y a la entrevista serán codificadas usando un número de identificación y, por lo tanto, serán anónimas. Todos los datos alcanzados serán analizados grupal y estadísticamente, los mismos que conformarán información científica importante a ser compartida de forma escrita u oral, bajo el carácter de confidencialidad de los datos.

De tener alguna duda sobre este proyecto, puedo hacer preguntas en cualquier momento durante mi participación comunicándome con Michele Vander Elst al 949288008 y/o escribir al correo electrónico michelevde@me.com. Entiendo igualmente que puedo retirarme del mismo en cualquier momento sin que eso lo perjudique en ninguna forma.

Asimismo, se me ha informado que puedo pedir información sobre los resultados globales de este proyecto cuando el mismo haya concluido

Firma del participante DNI

Fecha. 


\section{Anexo 7: Autorizaciones de uso de instrumentos}

$\mathbf{M}^{\mathrm{a}}$ de los Ángeles Rodríguez Campayo

A : Michele Vander Elst

Rép : Autorización para uso de version española del MPS
1 septembre 2017 12:27

Boîte de réception - iCloud

Estimada Michele:

Tiene autorización para hacer uso de la Escala de Perfeccionismo validada por mi y mi equipo.

La escala fue validada para que pueda ser utilizada por todas las personas a las que les resulte útil tanto para investigación como diagnóstico.

Le felicito por su trabajo de investigación y le animo a continuar trabajando.

Un saludo

$M^{\mathrm{a}}$ Ángeles

Enviado desde mi iPhone

Botica Natural Perú

1 septembre 2017 17:39

A : Michele Vander Elst

Boîte de réception - iCloud

Autorización EDI-2 Michele Vander

Yo, Diego Guerrero Canale autorizo a la Sra. Michele Vander Elst a aplicar el instrumento EDI2, validado y adaptado para la población peruana en el 2008.

\section{DIEGO GUERRERO CANALE}

DNI 42454687

PSICÓLOGO CLÍNICO DE LA PONTIFICIA UNIVERSIDAD CATÓLICA DEL PERÚ

guerrero.diego@pucp.pe 


\section{Anexo 8: Presupuesto}

\begin{tabular}{|c|c|c|}
\hline & Costo Unitario & Costo Total \\
\hline Rubro & Nuevos Soles & Nuevos Soles \\
\hline \multicolumn{3}{|l|}{ Costo de Materiales } \\
\hline Impresiones 166 hojas & $\mathrm{S} / 0,10$ & S/ 16.60 \\
\hline Anillados 2 & $\mathrm{~S} / 6.00$ & $\mathrm{~S} / 12.00$ \\
\hline Sub total & & S/ 28.60 \\
\hline \multicolumn{3}{|l|}{ Costo Investigación } \\
\hline Inscripción a Seminario TCA en Colegio de Psicólogos del Perú & & S/ 60.00 \\
\hline$\underline{\text { Sub total }}$ & & S/ 60.00 \\
\hline Gastos operativos & & \\
\hline Imprevistos & & $\mathrm{S} / .30 .00$ \\
\hline Sub total & & $\mathrm{S} / \mathbf{3 0 . 0 0}$ \\
\hline COSTO TOTAL & & $\underline{\underline{S} / 118.60}$ \\
\hline
\end{tabular}




\section{Anexo 9 - Cronograma}

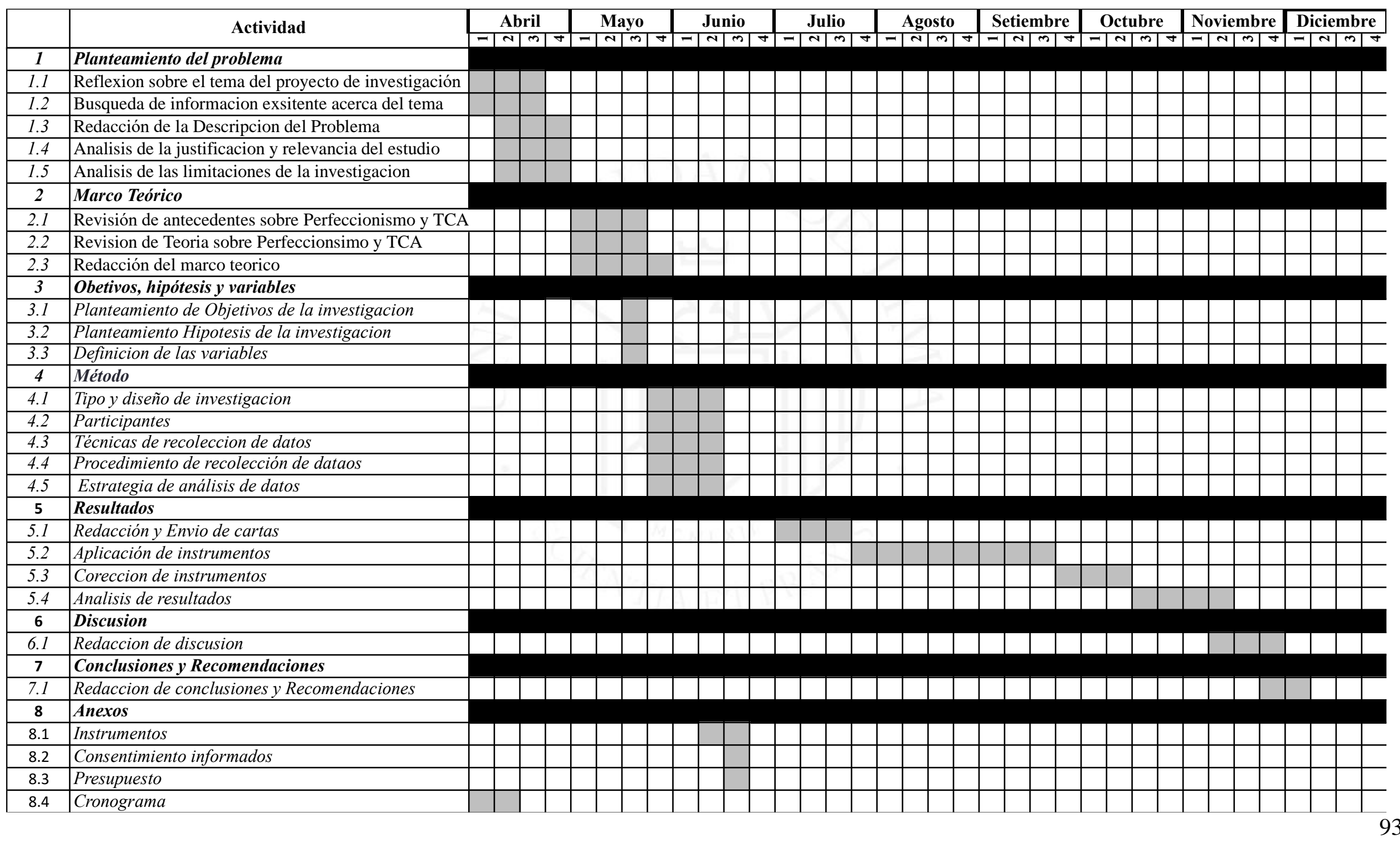




\section{Anexo 10}

Tabla 11

Correlación Spearman Brown (rs) de las dimensiones del instrumento EDI-2

\begin{tabular}{|c|c|c|c|c|c|c|c|c|c|}
\hline DT & B & $\mathrm{BD}$ & $\mathrm{I}$ & $\mathrm{P}$ & ID & IA & A & IR & IS \\
\hline $\begin{array}{l}\text { Obsesión por la } \\
\text { Delgadez (DT) }\end{array}$ & $.41^{* *}$ & $.65^{* *}$ & $.37^{* *}$ & $.23^{*}$ & .14 & \multicolumn{3}{|c|}{$.32^{* *}$} & $.22^{*}$ \\
\hline Bulimia (B) & & $.38^{* *}$ & $.41^{* *}$ & $.27^{* *}$ & $.21^{*}$ & $.51^{* *}$ & $.44^{* *}$ & $.40^{* *}$ & $.30^{* *}$ \\
\hline $\begin{array}{l}\text { Insatisfacción } \\
\text { Corporal (BD) }\end{array}$ & & & $.44^{* *}$ & $.26^{* *}$ & $.24^{*}$ & $.59^{* *}$ & $.47^{* *}$ & $.36^{* *}$ & $.40^{* *}$ \\
\hline Ineficacia (I) & & & & .16 & $.38^{* *}$ & $.55^{* *}$ & $.37^{* *}$ & $.27^{* *}$ & $.60^{* *}$ \\
\hline $\begin{array}{l}\text { Perfeccionismo } \\
\text { (P) }\end{array}$ & & & & & $.21^{*}$ & $.38^{* *}$ & $.46^{* *}$ & $.34^{* *}$ & $.21^{*}$ \\
\hline $\begin{array}{l}\text { Desconfianza } \\
\text { Interpersonal (ID) }\end{array}$ & & & & & & $.30^{* *}$ & $.20^{*}$ & $.27^{* *}$ & $.47^{* *}$ \\
\hline $\begin{array}{l}\text { Conciencia } \\
\text { Interoceptiva (IA) }\end{array}$ & & & & & & & $.51^{* *}$ & $.54^{* *}$ & $.53^{* *}$ \\
\hline $\operatorname{Ascetismo}(\mathrm{A})$ & & & & & & & & $.56^{* *}$ & $.32^{* *}$ \\
\hline Impulsividad (IR) & & & & & & & & & $.34^{* *}$ \\
\hline $\begin{array}{l}\text { Inseguridad Social } \\
\text { (IS) }\end{array}$ & & & & & & & & & \\
\hline
\end{tabular}




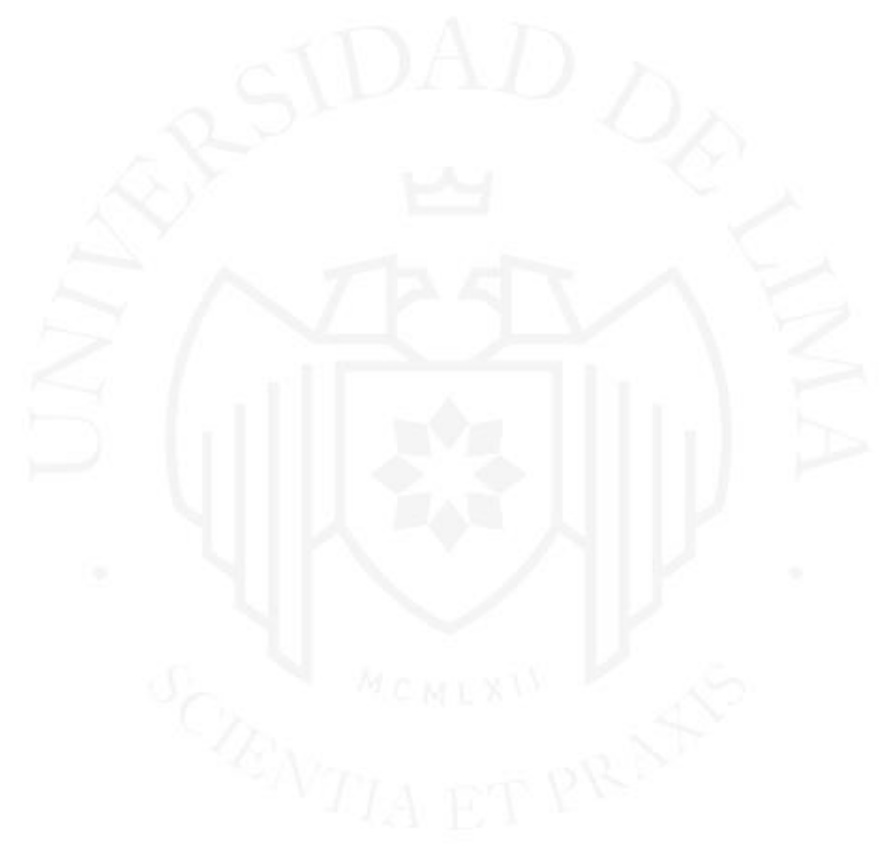

